\title{
MAURO KIERPEL
}

\section{Tráfego veicular e a espessura da camada intima média das carótidas no Estudo Longitudinal da Saúde do Adulto- ELSA Brasil}

Tese apresentada à Faculdade de Medicina da Universidade de São Paulo para obtenção do título de Doutor em Ciências

Programa de Medicina Preventiva

Orientador: Prof. Dr. Nelson da Cruz Gouveia

(Versão corrigida. Resolução CoPGr 6018/11, de 1 denovembro de 2011. A versão original está disponível na Biblioteca da FMUSP) 


\section{Dados Internacionais de Catalogação na Publicação (CIP)}

Preparada pela Biblioteca da

Faculdade de Medicina da Universidade de São Paulo

Creprodução autorizada pelo autor

\section{Kierpel, Mauro}

Tráfego veicular e a espessura da camada íntima média das carótidas no Estudo Longitudinal da Saúde do Adulto - ELSA Brasil / Mauro Kierpel -- São Paulo, 2017. Tese(doutorado)--Faculdade de Medicina da Universidade de São Paulo.

Programa de Medicina Preventiva.

Orientador: Nelson da Cruz Gouveia.

Descritores: 1.Poluição do ar 2.Emissões de veículos 3.Espessura íntima-média carotídea 4.Morbidade 5.Mortalidade

USP/FM/DBD-279/17 
"Bendito sejas Tu, Eterno, nosso D'us, Rei do Universo". Aos meus queridos pais Giecel ( $\left.z^{\prime} l^{\prime}\right)$ e Alice, minha eterna gratidão pelo inestimável apoio e confiança. À minha amada filha Sofia, pela inesgotável fonte de inspiração para tudo na minha vida. 


\section{NORMALIZAÇÃo AdOTADA}

Esta tese está de acordo com as seguintes normas, em vigor no momento desta publicação:

Referências: adaptado de International Committee of Medical Journals Editors (Vancouver).

Universidade de São Paulo. Faculdade de Medicina. Divisão de Biblioteca e Documentação. Guia de apresentação de dissertações, teses e monografias. Elaborado por Anneliese Carneiro da Cunha, Maria Julia de A. L. Freddi, Maria F. Crestana, Marinalva de Souza Aragão, Suely Campos Cardoso, Valéria Vilhena. 3a ed. São Paulo: Divisão de Biblioteca e Documentação; 2011.

Abreviaturas dos títulos dos periódicos de acordo com List of Journals Indexed in Index Medicus. 
SUMÁRIO

LISTA DE SIGLAS, ABREVIATURAS E SÍMBOLOS

LISTA DE GRÁFICOS

LISTA DE FIGURAS

LISTA DE TABELAS

RESUMO

ABSTRACT

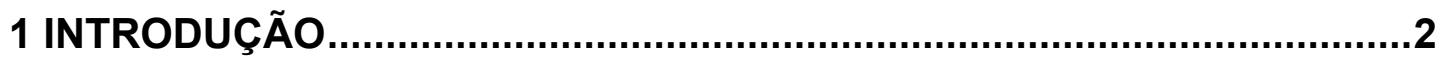

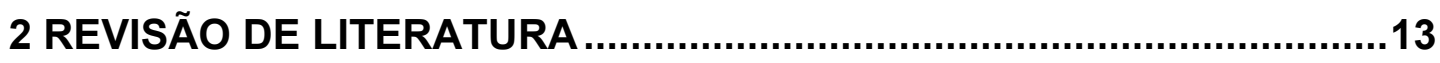

2.1 Doenças cardiovasculares: incidência e fatores de risco..................13

2.2 A poluição e a mortalidade por problemas cardiovasculares ..........16

2.3 Morbidade por problemas cardiovasculares e poluição ....................18

2.4 Poluição do ar e doença aterosclerótica ............................................24

2.5 Métodos diagnósticos auxiliares para avaliação de risco da doença

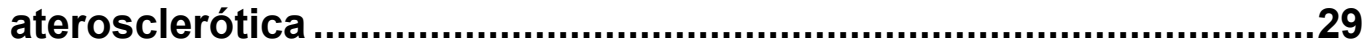

2.5.1 A ultrassonografia de carótidas como método para identificação da doença aterosclerótica .............................................................32

2.5.2 Medidas antropométricas que auxiliam na avaliação de situações de potencial risco cardiovascular ...................................................40

2.6 Métodos de avaliação da exposição ambiental aos poluentes atmosféricos gerados por tráfego veicular .........................................41

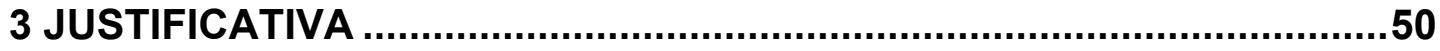

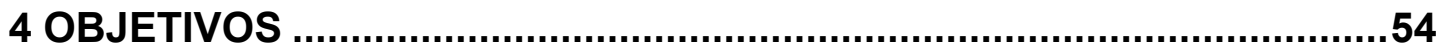

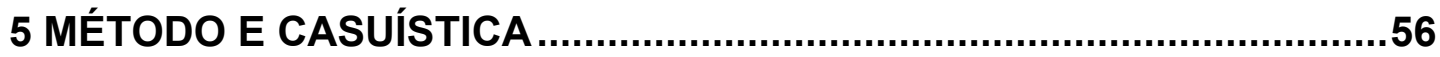

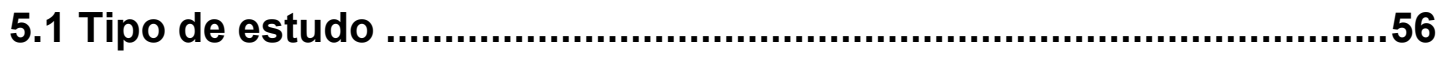

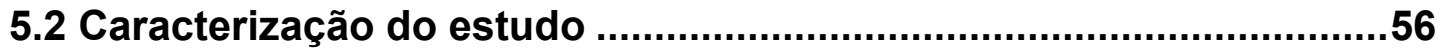

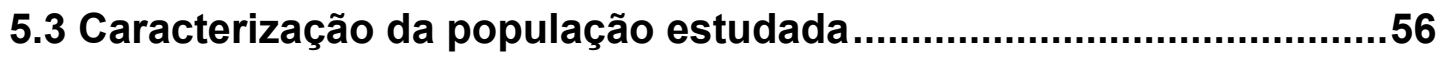

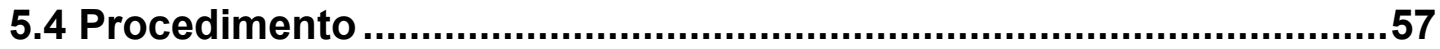

5.4.1 A medida da espessura da intima média das carótidas no ELSA-

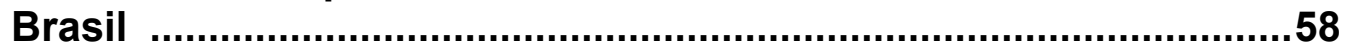

5.4.2 Obtenção dos dados viários e de tráfego.......................................59 
5.4.3 Cálculo da densidade de tráfego ponderada pela distância (DTPD) .60

5.4.4 Cálculo da densidade de tráfego ponderada pela distância combinada (DTPD comb)

5.4.5 Cálculo da exposição ao tráfego veicular tendo como indicador apenas a distância (DP)

5.4.6 Cálculo da distância entre o domicílio e o local de trabalho dos sujeitos do estudo

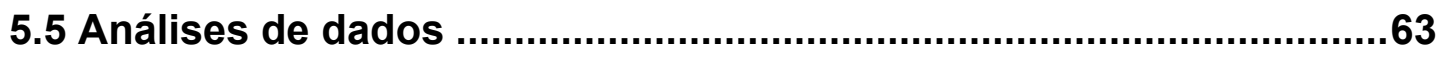

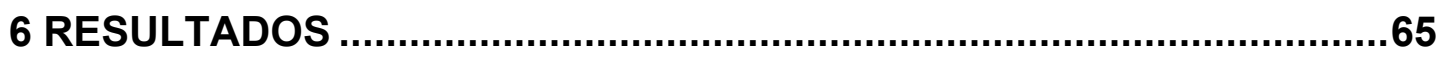

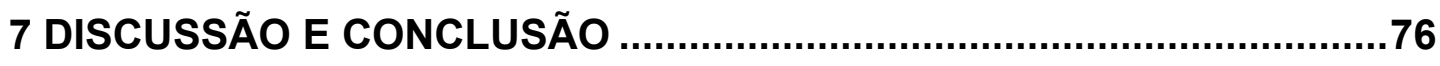

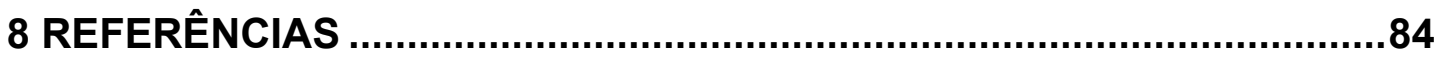




$\begin{array}{ll}\% & \text { Porcentagem } \\ < & \text { Menor } \\ > & \text { Maior } \\ \geq & \text { Maior ou igual } \\ \mu \mathrm{g} & \text { Micrograma }\end{array}$

APHEA Air Pollution and Health: European Approach

APHENA Air Pollution and Health: A European and North American Approach

ARIC Atherosclerosis Risk in Communities Study

AVE Acidente Vascular Encefálico

CA Circunferência abdominal

CAC Calcificação das artérias coronárias

CAPS Carotid Atherosclerosis Progression Study

CET Companhia de Engenharia de Tráfego

CO Monóxido de carbono

COMEAP Comittee on the Medical Effects of Air Pollution

COV Compostos orgânicos voláteis

CP Circunferência do pescoço

DAC Doença arterial coronariana

DALyS Disability Adjusted Life Years

DcBV Doenças cerebrovasculares

DCNT Doenças Crônicas Não Transmissíveis

DCV Doenças Cardiovasculares

DIC Doenças Isquêmicas do Coração

DNA Ácido desoxirribonucleico

DTC Doppler transcraniano

EIMC Espessura da íntima-média das carótidas

ELSA Estudo Longitudinal de Saúde do Adulto 


\begin{tabular}{|c|c|}
\hline EPA & Enviromental Protection Agency \\
\hline ER & Escores de risco \\
\hline ESCAPE & European Study of Cohorts for Air Pollution Effects \\
\hline FMC & Fumaça \\
\hline GBD & Global Burden of Disease Study \\
\hline GEE & Gases causadores do efeito estufa \\
\hline $\mathrm{H}_{2} \mathrm{O}_{2}$ & Peróxido de hidrogênio \\
\hline $\mathrm{H}_{2} \mathrm{SO}_{4}$ & Ácido sulfúrico \\
\hline $\mathrm{HbA} 1 \mathrm{c}$ & Hemoglobina glicada \\
\hline $\mathrm{HC}$ & Hidrocarbonetos \\
\hline HDL & High Density Lipoprotein \\
\hline $\mathrm{HNO}_{3}$ & Ácido nítrico \\
\hline HNR & Heinz Nidorf Recall \\
\hline IAM & Infarto Agudo do Miocárdio \\
\hline IMC & Índice de massa corpórea \\
\hline KIHD & Kuopio Ischemic Heart Disease Risk Factor Study \\
\hline $\mathrm{Km}$ & Kilômetro \\
\hline LILAC & $\begin{array}{l}\text { Longitudinal Investigation for the Longevity and Aging in } \\
\text { Hokkaido County }\end{array}$ \\
\hline $\mathrm{m}$ & Metro \\
\hline$m^{2}$ & Metro quadrado \\
\hline $\mathrm{m} 3$ & Metros cúbicos \\
\hline MESA & Multi-Ethnic Study of Atherosclerosis and Air Pollution \\
\hline $\mathrm{mm}$ & Milímetro \\
\hline MONICA & $\begin{array}{l}\text { Multinational MONItoring of trends and determinants in } \\
\text { CArdiovascular disease }\end{array}$ \\
\hline MP & Materiais particulados \\
\hline MRPA & Monitorização Residencial de Pressão Arterial \\
\hline NMMAPS & National Morbity, Mortality, and Air Pollution Study \\
\hline $\mathrm{NO}_{2}$ & Dióxido de nitrogênio \\
\hline $\mathrm{NO}_{3}$ & Nitratos \\
\hline
\end{tabular}




\begin{tabular}{|c|c|}
\hline NOx & Óxidos de nitrogênio \\
\hline O/D & Origem/Destino \\
\hline $\mathrm{O}_{3}$ & Ozônio \\
\hline OMS & Organização Mundial da Saúde \\
\hline OR & odds ratio \\
\hline PCPV & $\begin{array}{l}\text { Plano de Controle de Poluição Veicular do Estado de São } \\
\text { Paulo }\end{array}$ \\
\hline PCR & Proteína C Reativa \\
\hline PIB & Produto Interno Bruto \\
\hline $\mathrm{PM}_{10}$ & Partículas inaláveis \\
\hline PNS & Pesquisa Nacional em Saúde \\
\hline PTS & Partículas Totais em Suspensão \\
\hline $\mathrm{RCQ}$ & Razão cintura/quadril \\
\hline RMSP & Região Metropolitana de São Paulo \\
\hline ROS & Espécies reativas do oxigênio \\
\hline $\mathrm{RR}$ & Risco relativo \\
\hline SIG & Sistema de Informação Geográfica \\
\hline $\mathrm{SO}_{2}$ & Dióxido de enxofre \\
\hline $\mathrm{SO}_{3}$ & Trióxido de enxofre \\
\hline $\mathrm{SO}_{4}{ }^{2-}$ & Sulfatos \\
\hline SOx & Óxidos de enxofre \\
\hline SUS & Sistema Único de Saúde \\
\hline SVL & Segmentos de vias locais \\
\hline TC & Tomografia computadorizada \\
\hline USG & Ultrassonografia \\
\hline USP & Universidade de São Paulo \\
\hline
\end{tabular}




\section{LISTA DE GRÁFICOS}

Gráfico 1 - Velocidade média no trânsito de São Paulo ............................. 


\section{LISTA DE FIgURAS}

Figura 1 - Mecanismos hipotéticos (clássico e alternativo) por meio dos quais o material particulado determinaria os efeitos cardiovasculares .26

Figura 2 - Mecanismos estabelecidos para desfechos clínicos relacionados com a poluição atmosférica.

Figura 3 - Possíveis efeitos da poluição do ar na morbimortalidade por doenças cardiovasculares.

Figura 4 - Ilustração esquemática demonstrando exemplos de medida da EMI e de placas

Figura 5 - Perfil da concentração de poluentes emitidos pelo tráfego veicular conforme o modelo da Densidade de Tráfego Ponderada pela Distância. 45

Figura 6 - Espessura médio-intimal média da artéria carótida comum ....59 


\section{LISTA DE TABELAS}

Tabela 1 - Métodos de avaliação da exposição ambiental aos poluentes atmosféricos gerados por tráfego veicular.......................... 48

Tabela 2 - Análise descritiva das características dos sujeitos do estudo das (variáveis contínuas) ..................................................68

Tabela 3 - Análise descritiva das características dos sujeitos do estudo (variáveis categorizadas)

Tabela 4 - Análise de regressão linear univariada para os desfechos da EIMC (valores médios) ....................................................70

Tabela 5 - Análise de regressão linear univariada para os desfechos de EIMC (valores máximos)................................................... 71

Tabela 6 - Coeficiente de regressão (intervalo de confiança de 95\%) para a associação entre as medidas indiretas da poluição atmosférica e a média das medidas da espessura da camada íntima média das carótidas da linha de base do estudo ELSA Brasil-SP - 2008

Tabela 7 - Coeficiente de regressão (intervalo de confiança de 95\%) para a associação entre as medidas indiretas da poluição atmosférica e a medida máxima da espessura da camada íntima média das carótidas da linha de base do estudo ELSA Brasil-SP - 2008 .

Tabela 8 - Coeficiente de regressão (intervalo de confiança de 95\%) para a associação entre as medidas indiretas da poluição atmosférica e a medida média da espessura da camada íntima média das carótidas da linha de base do estudo ELSA - BrasilSP - 2008 para o grupo de sujeitos considerados de alto risco para doença aterosclerótica.

Tabela 9 - Coeficiente de regressão (intervalo de confiança de 95\%) para a associação entre as medidas indiretas da poluição atmosférica e a medida máxima da espessura da camada íntima média das carótidas da linha de base do estudo ELSA Brasil-SP - 2008 para o grupo de sujeitos considerados de alto risco para doença aterosclerótica 
Tabela 10 - Coeficiente de regressão (intervalo de confiança de 95\%) para a associação entre as medidas indiretas da poluição atmosférica e a medida média da espessura da camada íntima média das carótidas da linha de base do estudo ELSA - BrasilSP - 2008 para o grupo de sujeitos considerados de baixo risco para doença aterosclerótica .73

Tabela 11 - Coeficiente de regressão (intervalo de confiança de 95\%) para a associação entre as medidas indiretas da poluição atmosférica e a medida máxima espessura da camada íntima média das carótidas da linha de base do estudo ELSA - BrasilSP - 2008 para o grupo de sujeitos considerados de baixo risco para doença aterosclerótica .74

Tabela 12 - Coeficiente de regressão Beta (intervalo de confiança de 95\%) para a associação entre as medidas indiretas da poluição atmosférica e a medida média da espessura da camada íntima média das carótidas da linha de base do estudo ELSA - BrasilSP - 2008 para o grupo de sujeitos com idade menor do que 49 anos.

Tabela 13 - Coeficiente de regressão Beta (intervalo de confiança de 95\%) para a associação entre as medidas indiretas da poluição atmosférica e a medida máxima da espessura da camada íntima média das carótidas da linha de base do estudo ELSABrasil-SP - 2008 para o grupo de sujeitos com idade menor do que 49 anos. .74

Tabela 14 - Coeficiente de regressão Beta (intervalo de confiança de 95\%) para a associação entre as medidas indiretas da poluição atmosférica e a medida média da espessura da camada íntima média das carótidas da linha de base do estudo ELSA - Brasil SP - 2008 para o grupo de sujeitos com idade maior ou igual a 49 anos.

Tabela 15 - Coeficiente de regressão Beta (intervalo de confiança de 95\%) para a associação entre as medidas indiretas da poluição atmosférica e a medida máxima da espessura da camada íntima média das carótidas da linha de base do estudo ELSABrasil-SP - 2008 para o grupo de sujeitos com idade maior ou igual a 49 anos. .75

Tabela 16- Análise de regressão linear univariada para a variável de exposição Distância casa-trabalho (DIST casa_trab) 76 


\section{Resumo}

Kierpel M. Trafego veicular e a espessura da camada íntima média das carótidas no Estudo Longitudinal da Saúde do Adulto-ELSA Brasil (Tese). São Paulo: Faculdade de medicina, Universidade de São Paulo; 2017.

INTRODUÇÃO: Muito se conhece sobre os efeitos deletérios da poluição do ar sobre a saúde humana e a sua influência sobre a mortalidade e morbidade sobretudo por doenças cardiovasculares. A medida ultrassonográfica da espessura da camada íntima - média das artérias carótidas (EIMC), tem sido descrita como método complementar não invasivo de grande potencial na avaliação da doença aterosclerótica. Este estudo teve como objetivo avaliar a possível associação entre a exposição a poluentes atmosféricos oriundos de tráfego veicular e a medida da espessura da íntima-média das carótidas em participantes ativos do estudo ELSA-Brasil moradores do município de São Paulo, por meio da utilização de métodos indiretos de mensuração da poluição atmosférica, como o cálculo de tráfego veicular nos locais de trabalho e residência. METODOLOGIA: Estudo de corte transversal. Utilizou-se, para este projeto, uma parcela inicial do banco de dados referente à primeira avaliação (Onda 1) do Estudo Longitudinal sobre a Saúde do Adulto (ELSA) realizada entre 2008 e 2010, correspondente a 2600 funcionários ativos da Universidade de São Paulo. .RESULTADOS Os dados da pesquisa indicaram que não houve associação entre as variáveis de exposição à poluição do ar relacionada ao tráfego veicular e a EIMC.CONCLUSÃO: Os resultados deste projeto como o das meta-análises e das revisões sistemáticas apresentadas mostram a incerteza dos efeitos da poluição atmosférica sobre as medidas da EIMC. Estudos complementares poderiam avaliar se este indicador (EIMC) seria o ideal para avaliar os efeitos no sistema cardiovascular relacionados à poluição do ar. Estas mesmas análises deveriam contemplar várias espécies de poluentes como variáveis de exposição a fim de se identificar e analisar as interações latentes entre os mais prevalentes.

Descritores: poluição atmosférica; tráfego veicular; espessura da intima média das carótidas 


\begin{abstract}
Kierpel M. Vehicular traffic and the carotid intima-media thickness in Brazilian Longitudinal Study of Adult Health(ELSA-Brasil) [Thesis]. São Paulo: "Faculdade de medicina, Universidade de São Paulo"; 2017.

Air pollution has been well known to have deleterious effects, which leads to mortality and morbidity due to respiratory problems and cardiovascular diseases. Several methods have been used to evaluate the consequences of exposure to air pollutants on human health, to identify the mechanisms involving this relationship. Anthropometric data, imaging studies, and laboratory markers have been used to investigate the development of atherosclerotic disease and, based on this, we tried to identify the relationship between the risk factors, such as atmospheric pollutants and atherogenesis. Ultrasound measurement of the carotid intima-media thickness (CIMT) has been potentially described as a great complementary analysis in noninvasive assessment of vascular inflammatory activity, onset, and development of atherosclerotic disease, and is considered an independent predictor of risk for morbidity and mortality due to cardiovascular diseases. The database from the Longitudinal Study of Adult Health (ELSABrasil) in São Paulo was used in this study, to investigate the possible effects of air pollution produced by vehicular traffic in the CIMT of the subjects. The measurement of exposure to air pollutants was made through indirect measures of the density of vehicular traffic of georeferenced locations (work and home), the distance from the subjects' residence to high traffic flow areas, as well as the distance covered during subjects' commuting from their homes to workplace. A cross-sectional study using the univariate and multivariate linear regression models was conducted to evaluate the possible correlation between exposure to air pollutants and CIMT.
\end{abstract}

Descriptors: atmospheric pollution, vehicular traffic, carotid intima-media Ithickness 
1 INTRODUÇÃO 


\section{INTRODUÇÃO}

O ar limpo é uma condição básica e essencial para o bem-estar e a saúde da humanidade. A poluição atmosférica, como produto da contaminação ambiental por substâncias químicas, físicas ou biológicas, é capaz de modificar as características naturais da atmosfera, sendo um dos principais contribuintes para a carga global de doenças relacionadas ao meio ambiente afetando tanto países em desenvolvimento quanto aos já desenvolvidos (Bhola et al:; WHO, 2012).

Entende-se, por poluição atmosférica, a presença de substâncias (partículas ou gases) no ar, resultante da atividade humana ou de processos naturais, em concentrações suficientes para interferir na saúde dos seres vivos (Cançado et al., 2006). Estas substâncias denominadas poluentes podem ser classificadas, basicamente, em partículas totais em suspensão (PTS), fumaça (FMC), partículas inaláveis $\left(\mathrm{PM}_{10}\right)$, partículas inaláveis finas $\left(\mathrm{PM}_{2,5}\right)$ e, ainda, em gases, como o dióxido de enxofre $\left(\mathrm{SO}_{2}\right)$, monóxido de carbono $(\mathrm{CO})$, ozônio $\left(\mathrm{O}_{3}\right)$ e o dióxido de nitrogênio $\left(\mathrm{NO}_{2}\right)$ (CETESB, 2010), sendo os veiculares locais, o monóxido de carbono (CO); os hidrocarbonetos $(\mathrm{HC})$, ou compostos orgânicos voláteis (COV); os materiais particulados (MP); os óxidos de nitrogênio (NOx) e os óxidos de enxofre (SOx) que, em geral, são produtos da queima de combustíveis fósseis (IPEA, 2011).

Os poluentes atmosféricos de origem veicular também podem ser classificados em função da abrangência dos impactos causados por suas emissões em locais no entorno de onde é realizado o serviço de transporte. São exemplos a fuligem expelida pelos escapamentos e que se acomoda nas ruas, passeios e fachadas dos imóveis. Nessa categoria, também estão os poluentes que se deslocam de uma região para outra pelas correntes de ar, muitas vezes, sobre fronteiras de países, como é o caso dos gases que 
causam a chuva ácida. Os poluentes globais, por sua vez, alcançam a atmosfera e impactam todo o planeta, como no caso da emissão de gases causadores do efeito estufa (GEE). O principal poluente nessa categoria em consequência à queima de combustíveis fósseis é o dióxido de carbono $\left(\mathrm{CO}_{2}\right)$, que serve também como unidade de equivalência para os demais GEEs (IPEA, 2011).

Vários poluentes classificados como locais atuam no efeito estufa e alguns destes gases catalisam reações de poluentes locais secundários. Por serem mais reativos e de meia-vida mais curta, não são de grande importância numa análise de longo prazo. Outra forma de categorização divide os poluentes entre aqueles de interesse médico e os de interesse na mitigação do efeito estufa (IPEA, 2011).

O comprometimento da qualidade do ar causado pela poluição urbana, tanto interna, em domicílios e indústrias, quanto externa, produzida por veículos automotores a partir da queima de combustível fóssil, tem sido responsável por mais de 3.700 .000 mortes prematuras a cada ano em nível mundial, sendo que $88 \%$ destas mortes ocorrem em países de baixa ou média renda e que representam $82 \%$ da população global, sendo que $72 \%$ destas mortes prematuras foram originadas por cardiopatia isquêmica ou acidente vascular encefálico, enquanto que $14 \%$ das mortes foram por doença pulmonar obstrutiva crônica ou infecções do trato respiratório inferior e outros $14 \%$ por câncer de pulmão. No ano de 2012, ocorreram 1,67 milhão de mortes no Sudeste Asiático e mais 936.000 no Pacífico Ocidental atribuídas à poluição do ar. Aproximadamente, 236.000 ocorreram no Mediterrâneo Oriental, 200.000 na Europa, 176.000 na África e 58.000 nas Américas. As mortes remanescentes ocorreram em países desenvolvidos e de alta renda per capita, sendo na Europa (280.000), Américas (94.000), Pacífico Ocidental (67.000) e Mediterrâneo Ocidental (14.000) (WHO, 2012).

Dentre os fatores responsáveis pelo acúmulo de poluentes na atmosfera, está o padrão atual de desenvolvimento urbano, com a tendência à verticalização das metrópoles, a construção de edifícios cada vez mais altos e, ainda, pela ocupação desordenada em vários bairros de periferia, 
limitando, assim, as concentrações de áreas verdes e dispersão de poluentes atmosféricos, condições propícias ao desenvolvimento de problemas de saúde relacionados à má qualidade do ar. Além disso, a alta concentração do tráfego de veículos num espaço cada vez mais limitado e o aumento progressivo do parque industrial nas grandes cidades expõem grande parcela da população, diariamente, à emissão de poluentes liberados tanto por veículos automotores quanto pelas chaminés das indústrias (Paes et al., 2006).

Apesar dos esforços empreendidos e da redução sistemática da emissão de poluentes nas últimas décadas, os padrões de qualidade do ar são, frequentemente, ultrapassados e, com isso, vários programas governamentais em todo o mundo têm sido desenvolvidos no sentido de analisar e minimizar o impacto da poluição sobre a saúde humana, mas, apesar dos notáveis avanços obtidos nas últimas décadas em direção a um ambiente com ar mais limpo, os atuais níveis de poluição experimentados pela maior parcela da população humana continuam a se mostrar bastante danosos à saúde (Gouveia et al., 2006; Nardocci et al., 2013).

O maior exemplo deste padrão de desenvolvimento no Brasil é o estado de São Paulo que possui 645 municípios ocupando uma área de, aproximadamente, $249.000 \mathrm{~km}$. É a unidade da federação com maior ocupação territorial e maior contingente populacional, com cerca 44.750 .000 habitantes. Somente a Região Metropolitana de São Paulo (RMSP), que é formada por 39 municípios, concentra, aproximadamente, 20 milhões de habitantes, dos quais 12.038.175 vivem na capital (IBGE 2016). É o estado com maior desenvolvimento econômico, concentrando a maior frota automotiva, correspondente 18.286.849. Somente no município de São Paulo foram registrados, em números atualizados, 6.025.302 de automóveis (DETRAN SP- 2017).

A elevação da concentração populacional, do desenvolvimento industrial e do aumento da frota veicular contribui para o aumento da poluição atmosférica, afetando a todos de uma maneira geral, porém, a população de baixa renda é ainda mais vulnerável às mazelas do ar poluído 
nas grandes cidades, uma vez que a má alimentação, a exposição a ambientes insalubres, a precariedade das moradias, a falta de infraestrutura urbana básica e de saúde, o subemprego, entre outros aspectos, são condições agravantes para o desenvolvimento de doenças associadas à poluição (Freitas et al., 2004; Cançado et al., 2006; Danni-Oliveira et al.; Tresmondi et al., 2008).

Um dos principais problemas ainda nas grandes cidades na atualidade é a questão da mobilidade urbana. A cidade de São Paulo, a sexta maior cidade do mundo, com uma área territorial de $875,19 \mathrm{~km}^{2}$, concentrando uma população estimada em 11.895.893 habitantes (IBGE, 2014), e cerca de 18 milhões de deslocamentos diários por suas vias, cria uma permanente necessidade de monitoramento e geração de estratégias que visem facilitar o fluxo e o deslocamento veicular como projetos alternativos para o transporte coletivo (Ferrara, 2010; Freitag, 2012). A análise da dinâmica populacional e da mobilidade da RMSP mostrou que, quanto maior a faixa de renda, maior a tendência da mobilidade motorizada das pessoas. A capital paulista destaca-se como principal centro financeiro e econômico da América Latina, além de ter forte vocação turística (IPEA, 2013). Em apenas dez anos, entre 2002 e 2012, 1,6 milhão de carros passaram a circular na cidade de São Paulo. Isso equivale a uma média de 13 mil automóveis a mais todo mês nas ruas do município. Por outro lado, os investimentos em infraestrutura viária e no transporte coletivo de alta capacidade foram insuficientes para atender o aumento da demanda por locomoção na cidade. Seja devido ao trabalho, ao estudo, seja devido a questões de saúde, comércio ou lazer, as pessoas, os bens e os serviços precisam circular. Ir e vir em megalópoles como São Paulo tornou-se muito mais complexo do que era há uma década, tornando-se um desafio para grandes metrópoles e cidades de médio porte no mundo inteiro (Tatto, 2015). Esse descompasso tornou inevitável a crise de mobilidade no município, causando congestionamentos e implicando em perdas bilionárias de dois tipos: o tempo ocioso das pessoas no trânsito e os gastos pecuniários impostos à sociedade, com um custo anual ao município de mais de $\mathrm{R} \$ 40$ bilhões, 
valor equivalente a 1\% do PIB brasileiro e 7,5\% do PIB paulistano (Cintra, 2014). Os congestionamentos são limitantes do tempo dos cidadãos, elevam a poluição da atmosfera, e afetam a saúde e a economia. A mobilidade tornou-se um desafio aos governos com o crescimento das populações das cidades grandes. Aos poucos, os trens, os bondes elétricos, os ônibus e os metrôs foram substituindo-se uns aos outros, ou concorrendo entre si, num sistema de complementação de serviços para atenuação da demanda reprimida de passageiros. Mas, concomitantemente, a essa rápida transformação de tecnologias e uso de energias diversas pelos transportes coletivos, a produção automobilística teve uma curva de ascensão acentuada e sustentada (Silva \& Miraglia, 2009). Na cidade de São Paulo, uma pesquisa Origem/Destino (O/D), realizada pelo Metrô em 2007, apontou que $37,1 \%$ dos habitantes da Capital realizavam suas viagens por coletivo, enquanto outros $30,6 \%$ por transporte individual, $31,6 \%$ a pé e somente 0,7\% de bicicleta (IPEA, 2011b).

O transporte público coletivo, municipal e metropolitano, atualmente, é responsável por 10,1 milhões de viagens diárias, enquanto os demais passageiros utilizam-se do transporte individual motorizado e não motorizado. São Paulo possui milhares de vias e cruzamentos, o que acarreta um alto nível de semaforização aumentando consideravelmente o tempo de permanência no trânsito. O congestionamento pode ser avaliado e seus custos podem ser calculados de diferentes maneiras. Há quem observe o total de quilômetros de vias nas quais o fluxo de veículos está parado, o gasto de combustíveis, a emissão de gases poluentes, mas há aqueles que o contam em minutos ou horas de atraso, de tempo perdido (Vasconcelos, 2014). Um estudo do Programa Cidades Sustentáveis demonstrou a volta do crescimento da média de congestionamentos em dias úteis, nos horários de pico, na cidade de São Paulo. Enquanto que, em 2010, foram registrados 99 $\mathrm{km}$ de congestionamento, no ano seguinte a média caiu em $5 \mathrm{~km}$, mas voltou a subir em 2012, alcançando 105 km (Programa Cidades Sustentáveis, 2013). A média de velocidade automotiva no Município de São 
Paulo, atinge uma média de aproximadamente, $22 \mathrm{~km} /$ hora (CET, 2014) (Gráfico1)

Entre os modais de mobilidade, o transporte motorizado é o que mais ocupa o espaço público, causa congestionamentos, emite maior quantidade de gases de efeito estufa (GEE) na atmosfera, prejudicando a qualidade do ar, e produzindo um impacto significativo na saúde da população, além de causar enormes prejuízos à economia das cidades. No sentido de priorizar o transporte público e promover a sua velocidade, em 2013, a Prefeitura de São Paulo promoveu diversos sistemas em operação nas áreas de trânsito e transporte, com adoção de vários protocolos no sentido de otimizar as viagens com a diminuição das horas perdidas nos congestionamentos, na melhoria da qualidade do ar, na diminuição dos níveis de estresse e consequente diminuição de riscos à saúde (Tatto, 2015).

Gráfico 1 - Velocidade média no trânsito de São Paulo

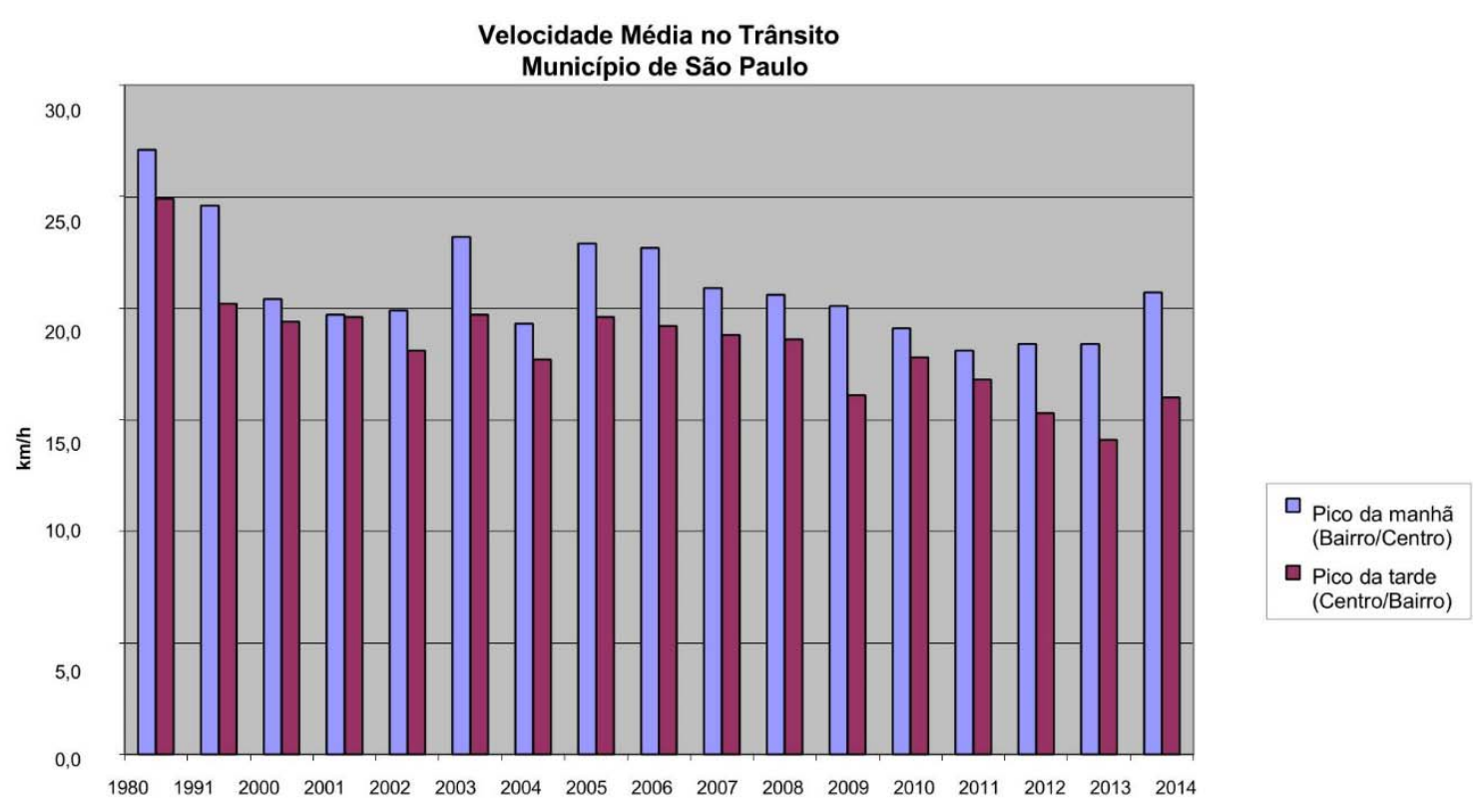

Fonte: Companhia de Engenharia de Tráfego/CET - Relatório de Desempenho -Velocidades Elaboração: SMDU/Deinfo

O aumento da frota veicular gerou um crescente aumento na concentração de poluentes atmosféricos, fato este observado em todo o mundo. Vários estudos têm demonstrado a associação entre níveis diários 
de diversos poluentes e uma série de efeitos deletérios à saúde, que vão desde as malformações congênitas ou menor ganho de peso durante a gestação, passando por adoecimentos por causas específicas ligadas, principalmente, ao trato respiratório e cardiovascular e, finalmente, um aumento na mortalidade total na população (Gouveia et al., 2006). Estudos de séries temporais realizados em Cubatão encontraram associação significativa entre as concentrações no ar de material particulado $\left(\mathrm{PM}_{10}\right)$ e o total de internações por doenças respiratórias, e doenças cardiovasculares em adultos (Nardocci et al., 2013). Outros estudos têm sido desenvolvidos no sentido de se demonstrar a consistente associação entre a poluição do ar e o aumento do risco de doenças cardiovasculares, não somente pelo aumento no número de mortes, mas também pela maior ocorrência de infarto agudo do miocárdio, de arritmias complexas e redução da variabilidade da frequência cardíaca, este último considerado um indicador de risco para morte súbita. Encontrou-se, também, uma predisposição ao aumento dos níveis da pressão arterial em pacientes previamente normotensos (Pope et al., 2004b).

Estudos epidemiológicos multicêntricos e de meta-análise evidenciaram um aumento na mortalidade de pessoas expostas a níveis distintos do material particulado (PM). Os principais foram o "APHEA-2" publicado por Anderson et al., em 2005, o estudo transversal "US 27 cities" (Franklin et al., 2007) e o "France 9 cities" por Le Tertre et al. (2002). Além desses, o estudo do Comittee on the Medical Effects of Air Pollution (COMEAP), realizado em 2006, demonstrou que pessoas expostas ao material particulado $\left(\mathrm{PM}_{10}\right)$, durante o período de um ano, apresentaram índices de mortalidade diferente de acordo com os níveis de concentração do poluente. Nos locais nos quais houve um aumento de $10 \mu \mathrm{g} / \mathrm{m} 3 /$ dia de $\mathrm{PM}_{10}$, encontrou-se um RR de 1,4 (IC 0,7-2,2) e, quando o aumento registrado foi de $20 \mu \mathrm{g} / \mathrm{m}^{3}$, este RR aumentou para 1,8 (IC 1,4-2,4).

O estudo HNR (Heinz Nidorf Recall) foi um estudo de coorte (de 2000 a 2003), que utilizou 4.814 participantes de ambos os sexos, de 45 a 75 anos, em que foram avaliadas as possíveis consequências a uma exposição 
prolongada à $\mathrm{PM}_{10}$ e também da influência da distância das residências destes sujeitos a local de maior tráfego de veículos (Bauer et al., 2010). Uma análise de regressão linear múltipla foi feita para estimar a associação entre os poluentes atmosféricos e tráfego, utilizando como desfecho a medida da espessura da camada íntima-média das carótidas (EIMC), que tem surgido como um teste de grande potencial para a avaliação não invasiva da doença aterosclerótica, sendo uma ferramenta valiosa também no diagnóstico e na classificação do risco cardiovascular.

Neste estudo, foram feitos ajustes das variáveis (fatores de risco) de acordo com a cidade ou residência, idade, sexo e estilo de vida. A média dos valores encontrados da EIMC para os 3.380 sujeitos analisados foi de 0,66 $\mathrm{mm}$ (desvio padrão de $0,16 \mathrm{~mm}$ ). Um aumento da $\mathrm{PM}_{2.5}$ de $4,2 \mu \mathrm{g} / \mathrm{m}^{3}$ produziu um aumento de $4,3 \%$ (IC $95 \% 1,9 \%$ a $6,7 \%$ ) na espessura da íntima média das carótidas, enquanto que um acréscimo de $6,7 \mu \mathrm{g} / \mathrm{m}^{3}$ de $\mathrm{PM}_{10}$ produziu um aumento $1,7 \%$ (IC $95 \%$ 0,7\% a 4,1\%) e, quando a variável analisada foi a distância dos locais de maior tráfego, cujo valor médio foi de $1.939 \mathrm{~m}$, encontrou-se um acréscimo na ordem de 1,2\% (IC 95\% 0,2\% a $2,6 \%)$ na espessura da íntima-média das carótidas. Concluiu-se, assim, sobre a clara associação entre uma longa exposição à PM 2.5 e aterosclerose, contribuindo, assim, para a hipótese que este material particulado possa ser um fator aterogênico (Bauer et al., 2010).

Baseado em dados já descritos sobre as diversas causas que implicam no desenvolvimento de doenças cardiovasculares e nos altos índices de morbimortalidade, há um constante interesse em se diagnosticar precocemente a doença arterial coronariana (DAC) em indivíduos ainda assintomáticos, visto que, mesmo a coronariopatia obstrutiva avançada, muitas vezes, pode se manifestar por mínimos sintomas ou mesmo cursar de forma silenciosa. Esta estratificação de risco permite a identificação de indivíduos com maior potencial para eventos cardíovasculares adversos, podendo se estabelecer condutas terapêuticas e profiláticas capazes de reduzir o risco cardiovascular (Rehdberg et al., 2009). 
Por conta de profundas transformações sociais, econômicas e demográficas já descritas, o Brasil passou a vivenciar um grande crescimento da ocorrência de doenças crônicas nas últimas décadas. Fatores como urbanização acelerada e modificações da estrutura familiar colaboraram para que, em 2002, tais enfermidades já respondessem por $75 \%$ dos gastos com internações hospitalares no Sistema Único de Saúde (SUS). Devido à escassez de estudos longitudinais em populações adultas que investigassem as mudanças ocorridas em várias regiões brasileiras, a incidência dessas doenças e seus fatores de risco ainda são pouco conhecidos. Buscando sanar essa lacuna, o Ministério da Saúde, em parceria com o Ministério da Ciência e Tecnologia, propôs o desenvolvimento do Estudo Longitudinal de Saúde do Adulto ELSA - estudo de coorte que busca investigar o desenvolvimento de doenças crônicas, em particular, das cardiovasculares e do diabetes. Para isso, foi selecionado um consórcio formado por seis instituições de diferentes estados do país: Fundação Oswaldo Cruz (Rio de Janeiro), Universidade de São Paulo (USP), e as universidades federais da Bahia (UFBA), Espírito Santo (UFES), Minas Gerais (UFMG) e Rio Grande do Sul (UFRGS).

O ELSA Brasil é uma investigação multicêntrica de coorte composta por 15 mil funcionários de seis instituições públicas de ensino superior e pesquisa das regiões Nordeste, Sul e Sudeste do Brasil. A pesquisa tem o propósito de investigar a incidência e os fatores de risco para doenças crônicas, em particular, as cardiovasculares e o diabetes. Em cada centro integrante do estudo, os sujeitos da pesquisa - com idade entre 35 e 74 anos - fazem exames e entrevistas nas quais são avaliados aspectos como condições de vida, diferenças sociais, relação com o trabalho, gênero e especificidades da dieta da população brasileira. Além de fomentar o desenvolvimento de novas investigações, o estudo teve a sua "onda 1" entre 2008 e 2010, a "onda 2 terminada em 2014 e já iniciou a "onda 3" que estava programada para o início de 2017. O estudo visa a uma fundamental contribuição para a adequação e criação de novas políticas públicas de saúde que atendam às necessidades nacionais. 
As doenças crônicas são responsáveis pelos maiores índices de mortalidade e morbidade no país, e seu aumento substancial não só traz consequências negativas para a qualidade de vida da população adulta do país, como também responde pelos maiores gastos com assistência hospitalar no Sistema Único de Saúde. No entanto, ainda existem importantes lacunas de conhecimento sobre a incidência das enfermidades crônicas e seus fatores de risco. Políticas de controle dessas doenças têm sido formuladas de acordo com informações de estudos oriundos de países desenvolvidos. Dentro dessa conjuntura, o ELSA surge como pesquisa essencial para uma gestão da saúde pública no Brasil. O estudo pretende investigar associações entre as doenças crônicas - principalmente cardiovasculares e diabetes - e fatores biológicos, comportamentais, ambientais, ocupacionais e sociais. Com Centros de Investigação distribuídos em seis estados, objetiva-se, também, a análise de possíveis variações regionais relacionadas a essas enfermidades no país (ELSABrasil, 2016). 
2 REVISÃo de LITERATURA 


\section{REVISÃO DE LITERATURA}

2.1 Doenças cardiovasculares: incidência e fatores de risco

Segundo a Organização Mundial da Saúde (OMS), as doenças cardiovasculares são responsáveis por $30 \%$ do total de mortes no mundo. Estima-se que 17,5 milhões de pessoas morreram em consequência de doenças cardiovasculares em 2012, sendo 7,4 milhões por doença aterosclerótica coronariana e 6,7 milhões por acidente vascular encefálico (WHO, 2016).

No Brasil, as doenças cardiovasculares (DCV) ainda são a principal causa de morte em ambos os sexos, sendo responsáveis por cerca de $20 \%$ de todas as mortes em indivíduos acima de 30 anos. Segundo o Ministério da Saúde, ocorreram no ano de 2016 aproximadamente 349338 mortes por doenças cardiovasculares (SBC, 2017).

Apesar de ser a principal causa de morte no Brasil, a mortalidade por DCV vem caindo nas últimas décadas, sendo que a redução maior ocorreu nas regiões Sul e Sudeste, e na faixa etária acima de 60 anos. Apesar dessa redução, ainda se observam taxas elevadas de morte por essas doenças que poderiam ter seus níveis minimizados com a intensificação do controle dos fatores de risco, com a criação de políticas públicas de saúde eficientes que facilitassem o acesso da população a serviços de saúde e programas de atenção primária sobre controle de obesidade, hipertensão, dislipidemias, tabagismo, diabetes e sedentarismo (Mansur et al., 2012).

Segundo Van Eyken \& Moraes (2009), cerca de $80 \%$ dos casos de morte por doenças cardiovasculares estariam associados a fatores de risco já conhecidos, sendo considerados mais importantes aqueles que apresentam alta prevalência em muitas populações e, ainda, os que têm maior impacto na estratificação de risco para doenças isquêmicas cardíacas e acidente vascular cerebral. O diabetes mellitus, seria responsável por $6 \%$ 
das mortes em todo o mundo, a obesidade (responsável por 5\%,) a inatividade física (6\%), a hiperlipidemia (5\%) e da hipertensão arterial por $13 \%$ das mortes em todo o mundo (WHO, 2012). Outro importante fator de risco modificável é o tabagismo, responsável por $9 \%$ das mortes em todo o mundo, que, assim como a inatividade física, a obesidade e o são importantes entraves no controle das doenças cardiovasculares (WHO, 2012). Com a idade, a obesidade apresenta tendência de aumento, em consequência das reduções nos níveis de atividade física e diminuição do metabolismo de repouso, agravada, ainda, pelo aparecimento de comorbidades, que podem limitar ainda mais a movimentação e, por consequência, o exercício físico. Esta associação pode ser observada em estudos que demonstraram prevalência do excesso de peso a partir dos 30 e 40 anos de idade (Viebig et al., 2006). Pessoas insuficientemente ativas aumentam de $20 \%$ a $30 \%$ o risco de mortalidade (WHO, 2010).

Estima-se que 3,2 milhões de pessoas morrem a cada ano devido à inatividade física, fato este que pode ser atribuído ao atual ritmo de vida das pessoas, como: avanço da tecnologia, estudos, ritmo de trabalho, maior oferta e consumo de produtos de alto valor energético; e menor tempo à prática de atividades físicas, a lazer e à alimentação saudável, sendo a obesidade e o sedentarismo considerados os principais fatores de risco para o desenvolvimento de doenças cardiovascular (Carlucci et al., 2013).

No Brasil, o Ministério da Saúde divulgou, recentemente, um levantamento que mostra um retrato do estilo de vida (alimentação e atividade física) da população brasileira. Segundo o inquérito Vigilância de Fatores de Risco e Proteção para Doenças Crônicas por Inquérito Telefônico (Vigitel), 52,5\% dos brasileiros estão acima do peso ideal, de acordo com dados de 2014 (Portal Brasil, 2015).

Em uma análise sistemática baseada no Global Burden of Disease Study 2010, que avaliou os níveis de mortalidade global e regional por 235 causas diferentes em 20 grupos etários entre 1990 e 2010, a exposição à poluição do ar passou a ser considerada como um dos dez principais fatores de risco para a saúde em nível mundial. A poluição do ar é a $11^{a}$ causa de 
mortalidade global para os países da Europa Ocidental, 14 para a Europa Central e $15^{\mathrm{a}}$ para a Europa Oriental, que inclui a Rússia (GBD, 2010). A exposição diária à poluição atmosférica na Europa é, agora, reconhecida como um dos grandes fatores de risco à saúde da população. Pela primeira vez desde o início da sua publicação, o Global Burden of Disease Study classificou o fator ambiental dentre os mais importantes para a carga de doenças em todo o mundo (Lozano et al., 2012).

A somatória de cada um destes fatores de risco descritos, mais o sinergismo entre alguns desses fatores aumenta exponencialmente os riscos de desenvolvimento da doença cardiovascular. Diversos algoritmos têm sido criados com base em análises de regressão de estudos populacionais, por meio dos quais a identificação do risco global é aprimorada substancialmente. Entre os algoritmos existentes, o Escore de Risco de Framingham, o Escore de Risco de Reynolds - que inclui a proteína Creativa e o antecedente familiar de doença coronariana prematura, ainda $\mathrm{O}$ Escore de Risco Global e o Escore de Risco pelo Tempo de Vida, são as opções de escores de risco (ER). O ER de Framingham estima a probabilidade de ocorrer infarto do miocárdio ou morte por doença coronariana no período de 10 anos em indivíduos sem diagnóstico prévio de aterosclerose clínica identificando adequadamente indivíduos de alto e baixo risco; o ER de Reynolds estima a probabilidade de infarto do miocárdio, acidente vascular encefálico (AVE), morte e revascularização do miocárdio em 10 anos; O ER Global estima o risco de infarto do miocárdio, AVE, insuficiência vascular periférica ou insuficiência cardíaca em 10 anos (Xavier et al., 2013). Já o ER pelo Tempo de Vida, utilizado a partir dos 45 anos, avalia a probabilidade de um indivíduo a partir dessa idade apresentar um evento isquêmico. A combinação de um escore de curto prazo com outro de longo prazo permite melhor estimativa de risco. Existem três etapas para esta estratificação do risco: (1) a determinação da presença de doença aterosclerótica significativa ou de seus equivalentes; (2) a utilização dos escores de predição do risco; e (3) a reclassificação do risco predito pela presença de fatores agravantes do risco. O ER Global deve ser utilizado na 
avaliação inicial entre os indivíduos para identificar aqueles que são considerados de baixo risco com probabilidade < $5 \%$ de apresentarem os principais eventos cardiovasculares (DAC, AVE, doença arterial obstrutiva periférica ou insuficiência cardíaca) em 10 anos. Os pacientes classificados nessa categoria e que apresentem histórico familiar de doença cardiovascular prematura serão reclassificados para risco intermediário. São considerados ainda de risco INTERMEDIÁRIO homens com risco calculado $\geq 5 \%$ e $\leq 20 \%$ e mulheres com risco calculado $\geq 5 \%$ e $\leq 10 \%$ de ocorrência de algum dos eventos citados. São considerados de ALTO RISCO aqueles com risco calculado $>20 \%$ para homens e $>10 \%$ para mulheres no período de 10 anos (Xavier et al., 2013).

Uma revisão sistemática apresentada no 2010 Global Burden of Disease (GBD, 2010), que avaliou os principais riscos para a saúde global, constatou que poluição do ar sob a forma de material particulado contribuiu anualmente para mais de 3,2 milhões de mortes prematuras em todo o mundo e mais de 74 milhões de pessoas com anos de vida saudável perdidos (HEI, 2012).

Dentre aqueles que estudaram os efeitos das exposições de curta duração, um deles realizado em 90 cidades dos EUA (incluindo 50 milhões de indivíduos), encontrou-se um aumento da mortalidade cardiopulmonar diária de $0,31 \%$ para cada aumento de $10 \mu \mathrm{g} / \mathrm{m}^{3}$ de $\mathrm{PM}_{10}$ medido em período de 24 horas (Samet et al., 2000).

Um grande estudo desenvolvido nesta área nos Estados Unidos, o National Morbity, Mortality, and Air Pollution Study (NMMAPS), avaliou a mortalidade causada por poluição atmosférica utilizando dados obtidos de 90 cidades. Procurou-se avaliar a associação entre pequenas variações de material particulado e a mortalidade dos cidadãos nesses municípios. As principais conclusões foram que o material particulado exerceu influência 
independente sobre a mortalidade, quando comparado a outros poluentes gasosos $\left(\mathrm{NO}_{2}, \mathrm{SO}_{2}\right.$ e $\left.\mathrm{O}_{3}\right)$ (Bell et al., 2004, 2007).

Outro estudo também nos Estados Unidos, Zanobetti et al. (2007) avaliaram 196.000 sobreviventes de Infarto Agudo do Miocárdio (IAM) em 21 cidades americanas e concluíram que o risco de complicações, como morte por insuficiência cardíaca descompensada, era maior naqueles expostos a uma maior quantidade de $\mathrm{PM}_{10}$ por um maior período de tempo.

Muitos outros estudos, então, passaram a ser desenvolvidos fora dos Estados Unidos, dentre eles e um dos mais importantes o Air Pollution and Health: European Approach (APHEA), que foi desenvolvido na Europa, avaliou os efeitos da poluição atmosférica, por meio da mensuração diária dos níveis de material particulado $\left(\mathrm{PM}_{10}\right)$, sobre as taxas de mortalidade e o resultado mostrou um incremento de 0,2 a $0,6 \%$ de mortes diárias para cada aumento de $10 \mu \mathrm{g} / \mathrm{m}^{3}$ na concentração diária de $\mathrm{PM}_{10}$. As conclusões foram parecidas com outros estudos anteriores realizados nos Estados Unidos, como foi o caso do NMMAPS (Katsouyanni, 2003) e do estudo Air Pollution and Health: A European and North American Approach (APHENA) (Samoli et al., 2008).

Em relação aos efeitos crônicos, Pope et al. (2004), em um acompanhamento de 500.000 adultos por um período de 16 anos, encontraram aumentos de $8 \%$ a $18 \%$ na mortalidade por doença cardíaca isquêmica, insuficiência cardíaca e arritmias para cada $10 \mu \mathrm{g} / \mathrm{m} 3$ de elevação na concentração de $\mathrm{PM}_{2,5}$ em exposições prolongadas. Com a redução da $\mathrm{PM}_{2,5}$ verificada num período de oito anos posterior ao início do estudo (1974-1989), houve uma redução do risco da mortalidade total $(R R=0,73)$ e de mortalidade cardiovascular $(R R=0,69)$ para cada $10 \mu \mathrm{g} / \mathrm{m}^{3}$ de redução de $\mathrm{PM}_{2,5}$ em médias diárias. Em outra pesquisa, o mesmo autor demonstrou que o aumento de $10 \mathrm{~g} / \mathrm{m}^{3}$ na média diária na concentração de $\mathrm{PM}_{2.5}$, seria capaz de incrementar o risco relativo (RR) de mortalidade por doenças cardiovasculares de 0,4\% a 1,0\% (Pope \& Dockery, 2006).

Dentro do estudo multicêntrico European Study of Cohorts for Air Pollution Effects (ESCAPE, 2014), houve uma investigação específica no 
sentido de se avaliar a associação da exposição a longo prazo a diversos poluentes atmosféricos e mortalidade por doença cardiovascular (DCV) e foram utilizados dados de 22 estudos de coorte europeus. Usando um protocolo padronizado, a exposição à poluição do ar específico da área de estudo no endereço residencial foi caracterizada como concentrações médias anuais de: óxidos de nitrogênio ( $\mathrm{NO} 2$ e NOx); partículas com diâmetros inferiores a 2,5 um $\left(\mathrm{PM}_{2,5}\right)$, inferior a $10 \mathrm{~m}\left(\mathrm{PM}_{10}\right)$, e $10 \mu \mathrm{m}$ a 2,5 $\mu \mathrm{m}$ (PM grossa). A absorção $\mathrm{PM}_{2.5}$ foi estimada por modelos de regressão de uso do solo e indicadores de tráfego. A população estudada foi de 367.383 participantes, com 9.994 mortes por doenças cardiovasculares (incluindo 4.992 de doença cardíaca isquêmica, 2264 por infarto do miocárdio e 2.484 por doença cerebrovascular). A maioria das taxas de risco obtiveram resultados de, aproximadamente, 1,0, exceto para a massa das partículas e mortalidade por doença cerebrovascular; para $\mathrm{PM}_{2.5}$, o hazard ratio foi de 1,21 (IC 95\% 0,87-1,69) por $5 \mu \mathrm{g} / \mathrm{m}^{2}$ e para $\mathrm{PM}_{10}$ de 1,22 (IC $95 \%$ 0,91-1,63) por $10 \mu \mathrm{g} / \mathrm{m}^{2}$. Na análise conjunta dos dados de 22 grupos europeus, a maioria das taxas de risco para a associação entre poluentes atmosféricos e mortalidade por doenças cardiovasculares em geral e com as doenças cardiovasculares em específico foi de, aproximadamente, 1,0; com exceção da mortalidade por doença cerebrovascular para os quais não havia evidências sugestivas de associação (Beelen et al., 2014).

Diversos trabalhos demonstram haver efeitos deletérios à saúde humana, especificamente no que diz respeito à morbidade por doenças cardiovasculares em pessoas expostas tanto em períodos de curta duração como em longos períodos de contato com poluentes atmosféricos.

Dados do Global Burden of Disease, Injuries and Risk Factor study, que foi o primeiro artigo de atualização do Global Burden of Disease de 2013, evidenciam que parte importante da carga de doenças no Brasil e no 
mundo está ligada às doenças cardiovasculares. Nesse estudo, a doença aterosclerótica coronariana (DAC) aparece como a principal causa de anos de vida perdidos (years of life lost) e de anos de vida ajustados para incapacitação (disability-adjusted life years) no mundo e no Brasil dentre 79 fatores de risco avaliados em três grupos principais: comportamental, ambiental e ocupacional, e ainda fatores de risco metabólicos, sendo que os fatores mais significativos para avaliação da carga global de doenças foram: dieta, hipertensão arterial sistólica, má nutrição materno infantil, tabagismo, poluição atmosférica e aumento do índice de massa corpórea (IMC), sendo que a poluição do ar foi responsável por 5,5 milhões de mortes e 141,5 milhões de indivíduos incapacitados em todo o mundo. O acidente vascular encefálico (AVE) ocupa a terceira posição como principal causa de anos de vida perdidos e de anos de vida perdidos ajustados para incapacitação no mundo, perdendo para as infecções respiratórias. No Brasil, o AVE também ocupa a terceira posição como principal causa de anos de vida perdidos (GBD, 2013). Segundo este levantamento, a partir dos dados dos relatórios de 2010 e 2013, 22\% da população mundial teve redução nos anos de vida com qualidade por efeitos da poluição do ar.

Foi também demonstrado por outros autores um aumento de 0,8\% e $0,7 \%$ nas internações por insuficiência cardíaca e por doença isquêmica coronariana, respectivamente, para cada elevação de $10 \mu \mathrm{g} / \mathrm{m}^{3}$ de $\mathrm{PM}_{10}$ (Morris et al., 2011). Outro estudo, utilizando, desta vez, a $\mathrm{PM}_{2.5}$, observou um aumento de $1,28 \%$ no risco de insuficiência cardíaca e de 4,5\% nos eventos por síndromes coronárias agudas, para cada elevação de $10 \mu \mathrm{g} / \mathrm{m}^{3}$ diário deste poluente (Dominici et al., 2006).

Várias outras pesquisas mostraram que a associação entre elevações transitórias de poluição por $\mathrm{PM}_{2,5}$ e a incidência de infarto agudo do miocárdio, quer fosse quando avaliado por apenas algumas horas após a exposição, ou ainda, num período de 24 horas (Pope et al., 2006; Torén et al., 2007; Brook et al., 2008).

Estudos demonstraram, ainda, uma maior incidência de acidentes vasculares encefálicos (AVE) isquêmicos e hemorrágicos, diretamente 
relacionada com um aumento transitório dos níveis de $\mathrm{PM}_{10}$ em avaliações diárias dos níveis do poluente (Hong et al., 2002).

Um estudo em nove cidades americanas foi realizado para avaliar também a associação entre variações nos níveis de $\mathrm{PM}_{10} \mathrm{e}$ o número de internações hospitalares por AVE isquêmico e hemorrágico. Foram incluídos indivíduos com idade maior ou igual a 65 anos. Os resultados foram avaliados separadamente em relação aos episódios isquêmicos $(n=155.503)$ e aos hemorrágicos $(n=19.314)$. Só houve associação entre as variações da $\mathrm{PM}_{10}$ com as internações por $\mathrm{AVE}$ isquêmico, sendo que, para cada aumento de $23 \mu \mathrm{g} / \mathrm{m}^{3}$ de concentração de $\mathrm{PM}_{10}$, havia um aumento de $1,03 \%$ (IC 95\% 0,04\% a 2,04\%) nas internações hospitalares (Wellenius et al., 2005).

Vários trabalhos têm, por outro lado, chamado a atenção para elevações nos níveis de pressão arterial em períodos de maior poluição atmosférica como aconteceu, por exemplo, em janeiro de 1985 na Europa Central, quando se verificou uma associação entre a poluição por material particulado e o aumento significativo dos níveis pressóricos. Esta observação foi registrada em habitantes residentes na cidade de Augsburg na Alemanha, participantes do estudo MONICA (Multinational MONItoring of trends and determinants in CArdiovascular disease), mesmo após o ajuste de outras variáveis (fatores de risco para hipertensão arterial) (Ibald et al., 2001).

Na cidade de Boston, doentes em reabilitação cardíaca pós-internação hospitalar foram mantidos em observação para controle dos níveis de pressão arterial por meio da monitorização residencial de pressão arterial (MRPA), tendo sido verificado um aumento de $2,8 \mathrm{~mm}$ de $\mathrm{Hg}$ na pressão sistólica e de 2,7 mm de $\mathrm{Hg}$ na pressão diastólica na média da aferição diária. Estes achados foram correlacionados com um aumento médio de $10,5 \mu \mathrm{g} / \mathrm{m}^{3}$ de $\mathrm{PM}_{2,5}$ nos cinco dias que antecederam o registro das alterações nos níveis pressóricos (Brook et al. , 2007).

Além da evidência da relação linear entre o risco de doenças cardiovasculares e as variações nas concentrações de $\mathrm{PM}_{10}$ e de $\mathrm{PM}_{2,5}$, foi 
também demonstrado que os efeitos deletérios cardiovasculares das partículas inaláveis eram acentuados pela presença de diabetes (duplicação do risco), obesidade, hipertensão, doenças pulmonares crônicas e cardiovascular prévia, sendo também mais evidentes em indivíduos mais idosos (Zanobetti et al., 2001; Dubowsky et al., 2006; Peel et al., 2007).

Tal como para os efeitos agudos, foi também evidenciado um risco cardiovascular maior em indivíduos expostos cronicamente a partículas $\mathrm{PM}_{10}$ e $\mathrm{PM}_{2,5}$, mesmo sendo portadores de outros fatores de risco, como dislipidemia, diabetes, obesidade, hipertensão, idade avançada ou antecedente de doenças pulmonares ou outras de origem cardiovascular (Bateson et al., 2004; Peel et al., 2007).

De acordo com Pope et al. (2007), a evidência epidemiológica sugere que os efeitos cardiovasculares adversos dependem não só das concentrações dos poluentes, mas, também, do tempo de exposição e que as mais prolongadas têm efeitos cumulativos mais persistentes e mais importantes do que as curtas, embora estas últimas possam ter um impacto imediato mais evidente.

O Multi-Ethnic Study of Atherosclerosis and Air Pollution (MESA) foi um estudo prospectivo de coorte de 10 anos, em que foi repetida sequencialmente a medida do escore de cálcio da artéria coronária por tomografia computadorizada em 6.795 participantes com idades entre 45-84 anos inscritos em seis regiões metropolitanas nos EUA. Análises repetidas foram feitas em quase todos os participantes entre 2002 e 2005, para um subconjunto de participantes entre 2005 e 2007, e por metade de todos os participantes entre 2010 e 2012. A EIMC foi medida por ultrassonografia (USG) em todos os participantes no início do estudo e em 3.459 participantes no período entre 2010-2012. O principal objetivo foi examinar a associação entre ambos e a progressão da calcificação da artéria coronária, e da EIMC em sujeitos submetidos a longos períodos de exposição a concentrações de poluentes do ar ambiente (dentro dos seis regiões metropolitanas), ajustando-se o modelo estatístico para idade, sexo, etnia, características socioeconômicas, fatores de risco cardiovascular, e técnicas 
utilizadas na realização da tomografia computadorizada e o USG Doppler de carótidas.

A principal conclusão do estudo MESA foi de que o aumento da exposição em longo prazo da $\mathrm{PM}_{2,5}$ estaria associada a uma progressão mais rápida da aterosclerose coronária e a um risco aumentado de eventos coronários, tais como síndromes coronarianas agudas. Para testar esta hipótese, foram realizadas medidas seriadas de poluentes do ar e, simultaneamente, os dados da EIMC dos participantes e analisados por pesquisadores da Universidade de Washington. Concomitantemente à medição das concentrações dos poluentes, foi analisada a variabilidade destes dados de acordo com a características das seis cidades incluídas no estudo.

Os resultados forneceram evidências diretas de que a exposição em longo prazo a material particulado fino $\left(\mathrm{PM}_{2,5}\right)$ e o óxido de nitrogênio (NOx) do ar aceleram o desenvolvimento da aterosclerose em indivíduos saudáveis. O estudo constatou, ainda, que algumas pessoas podem ser mais suscetíveis, incluindo indivíduos mais idosos e aqueles com quadro prévio de hipertensão. Não houve diferenças significativas nos resultados quando o modelo foi ajustado para gênero e raça (Kaufman, 2016).

Outros estudos ainda observaram a relação entre o material particulado fino e outros poluentes correlatos, com uma maior predisposição a arritmias cardíacas, dados estes encontrados em registros de pacientes que faziam controle periódicos do funcionamento de marca-passos cardíacos implantados (Rich et al.; Vedal et al., 2004; Metzger et al., 2007).

O European Study of Cohorts for Air Pollution Effects (ESCAPE) também investiga na Europa os efeitos de longo prazo da poluição atmosférica sobre a saúde humana. O projeto estima que o impacto da poluição do ar, em especial o material particulado fino, sobre a população europeia seja bastante alto. No entanto, estas projeções sempre foram baseadas, principalmente, em estudos realizados na América do Norte. A estratégia propõe utilizar, de forma eficiente, os dados de saúde obtidos de estudos de coortes europeias. 
Para estes estudos, a avaliação da exposição à poluição do ar baseiase no georreferenciamento domiciliar de cada um dos sujeitos participantes. Dentre os objetivos, está, ainda, o projeto de desenvolvimento de uma metodologia flexível para avaliação da exposição da população aos poluentes do ar (material particulado fino) em longo prazo e analisar as associações com índices de morbimortalidade por doenças crônicas na Europa, além das possíveis interferências na saúde perinatal, no aparecimento e agravamento de doenças respiratórias, como a asma em criança e a doença pulmonar obstrutiva crônica nos idosos e das doenças cardiovasculares nos adultos.

Pretende-se, ainda, estabelecer uma relação entre níveis de poluentes do ar e a incidência de câncer em suas diversas formas. Está sendo criada uma base de dados para estimativas quantitativas dos impactos em longo prazo da poluição do ar sobre a saúde da comunidade europeia (Escape, 2014). Em seus resultados preliminares referentes exclusivamente à metaanálise, os dados mostraram que a exposição por longos períodos à poluição do ar estaria associada a uma maior probabilidade de um primeiro evento coronariano (Stafoggia et al., 2014).

Estudos escandinavos indicaram diferentes níveis de exposição a determinados poluentes entre pessoas com diferentes níveis de educação e ocupação (Wittekoek et al., 1999; Zhu et al., 2002). Outra razão justificável para maior incidência de morbidade nesta população seria pelo fato de que a maioria das pessoas que tem menor instrução, geralmente, tem piores condições de vida, com alimentação inadequada e maior incidência de doenças preexistentes, muitas vezes, com assistência e tratamentos médicos precários e inadequados, o que levaria a uma maior predisposição a enfermidades relacionadas à poluição do ar.

Em estudo realizado no Brasil, Gouveia et al. (2003), num levantamento de séries temporais, mostraram que os indivíduos idosos são os mais suscetíveis a doenças causadas por poluentes atmosféricos. $O$ incremento progressivo dos níveis de poluentes estaria associado a uma 
maior morbidade por doenças cardiovasculares (Lin et al., 2003; Cendo et al.; Gouveia et al., 2006). Alterações nos níveis de pressão arterial e variação na frequência cardíaca foram observadas em controladores de tráfego monitorados no município de São Paulo (Lombardi et al., 2010).

Em outro estudo, foi observado também um aumento na incidência de arritmias cardíacas, principalmente agudas, em pessoas expostas a maiores níveis de $\mathrm{CO}$ e $\mathrm{NO}_{2}$ emitidos por veículos automotores (Santos, et al., 2008) e que os pacientes diabéticos também teriam uma maior suscetibilidade ao desenvolvimento de doenças cardiovasculares ligadas à poluição atmosférica (Pereira Filho et al., 2008).

Após levantamento de dados sobre internações hospitalares de pacientes idosos (64 anos ou mais), chegou-se à conclusão de que a poluição atmosférica em São Paulo exerce forte influência sobre o desenvolvimento de doenças cardiovasculares, gerando um impacto grande sobre as despesas de saúde pública do município (Miraglia et al., 2008)

A aterosclerose é um processo dinâmico e evolutivo a partir do dano endotelial que tem origem multifatorial e é considerada uma doença inflamatória da parede vascular, acometendo, principalmente, a camada íntima de artérias de médio e grande calibres (Santos et al., 2001).

A formação da placa aterosclerótica se inicia com a agressão ao endotélio vascular devido a diversos fatores de risco, como dislipidemia, diabetes, hipertensão arterial ou tabagismo. Como consequência, a disfunção endotelial aumenta a permeabilidade da íntima às lipoproteínas plasmáticas, favorecendo a retenção dessas no espaço subendotelial. Estas sofrem oxidação, causando a exposição de diversos determinantes antigênicos, tornando-as imunogênicas. O depósito de lipoproteínas na parede arterial, processo-chave no início da aterogênese, ocorre de maneira proporcional à concentração dessas lipoproteínas no plasma. Além do 
aumento da permeabilidade às lipoproteínas, outra manifestação da disfunção endotelial é o surgimento de moléculas de adesão leucocitária na superfície endotelial, processo estimulado pela presença de LDL oxidada (LDL-ox). Os monócitos e linfócitos são atraídos para a intimidade da parede arterial até o espaço subendotelial, em que se diferenciam em macrófagos, que, por sua vez, captam as LDL, transformando-se em células espumosas, que são o principal constituinte das estrias gordurosas. Uma vez ativados, os macrófagos são, em grande parte, responsáveis pela progressão da placa aterosclerótica mediante a secreção de citocinas, e de enzimas proteolíticas, que amplificam a inflamação. Os linfócitos $T$, embora menos numerosos que os macrófagos no interior do ateroma, são de grande importância na aterogênese (Hansson, 2005).

Alguns mediadores da inflamação estimulam a migração e proliferação das células musculares lisas da camada média arterial que formarão parte da capa fibrosa da placa aterosclerótica. As placas estáveis têm o predomínio de colágeno, organizado em capa fibrosa espessa. As instáveis apresentam atividade inflamatória intensa, especialmente nas suas bordas laterais, com grande atividade proteolítica, núcleo lipídico e necrótico proeminente, e capa fibrótica tênue passível de ruptura, expondo o material lipídico altamente trombogênico. Este processo, também conhecido por aterotrombose, é um dos principais determinantes das manifestações clínicas da aterosclerose (Libby \& Theroux, 2005).

Há dois mecanismos descritos sobre os efeitos da poluição do ar, em especial, do material particulado, que contribuem para o desenvolvimento da doença aterosclerótica. O primeiro é um processo de estresse oxidativo que ocorre nos pneumócitos após o contato de agentes poluentes externos inalados como material particulado, fibras minerais, metais e policarbonetos com a superfície dos alvéolos desencadeando a liberação de mediadores pró-inflamatórios diretamente pelas células pulmonares (Brook et al., 2010). Apesar de todos os organismos aeróbios serem protegidos por processos antioxidantes enzimáticos e não enzimáticos, um desbalanço entre agentes pró-oxidantes e antioxidantes pode resultar no desencadeamento de 
mecanismos oxidantes, de inflamação. A produção de espécies reativas do oxigênio (ROS) induz a destruição e alteração na configuração do ácido desoxirribonucleico (DNA) celular e a inibição da apoptose. A peroxidação lipídica das membranas celulares e o acúmulo de produtos modificados do DNA contribuem também para o envelhecimento precoce das células e a carcinogênese pulmonar. Há outro possível mecanismo alternativo que consiste na translocação direta do material particulado, especialmente a partículas ultrafinas, para a corrente sanguínea (Valavanidis et al., 2013) (Figura 1).

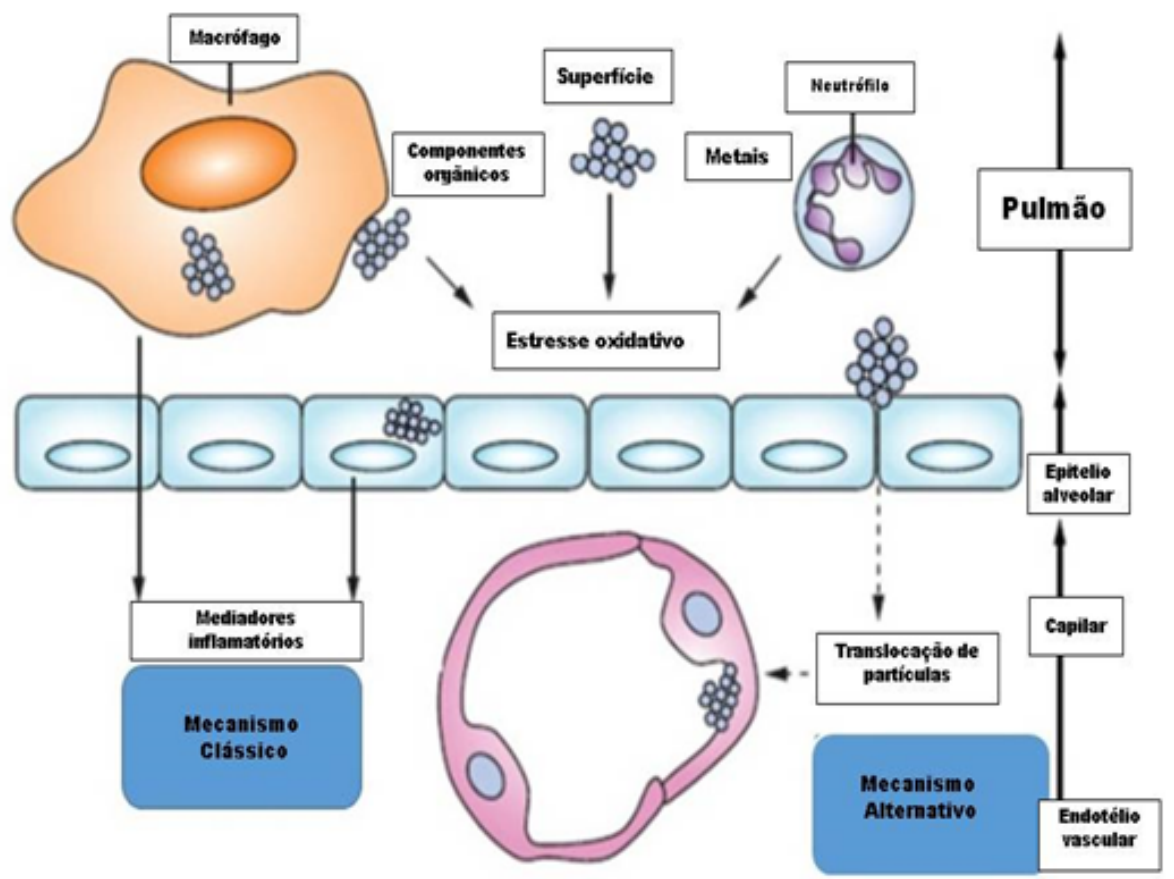

Figura 1 - Mecanismos hipotéticos (clássico e alternativo) por meio dos quais o material particulado determinaria os efeitos cardiovasculares. Baseado em Mills et al., 2009, e Forastiere, 2013.

O estresse oxidativo causado pelos poluentes atmosféricos seria capaz de sensibilizar genes ligados à atividade inflamatória, podendo agravar doenças pulmonares pré-existentes, como doença pulmonar obstrutiva crônica e asma, além de precipitar exacerbações agudas com maior predisposição a processos infecciosos (Smeeth et al., 2004).

Por meio do segundo mecanismo (alternativo), haveria a passagem direta de material particulado ultrafino $\left(\mathrm{PM}_{0.1}\right)$ ou constituintes como metais e compostos orgânicos para a circulação através da interface alvéolo-capilar 
desencadeando, assim, um processo de vasoconstrição sistêmica com elevação da pressão arterial, uma maior adesividade plaquetária e um aumento no processo inflamatório com consequente disfunção endotelial e potencial para desencadeamento de eventos como síndrome coronariana, insuficiência cardíaca, arritmias cardíacas, acidente vascular encefálico e doença arterial obstrutiva periférica.

Estes mecanismos ocorreriam também pelo aumento na produção de substâncias reativas do oxigênio (Nenmar et al., 2002) (Figura 2). Efeitos inflamatórios sistêmicos das citocinas ou moléculas oxidantes que emanam dos pulmões também poderiam afetar as placas ateroscleróticas, levando à progressão, à desestabilização e/ou à ruptura. Entre outros efeitos sistêmicos, uma maior resistência à insulina, aumento dos níveis séricos de colesterol, diminuição da função da High Density Lipoprotein (HDL), aumento da coagulabilidade sanguínea e diminuição da fibrinólise, predispondo ao desencadeamento de fenômenos tromboembólicos (Nenmar et al., 2006).

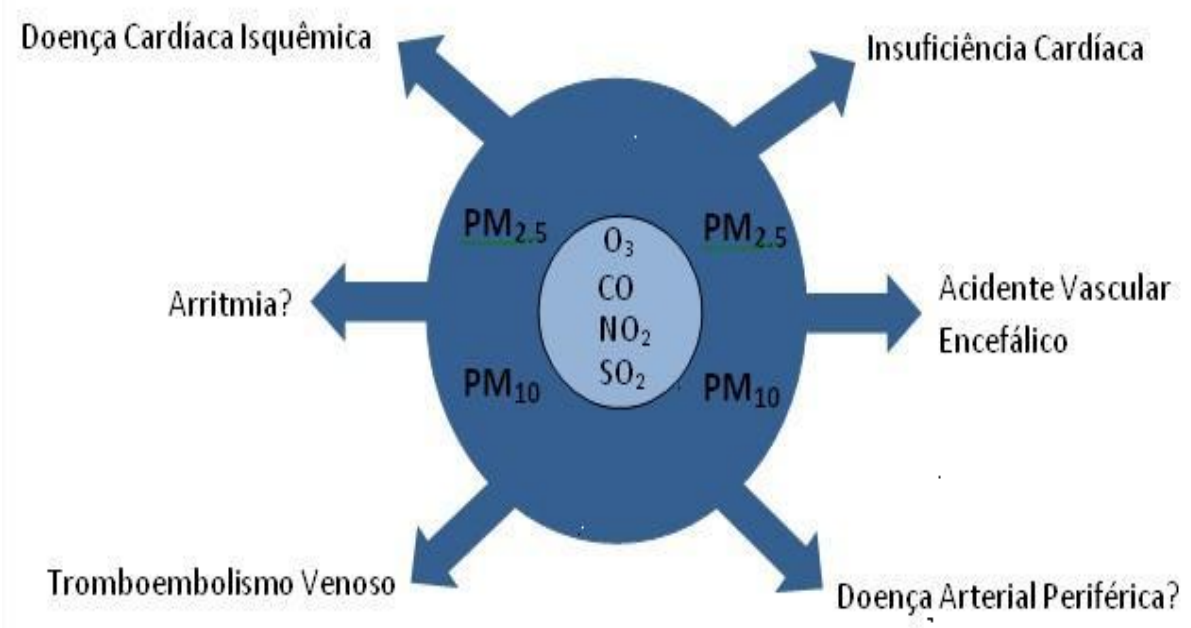

Figura 2- Mecanismos estabelecidos para desfechos clínicos relacionados com a poluição atmosférica (Baseado em Newby et al., 2014).

As células inflamatórias como macrófagos, linfócitos, neutrófilos e mastócitos participam ativamente do processo de aterogênese. Essas células passam a influenciar a remodelação vascular e iniciam o processo de desestabilização das placas mais avançadas, favorecendo o aparecimento de fenômenos tromboembólicos (Monteiro et al., 2006), que são 
responsáveis pela etiopatogenia de várias doenças cardiovasculares (Figura 3). Muitas experiências em animais também apoiaram o ponto de vista de que a exposição a $\mathrm{PM}_{2,5}$ pode contribuir para o processo de aterosclerose por mecanismos potenciais, incluindo estimulação da medula óssea, liberação de monócitos e alteração do tônus vasomotor (Fuji et al.; Suwa et al., 2002; Sun et al., 2005).

Num estudo em que ratos foram submetidos à exposição a $\mathrm{PM}_{2.5}$, observou-se um efeito sobre o tônus, dos níveis de inflamação vascular e aumento da aterosclerose aórtica (Sun et al., 2005).

Além disso, experimentos com animais possibilitaram o estudo de outros mecanismos biológicos, que conectam a exposição a partículas do ar ao progresso da aterosclerose em longo prazo, e que a exposição a determinados poluentes poderia influenciar nos níveis de pressão arterial, na função autonômica e na oxidação de lipoproteínas de baixa densidade (Sharman, 2002; Brook et al., 2004).

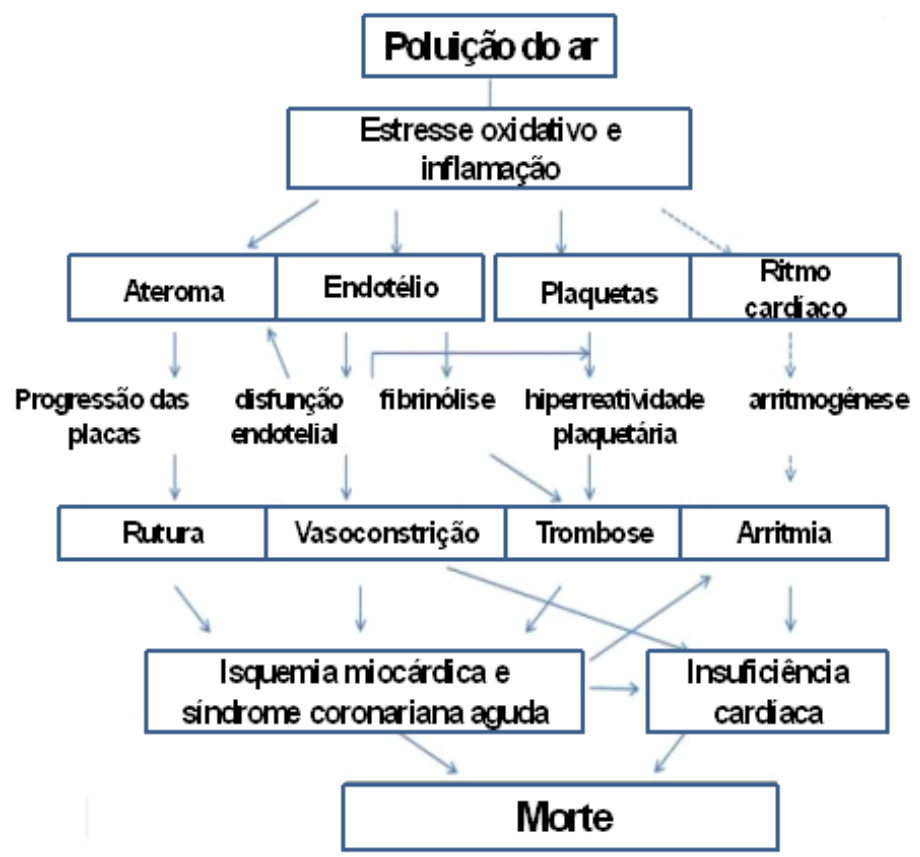

Figura 3 - Possíveis efeitos da poluição do ar na morbimortalidade por doenças cardiovasculares. Baseado em Mills et al., 2009 e Forastiere et al., 2013. 
Vários estudos têm apontado uma relação entre a função endotelial e a exposição ao material particulado. Briet et al. (2007) e Santoro et al. (2012) demonstraram que a disfunção endotelial pode ocorrer sem alterações estruturais ateroscleróticas em mulheres jovens com endometriose, o que sublinhou a importância de investigar este parâmetro especialmente em pessoas jovens e saudáveis, para confirmar a precocidade da disfunção endotelial por meio da mensuração da EIMC. Hoffmann et al. (2007) mostraram que a exposição a partículas finas estava associada à calcificação das artérias coronárias (CAC), e relacionada de forma relevante com a EIMC. Wilker et al. (2013) relataram que a concentração média anual de carbono negro foi associada ao aumento da EIMC na população de idosos.

Métodos diagnósticos auxiliares para avaliação de risco da doença aterosclerótica

Há um constante interesse em se diagnosticar a doença aterosclerótica nos indivíduos assintomáticos, visto que, mesmo a doença vascular obstrutiva grave, muitas vezes, pode se manifestar por mínimos sintomas, de maneira insidiosa, ou, ainda, ser totalmente assintomática. A morte súbita é a manifestação inicial mais temida do Infarto Agudo do Miocárdio (IAM). A maioria das mortes por IAM ocorre nas primeiras horas de manifestação da doença, sendo 40\%-65\% dos casos na primeira hora e, aproximadamente, $80 \%$ nas primeiras 24 horas, sendo as arritmias ventriculares complexas a principal causa responsável pelo por este tipo de desfecho, (Myeburg \& Castellanos, 2011).

O evento coronariano agudo é a primeira manifestação de DAC em cerca de metade dos indivíduos, sendo $50 \%$ desses fatais. A alta mortalidade associada e a ausência de sintomas prévios tornam a identificação dos indivíduos em risco crucial para a prevenção efetiva das mortes por DCV (Freire et al., 2015). 
Os métodos de rastreamento mais comumente utilizados, como o escore de Framingham, que utiliza um cálculo de porcentagem de risco para doença cardiovascular nos próximos 10 anos, usa como parâmetros o sexo, colesterol total, HDL, níveis pressóricos, presença de diabetes e tabagismo, apresenta algumas limitações, tais como não se considerar a história familiar, o sedentarismo, além da não avaliação de alguns marcadores inflamatórios, tais como a proteína $C$ reativa (PCR), que é considerado um marcador de risco independente e forte preditor de eventos cardiovasculares, e sinaliza possível processo de inflamação da camada endotelial (Pasceri et al., 2003).

Outros marcadores séricos, como a Lipoproteínas $A$, as frações apoliproteina a1/b, a interleucina 6 e a homocisteína, parecem atuar também como fatores que podem modular a aterogênese e a trombogênese (Tsimikas et al., 2006), além da mieloperoxidase, que é uma enzima cujos níveis elevados têm sido localizados nos sítios de inflamação e em placas vulneráveis após sua ruptura (Meuwese et al., 2007).

Como a aterosclerose subclínica constitui uma inflamação crônica, difusa e multissistêmica, que envolve aspectos vasculares, metabólicos e imunológicos, o conceito principal de prevenção de eventos cardiovasculares envolve exames subsidiários que possibilitem a detecção precoce de lesões nos vasos.

Baseado nisso, além dos exames laboratoriais, outros de imagem, como a ultrassonografia intravascular, a tomografia de coronária agregada ao escore de cálcio e o ecodoppler transcraniano, têm sido empregados com este propósito (Rumberger et al., 2001). Desde sua introdução por Aaslid et al. (1982), o doppler transcraniano (DTC) vem sendo aplicado com praticidade em várias situações diagnósticas. Com o auxílio de um sistema Doppler de baixa frequência $(2 \mathrm{MHz}$ ), é possível medir os parâmetros fisiológicos da velocidade do fluxo sanguíneo nas artérias intracranianas. $O$ DTC é um método útil para o estudo das alterações hemodinâmicas secundárias à estenose ou à oclusão do segmento extracraniano da artéria carótida interna e também pode ser utilizado como um teste de rastreamento 
para estenose em pacientes com risco de doença aterosclerótica intracraniana. Possui como principais vantagens a possibilidade de uso à beira do leito e de ser repetido quando necessário, permitindo, assim, uma monitorização contínua, além de ser mais barato que outras técnicas e não necessitar de contrastes potencialmente letais.

Por outro lado, algumas desvantagens são o fato de ser operador dependente e com potencial de demonstração de fluxo apenas em certos segmentos de grandes vasos intracranianos distais (Brucki \& Massaro, 2001).

A avaliação da doença arterial coronariana (DAC) pode ser feita, ainda, por meio da tomografia computadorizada (TC), pela determinação do escore de cálcio (EC) coronariano ou, ainda, pela angiotomografia coronariana propriamente dita. O EC coronariano proporciona importantes informações prognósticas quando adicionadas aos escores clínicos de risco tradicionais e a outras modalidades diagnósticas, como a dosagem da proteína $\mathrm{C}$ reativa, por exemplo. Está indicada para a estratificação do risco cardiovascular global de pacientes assintomáticos com risco intermediário pelo escore de Framingham.

Já a angiotomografia coronariana proporciona avaliação detalhada da anatomia das artérias coronárias, permitindo visualizar não apenas o lúmen, mas também as paredes arteriais coronarianas. Comparada à coronariografia invasiva convencional, a angiotomografia apresenta excelente acurácia para identificar e, principalmente, excluir a presença de lesões obstrutivas significativas. Adicionalmente, demonstrou-se ser capaz de proporcionar informações quando associadas a fatores de risco tradicionais e ao EC coronariano (Azevedo et al., 2012). Destaca-se, então, como método propedêutico na estratificação de risco e predição de eventos cardíacos adversos, especialmente em grupos de risco intermediário (Oudkerk et al., 2008), mas possui valor limitado como desfecho em estudos de progressão/regressão seriados, além de não se haver, ainda, valores de referência estabelecidos para a população brasileira (Budoff \& Gul, 2008). 


\subsubsection{A ultrassonografia de carótidas como método para identificação da doença aterosclerótica}

Visando a um aperfeiçoamento maior na detecção precoce da doença aterosclerótica e da consequente aterotrombose, alguns exames subsidiários, como a ultrassonografia de carótidas, mais precisamente, a medida da espessura da camada intima média de carótida (EIMC), cujo procedimento é rápido e não invasivo (Todd et al., 2007), tem sido progressivamente utilizada nos desfechos de vários estudos sobre eventos cardiovasculares, entre eles, o acidente vascular cerebral e infarto agudo do miocárdio (Nambi et al., 2010). É uma técnica validada e bastante utilizada na avaliação da progressão da doença aterosclerótica desde as fases iniciais. Utiliza-se a ultrassonografia no modo bidimensional com um transdutor de alta resolução acoplado a processador automático de imagens e Softwares com pacotes vasculares para cálculos de velocidade de pico sistólica, velocidade diastólica final, relação de velocidades dos fluxos, índices de resistência e pulsatilidade, tempo de aceleração do fluxo, integral da velocidade de fluxo e do volume de fluxo, e medida automática da EIMC.

A reprodutibilidade das medidas depende do segmento avaliado, da espessura total medida e do tipo de aferição realizada. Tem-se sugerido que a variabilidade da medida é menor quando se determina a espessura média do segmento distal da artéria carótida comum em mais de uma direção. Além disso, há descritos também resultados distintos nas medidas causados por diferenças entre observadores, sendo que este viés é minimizado quando o procedimento é realizado pelo mesmo observador (Torres et al., 2007) ou quando se utilizaram os detectores automáticos por meio de Softwares., de forma automática/semiautomática ou manual, utilizando-se imagem ultrassonográfica ao modo bidimensional. As medidas podem ser realizadas "offline" ou "online". Mais recentemente, alguns equipamentos de ultrassom fornecem outra maneira de se medir a EIMC em tempo real por sinal de radiofrequência; porém não existem estudos com tabelas normativas utilizando-se essa medida. A caracterização ultrassonográfica da EIMC deve ser realizada com o vaso sanguíneo em corte longitudinal, as 
paredes bem alinhadas, de maneira que se forme um padrão de dupla linha com definição das interfaces luz-íntima e média-adventícia. A distância entre as duas interfaces acústicas é considerada a medida da EIMC. Define-se como placa carotídea ateromatosa uma estrutura focal estendendo-se, no mínimo, 0,5 mm para a luz do vaso, e/ou medindo mais do que $50 \%$ do valor da medida da EIMC adjacente, e/ou, ainda, uma medida da EIMC maior que 1,5 mm (Freire et al., 2015) (Figura 4).

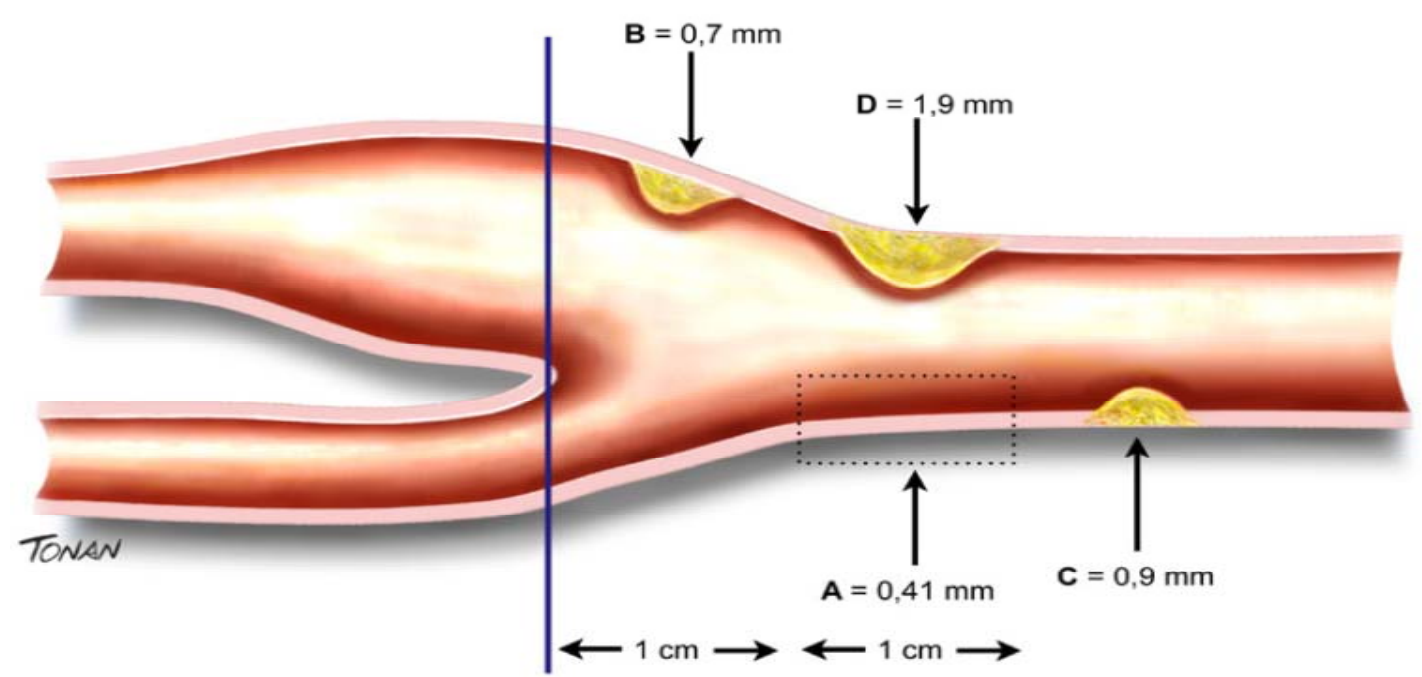

Figura 4 - Ilustração esquemática demonstrando exemplos de medida da EMI e de placas. Medida da EMI: (A). Medidas diferentes de três placas carotídeas (B) protusão $\geq 0,5 \mathrm{~mm}$ para a luz do vaso; (C.) medida $>50 \%$ do valor da medida da EMI adjacente; (D). Medida de EMI > 1,5 mm (Freire et al., 2015).

Den Ruijter (2012) conduziu uma meta-análise para avaliar a acurácia do método e obteve resultados contraditórios, pelas diferentes metodologias empregadas na medida da EIMC, como o local, a técnica, o equipamento e o tipo de medida considerada para a análise. Talvez não só a variação na maneira de medir mas também as variações relacionadas à idade, ao sexo, à raça, ao número de eventos, aos valores de corte para os grupos de risco e às definições dos desfechos sejam suficientes para explicar por que as evidências não são consistentes nos diversos estudos clínicos. A evidência de que a medição da espessura da carótida comum íntima-média (EIMC) melhora os escores de risco na previsão do risco absoluto de eventos cardiovasculares é inconsistente. Nesta meta-análise, foram incluídos 
estudos nos quais os participantes foram retirados da população em geral, mas sem patologia cardiocerebrovascular prévia. A EIMC e o Escore de Framingham foram medidos no início do estudo, tendo como desfecho a ocorrência do infarto agudo do miocárdio ou acidente vascular cerebral pela primeira vez. Sabe-se que os principais fatores de risco para essas doenças são a hipertensão arterial, a dislipidemia, o tabagismo e o diabetes.

Foram incluídos 14 coortes de base populacional com 45.828 indivíduos. Durante um seguimento médio de 11 anos, 4.007 sujeitos desenvolveram, pela primeira vez, um evento coronariano ou acidente vascular cerebral. Primeiro, o modelo foi reajustado para o Escore e, depois, para as medidas do EIMC. A conclusão foi que a adição das medidas da EIMC ao escore de risco de Framingham foi associada a uma melhor predição do risco de eventos cardiovasculares em 10 anos, mas essa melhoria não teria significância clínica.

Diante dessa lacuna entre os estudos e a aplicabilidade clínica, as diretrizes mundiais sobre ultrassonografia de carótidas colocam recomendações distintas. O consenso da Sociedade Americana de Ecocardiografia recomenda a medida da EIMC das carótidas para refinar a classificação de risco cardiovascular, em indivíduos assintomáticos, principalmente naqueles com risco intermediário. A última diretriz americana, porém, não recomenda esta metodologia para avaliação do risco de primeiro evento cardiovascular. Já pelas últimas diretrizes brasileiras, a placa carotídea ateromatosa poderia ser definida como uma estrutura focal, estendendo-se, no mínimo, 0,5 mm para a luz do vaso, e/ou medindo mais do que $50 \%$ do valor da medida da EIMC adjacente, e/ou, ainda, uma medida de EIMC maior que $1,5 \mathrm{~mm}$ em valores absolutos. $O$ aumento da EIMC acima de $1,0 \mathrm{~mm}$ seria considerado um dos fatores agravantes que indicaria uma reclassificação dos indivíduos de risco intermediário para alto risco (Freire et al., 2014). É muito utilizada, ainda, para se avaliar o efeito cumulativo produzido pelos diversos fatores de risco no desenvolvimento da doença aterosclerótica, além de ser um preditor independente de riscos futuros de doença cardiovascular (O'Leary et al., 1999; Greenland et al., 
2000). É comumente utilizado como modelo de desfecho intermediário em pesquisas como marcador da doença aterosclerótica (Lorenz et al., 2006). Sob condições padronizadas, a reprodutibilidade tem se mostrado útil em grandes estudos clínicos multicêntricos (Bots \& Grobbee, 2002; Touboul et al., 2005).

O Cardiovascular Health Study avaliou 5.858 indivíduos com idade acima de 65 anos sem sinais ou sintomas de doença cardiovascular por um período médio de 6,2 anos. Aqueles que se encontravam no maior quintil para os valores da EIMC tiveram risco relativo (RR) de 3,87(ajustado para idade e sexo) maior para desenvolvimento de infarto agudo do miocárdio (IAM) ou acidente vascular encefálico (AVE), comparado com aqueles que se encontravam no menor quintil. A conclusão foi que a EIMC foi considerada como um forte preditor de eventos cardiovasculares comparável aos demais fatores de risco tradicionais e, ainda, quando ajustado a eles, a EIMC foi a variável que mais fortemente estava associada com eventos cardíacos (O'Leary et al., 1999).

O Kuopio Ischemic Heart Disease Risk Factor Study encontrou um incremento na ordem de $11 \%$ nas chances para eventos cardiovasculares para cada 0.1-mm no aumento da EIMC (Salonen et al., 1993). O Rotterdam Study foi um estudo desenvolvido em um único local, do tipo longitudinal, envolvendo 7.983 pacientes com idade acima de 55 anos e seguimento por um período de 2,7 anos. Quando ajustado para idade e sexo, a razão de chances (odds ratio - OR) para o aumento do EIMC foi de 1,41 para AVE e 1,43 para IAM (Bots et al., 1997).

Uma revisão sistemática e de meta-análise sobre a predição de eventos clínicos cardiovasculares em relação ao espessamento da íntima média carotídea foi realizada utilizando-se oito grandes estudos: KIHD (Kuopio Ischemic Heart Disease Risk Factor Study), ARIC (Atherosclerosis Risk in Communities Study), o Rotterdam Study, o Cardiovascular Health Study, o Malmo Diet and Cancer Study, o LILAC (Longitudinal Investigation for the Longevity and Aging in Hokkaido County) e o CAPS (Carotid Atherosclerosis Progression Study). As conclusões dos autores foram de 
que a medida da EIMC foi considerada uma técnica bem validada para seguimento da progressão da aterosclerose em estudos clínicos.

\subsubsection{1 -Poluição atmosférica, tráfego veicular e EIMC}

Em conjunto com outras técnicas de avaliação não invasivas, o estudo da progressão da EIMC é particularmente atraente para estudos sobre poluição atmosférica e é considerado o único desfecho validado em estudos longitudinais (Kunzli et al., 2010). Os mesmos autores concluíram que a EIMC é um bom marcador para estudos que pretendam investigar a influência de longas exposições aos poluentes atmosféricos na aterogênese.

No Ambient Air Pollution and Atherosclerosis in Los Angeles, foi evidenciada uma maior espessura da íntima-média carotídea em comunidades com sujeitos sem doença cardiovasculares clínica e cronicamente mais expostas à poluição atmosférica. Ficou demonstrado um aumento de 4-6\% desta espessura para cada aumento de $10 \mu \mathrm{g} / \mathrm{m}^{3}$ da concentração média de $\mathrm{PM}_{2,5}$ em exposições prolongadas. Neste estudo, verificou-se, ainda, um aumento maior da EIMC em indivíduos com idade superior a 60 anos, do sexo feminino, naqueles que nunca tinham fumado e também nos que estavam em uso de alguma terapêutica específica para dislipidemia. Nestes últimos, o aumento da espessura foi de $12-16 \%$ e, nas mulheres com mais de 60 anos, de 14-19\% para cada aumento de $10 \mu \mathrm{g} / \mathrm{m}^{3}$ de $\mathrm{PM}_{2,5}$ de média diária avaliados num período de um ano (Kunzli et al., 2005).

Estudos ainda mostram que a espessura da íntima média correlacionase com os demais fatores de risco de doenças cardíacas e é considerada também como um preditor de vasculopatia (Oren et al., 2003). A correlação entre EIMC e os eventos cardiovasculares tem sido avaliada por meio de longos ensaios clínicos prospectivos em sujeitos sabidamente portadores de doença cardiovascular (DCV) ou, ainda, em indivíduos com idade de 45 anos ou mais sem evidências clínicas de DCV e de maneira consistente a EIMC sempre esteve associada com o risco de eventos cardiovasculares 
(Todd et al., 2007). Outra meta-análise realizada por Liu et al., (2015) sobre os impactos da poluição ar $\left(\mathrm{PM}_{2,5}, \mathrm{PM}_{10}\right)$ sobre a EIMC pesquisou 56 estudos, sendo que 11 artigos preencheram os critérios de inclusão. $\mathrm{Na}$ análise global, aumentos de $10 \mu \mathrm{g} / \mathrm{m}^{3}$ nas $\mathrm{PM}_{2,5}$ e $\mathrm{PM}_{10}$ foram associados a

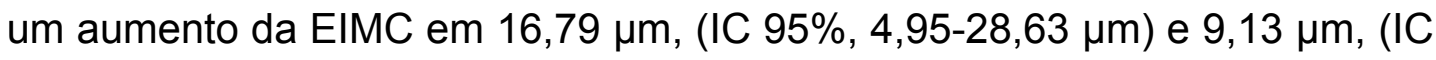
95\% 5,79-14,04 $\mu \mathrm{m})$, respectivamente. Os resultados apresentados na análise de subgrupos individualmente (dos 11 artigos) foram comparados com os da análise global (meta-análise) em relação aos valores de referência e a conclusão foi de que o impacto da proximidade do tráfego na EIMC foi considerado incerto.

Vários estudos dentro desta mesma meta-análise sobre exposição em longo prazo ao material particulado $\left(\mathrm{PM}_{2,5}, \mathrm{PM}_{10}\right)$ mostraram que as concentrações mais elevadas estavam diretamente associadas ao aumento da EIMC. No entanto, nem todos os estudos encontraram resultados significativos, de modo que a associação entre o material particulado e a EIMC também foi considerada incerta. Porém, na estimativa geral dos resultados, observou-se associação significativa e positiva entre $\mathrm{PM}_{2,5} \mathrm{e}$ EIMC. Quando comparadas à análise geral, os subgrupos foram associados com menor heterogeneidade e mantiveram a mesma direção de efeito estimado, quando os modelos foram ajustados para idade, sexo, raça, fatores socioeconômicos, dieta, tabagismo, atividade física, lipídios no sangue, diabetes, hipertensão e índice de massa corporal.

Cinco outros estudos desta revisão sistemática (Künzli et al.; Lenters et al., 2010; Gan et al., 2014; Perez et al., 2015) referiram-se à relação entre EIMC e proximidade ao tráfego. Devido à expressão de dados diferentes resultados de metodologias distintas, não foi possível realizar meta-análise. Viver perto de estradas principais pode indicar uma alta exposição a emissões de poluentes veiculares relacionadas ao tráfego, como partículas ultrafinas e outros poluentes com alta atividade pró-oxidante especialmente partículas a partir da combustão de diesel (Zhu et al., 2002). Perez et al. (2015) concluíram, também, em seu estudo, que morar na proximidade de vias de alto tráfego pode ser positivamente associado às medidas da EIMC. 
Künzli et al. (2010) mostraram que um incremento de $10 \mu \mathrm{g} / \mathrm{m}^{3}$ nas $\mathrm{PM}_{2,5}$ anuais foi associado a um aumento de 2,5 $\mu \mathrm{m}$ (IC95\%, 0,3-5,4 $\mu \mathrm{m}$ ) na EIMC, que não teve efeito significativo.

Pessoas que habitam num raio de até $100 \mathrm{~m}$ da via principal tiveram

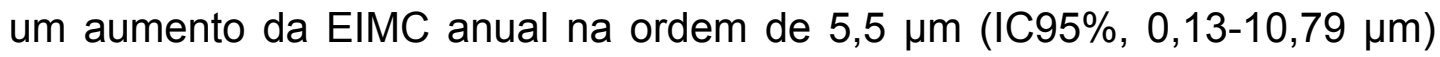
em comparação com pessoas que vivem mais longe do tráfego. Lenters et al. (2010) não encontraram uma direção consistente de associação entre indicadores de tráfego (proximidade do tráfego, densidade de tráfego) e EIMC. Similarmente, os resultados foram também representados por Gan et al. (2014).

Vários outros estudos recentes observando as associações de EIMC com exposição ao combustível de biomassa descrito por Painschab et al. (2013) e a poluição do ar relacionada com o tráfego (Rivera et al., 2013) mostraram resultados estatisticamente significativos. Armijos et al. (2015) examinaram a associação da exposição em longo prazo ao tráfego com EIMC em crianças. Os resultados mostraram que as que residem a menos de 100 metros da estrada de tráfego intenso tiveram um aumento médio e máximo da EIMC de $15 \%$ e $11 \%$ em comparação com os que vivem a mais de 200 metros de distância $(p=0,0001)$. Os participantes com menor escolaridade foram considerados mais vulneráveis quando expostos a $\mathrm{PM}_{2,5}$. Uma das razões foi que, devido às más condições de vida e ao baixo poder socioeconômico, as pessoas com menor escolaridade tendem a viver em regiões mais retiradas e com habitações próximas a estradas movimentadas, ficando, assim, mais expostas a múltiplos poluentes atmosféricos.

Quase todos os estudos incluídos nessa meta-análise usaram modelo de regressão linear para estimar a relação entre determinada matéria $\left(\mathrm{PM}_{2.5}\right.$, $\left.P M_{10}\right)$ e EIMC.

Outro estudo realizado pela United States Enviromental Protection Agency (EPA), em 2014, indicou que as vias, geralmente, influenciam a qualidade do ar em poucas centenas metros - cerca de 100 a $200 \mathrm{~m}$ a favor do vento a partir da vizinhança de vias ou, ainda, corredores com 
significativo tráfego de caminhões ou atividades ferroviárias. Esta distância varia de acordo com a localização e hora do dia, do ano, da meteorologia predominante, topografia, intensidade do uso do solo das proximidades, padrões de tráfego, bem como o tipo de poluente, categoria de veículos e de combustível utilizado, a intensidade de tráfego, e a velocidade e direção do vento, gerando grandes alterações sobre os níveis de poluentes perto das principais estradas.

Geralmente, quanto mais tráfego, maiores são as emissões. No entanto, certas situações, como congestionamento, movimento de anda e para ou alta velocidade, combinação entre horário de pico de trânsito e períodos de menor fluxo veicular, como a madrugadas, a evaporação do combustível, o desgaste dos freios e dos pneus, e, ainda, a poeira levantada pela sujidade das vias de tráfego são variáveis, normalmente, não mensuradas. Certas condições de vento e terreno, certas horas do dia, incluindo, a presença de paredes para proteção sonoras, edifícios, a presença e distribuição de vegetação no entorno também têm impacto sobre a dispersão de poluentes.

Outra meta-análise conduzida por Lockhart et al. (2015) demonstrou que a associação mais forte encontrada foi entre a poluição do tráfego veicular e o desenvolvimento de placas ateroscleróticas, sendo que outros efeitos sobre a saúde apresentarem vários e menores níveis de evidência. Além disso, a análise dos efeitos causados pelos poluentes individuais é limitada à medida que as pessoas são expostas a uma mistura de poluentes atmosféricos, sem se definir o impacto específico de cada um. Também se concluiu que os níveis de tráfego relacionados com a poluição do ar são afetados por vários fatores ambientais, como o clima, estações do ano, configuração de ruas e avenidas, projeto de estradas e a composição da vegetação circundante.

Devido a estes inúmeros fatores, cada localização espacial e temporal é única, tornando difícil a estimativa da poluição do ar relacionada ao tráfego e, em muitas pesquisas já realizadas, esses fatores foram analisados de 
forma isolada e, portanto, suas interações sinérgicas não ficaram exatamente claras.

\subsubsection{Medidas antropométricas que auxiliam na avaliação de situações de potencial risco cardiovascular}

A obesidade contribui para o desenvolvimento de várias doenças crônicas, incluindo a doença arterial coronariana, a hipertensão arterial sistêmica, a dislipidemia e o diabetes melito tipo 2, levando a um maior risco de complicações cardiovasculares e morte. No cenário brasileiro, o aumento da obesidade em todas as faixas etárias tem se tornado igualmente preocupante (IBGE, 2014). Os jovens com idade entre 18 a 24 anos registram $38 \%$ de sobrepeso e a proporção de pessoas com mais de 18 anos com obesidade, embora tenha se mantido estável nos últimos anos, é um dado preocupante apontado pela pesquisa e chega a $17,9 \%$ Os maiores índices de excesso de peso foram encontrados em pessoas com idade entre 45 e 64 anos, e 61\% estão acima do peso ideal (Lima, 2013).

O índice de massa corporal (IMC) permite avaliar a obesidade, e tem sido utilizado na estratificação de risco cardiovascular e nas decisões terapêuticas relacionadas às situações clínicas associadas. Entretanto, sabe-se, desde a década de 50, que o tipo de distribuição de gordura corporal confere um risco variável de eventos cardiovasculares. A deposição excessiva de gordura visceral na região abdominal, chamada de obesidade androgênica, está associada a um risco maior de eventos coronarianos, diabetes do tipo II e hipertensão arterial sistêmica, em ambos os sexos e em diferentes etnias. Acredita-se que esse aumento no risco de complicações vasculares deve-se à heterogeneidade das propriedades metabólicas e à localização anatômica dos adipócitos, as quais levariam à resistência à ação da insulina. Apesar da quantificação acurada de tecido adiposo em compartimentos corporais, ela também pode ser realizada por meio de técnicas de imagem, como ressonância magnética, tomografia computadorizada e densitometria corporal total. Entretanto, essas técnicas são onerosas e complexas, sendo impraticável sua utilização na rotina 
clínica. Já as medidas antropométricas simples, como a circunferência abdominal (CA) e a razão cintura/quadril (RCQ), demonstraram ser adequadas para estimar a quantidade de gordura abdominal. Recentemente, foi sugerido que a $R C Q$ define melhor indivíduos de risco para doença cardiovascular, sendo que outros autores consideram que a medida da cintura é melhor preditor de obesidade, dislipidemia e risco cardiovascular (Picon et al., 2007). Alguns estudos demonstraram que a circunferência do pescoço (CP), assim como o IMC, a CA, e a RCQ, pode ser utilizada como marcador antropométrico para estimar risco cardiovascular (Pitanga et al., 2005). Indivíduos com CP aumentada apresentaram maior proporção de hipertensão, diabetes, dislipidemias, obesidade e alteração nos marcadores de aterosclerose estudados. Apesar da escassez de estudos sobre a mensuração da CP como indicador de DCV, pode-se concluir que a CP é uma medida simples de ser realizada e pode, na prática clínica, ser utilizada como marcador antropométrico relevante, capaz de estimar fatores de risco cardiovascular (Pitanga et al., 2005). atmosféricos gerados por tráfego veicular

A complexidade dos ambientes urbanos, o aumento da contribuição das fontes móveis, a diversidade de poluentes e dos efeitos à saúde da população têm impulsionado o desenvolvimento de métodos para a avaliação da exposição humana à poluição relacionada ao tráfego em áreas urbanas (Toledo et al., 2011). São Paulo tem uma das maiores frotas de veículos do mundo circulando em, aproximadamente, $16.300 \mathrm{~km}$ de estradas em uma área densamente povoada. As emissões do tráfego de veículos são o principal contribuinte para níveis elevados de poluição atmosférica (CETESB, 2010). A cidade é de complexidade heterogênea no que se refere à emissão e exposição aos poluentes do ar. 
Fatores como o tráfego mais intenso em algumas regiões, a maior proximidade de instalações industriais, estações ferroviária e aeroportos podem aumentar a concentração e limitar a dispersão dos poluentes, bem como, a existência de uma grande e complexa distribuição de fontes móveis e estacionárias que contribuem para a poluição do ar. A dispersão destes poluentes depende de parâmetros atmosféricos e do uso do solo, como, por exemplo, a existência de altos edifícios que influenciam o deslocamento de ventos. São variáveis, ainda, a diversidade da intensidade, distribuição e constituição dos poluentes emitidos por tipo de veículo (diesel, gasolina, álcool e flex), além do longo tempo gasto em congestionamentos diários.

A quase totalidade dos estudos sobre os efeitos da poluição do ar sobre a saúde utiliza para a caracterização da exposição à poluição do ar os resultados fornecidos pelas estações de monitoramento da qualidade do ar. Entretanto, estes dados são dispersos e não evidenciam gradientes de exposição na região intraurbana pela heterogeneidade espacial da dispersão dos poluentes emitidos por fontes móveis, o que pode levar a erros de classificação da exposição entre sujeitos. Embora esta abordagem permita a avaliação de determinados poluentes do ar separadamente e com uma precisão temporal, alguns argumentam que as estações de monitorização são escassas e não localizadas em todos os lugares em que as pessoas vivem. Por motivos econômicos e administrativos, existem limitações no número e na distribuição dessas estações, e, portanto, não se pode detectar com precisão a heterogeneidade espacial da concentração de poluentes (Sahsuvaroglu et al., 2006; Woodruff et al., 2008; Habermann \& Gouveia, 2014). Portanto, se as informações usadas para avaliar a exposição da população só viessem das estações de monitoramento, talvez não fosse possível identificar uma fonte específica de poluição (Zhu et al., 2002; Habermann et al., 2010).

Diversos estudos avaliam a densidade de poluentes de maneira direta por meio de dados de concentração médias destes e de medidas realizadas por estações de monitoramento da qualidade do ar. Entretanto, a distribuição dessas estações nas áreas urbanas avalia a concentração regional dos 
poluentes, e não é precisa o suficiente para detectar a heterogeneidade espacial da concentração e dispersão dos poluentes emitidos por fontes móveis. Desta forma, outros estudos têm examinado os efeitos da poluição atmosférica na saúde, utilizando medidas indiretas a partir da exposição ao tráfego de veículos. Esta abordagem tem sido empregada em associação ou em substituição à medida direta obtida pela concentração média dos poluentes nas estações de monitoramento. $O$ interesse no emprego da medida indireta em alguns estudos ocorre pela possibilidade de se obter uma estimativa da exposição para um local específico (Habermann et al., 2010). Os principais métodos de avaliação de exposição humana aos poluentes de fontes veiculares utilizados mundialmente são:

Avaliação da exposição humana baseada na proximidade das vias de tráfego intenso e na concentração veicular: Embora estes estudos considerem que, quanto mais próximo da fonte de poluição, maiores serão as concentrações dos poluentes e, portanto, maior a exposição, a distância entre as pessoas e a via é tomada como uma proxy da exposição aos poluentes relacionados ao tráfego, podendo avaliar o decaimento de poluentes e de seus efeitos em função da distância. Porém, não há uma distinção dos tipos de poluentes envolvidos, e da influência das condições meteorológicas e topográficas locais (Jerret et al., 2005).

Outro indicador utiliza apenas a intensidade de tráfego veicular para avaliar a exposição aos poluentes por meio da média anual de tráfego diário e utiliza a contagem de carros/hora para estimar esta exposição. De acordo com o objetivo de cada trabalho, leva-se em consideração o tráfego da via principal mais próxima, o da rodovia mais próxima ou o tráfego das vias (vias principais ou não) contidas em distâncias (buffers) de 50 m, 100 m e 300 m (Medina-Ramon; Kim et al., 2008). Outra abordagem inclui a operação de multiplicação do comprimento das vias próximas às residências da população estudada pela média diária do fluxo de veículo dessas (Meng et al., 2007; Wilhem et al., 2008).

Pode ser utilizada apenas a densidade de vias/veículos. A partir do endereço do sujeito georreferenciado e de dados do censo, calcula-se a 
densidade de veículos obtida pela divisão do total de veículos do setor censitário por uma área (em quilômetros quadrados), referindo-se ao número de proprietários de veículos e não a sua circulação nas vias desta área (Reynolds et al., 2002). Estes dados fornecem uma estimativa do potencial de exposição às emissões por evaporação noturna de combustíveis. Existem estudos ainda que utilizam a combinação de vários indicadores da exposição ao tráfego veicular para estimar indiretamente a poluição atmosférica. Uma das metodologias mais amplamente utilizadas baseia-se na combinação de dados sobre o fluxo de veículos e a distância das vias no entorno do ponto de interesse (representando a dispersão de poluentes advindo dos veículos a partir do centro da rua) denominado densidade de tráfego ponderada pela distância (DTPD) (Pearson et al., 2000; Reynold et al., 2004; Medeiros et al., 2009). Neste modelo, se assume que as emissões dos veículos nas vias se aproximam de uma distribuição gaussiana (normal) e que 96\% dos poluentes emitidos pelo tráfego veicular se dispersam em até 500 pés/150 m do centro da via. Quanto maior o fluxo na via, maior a emissão de poluentes veiculares, aumentando as concentrações desses no espaço urbano, principalmente nas residências próxima às vias mais movimentadas (Figura $5)$.

O cálculo é feito individualmente para cada sujeito a ser estudado. Em síntese, os indicadores de exposição baseados em tráfego veicular têm sido aplicados em diversos estudos, porque são relativamente fáceis de interpretar e descrevem o quanto estão expostos às emissões veiculares aqueles que residem, principalmente, próximos de ruas movimentados e que as concentrações de poluentes perto de vias são bem correlacionadas com tráfego, de modo que estes indicadores podem ser usados como um indicador da exposição da população aos poluentes atmosféricos urbanos (Habermann et al., 2010). 


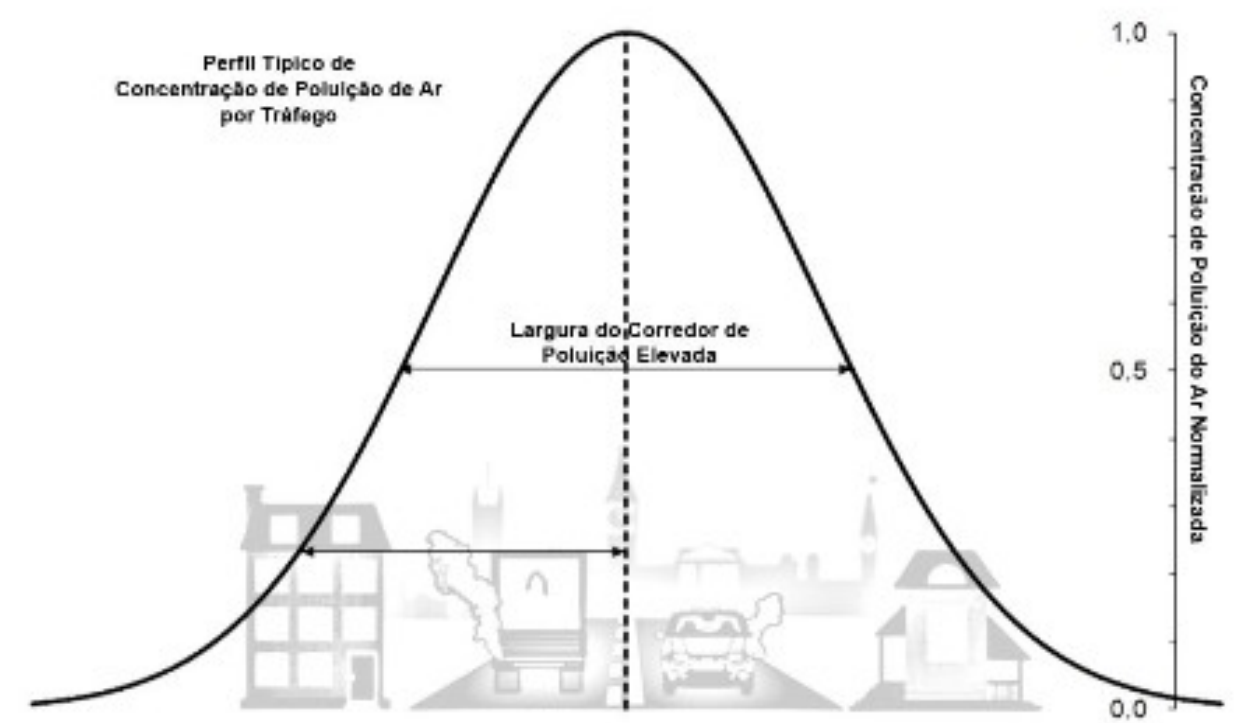

Figura 5 - Perfil da concentração de poluentes emitidos pelo tráfego veicular conforme o modelo da Densidade de Tráfego Ponderada pela Distância. Adaptado de Pearson et al., 2000).

Modelos de interpolação geoestatística estocática: Para se avaliar os níveis de exposição, os dados de concentrações dos poluentes obtidos em estações de monitoramento são interpolados por meio de técnicas de geoestatística. Os modelos de interpolação dependem destas técnicas determinísticas e estocásticas (emprego para uso estatístico do cálculo de probabilidade). As medições do poluente-alvo são obtidas num conjunto de estações de monitorização distribuídas por toda a área de estudo. Com base nessa informação, geram-se estimativas da concentração de poluentes em locais diferentes da localização das estações de monitoramento. A técnica geoestatística mais comum usada no campo da poluição do ar é a "krigagem" (Jerrett et al., 2001). É um método de regressão usado em geoestatística para aproximar ou interpolar dados. A vantagem deste método é o uso de dados reais de poluição e a possibilidade da realização de estudos de dose-resposta com limitações em relação às possíveis influências das condições meteorológicas, fatores específicos do terreno na dispersão dos poluentes e da existência de uma densa rede de monitoramento ou da coleta primária de dados com significante elevação do custo operacional (Toledo \& Nardocci, 2011). 
Modelos de análise de uso do solo: A análise baseia-se na avaliação da exposição a partir dos padrões de emissão, das formas utilização deste solo e do tráfego da área, sem necessidade de monitoramento específico, além de ser de baixo custo (Briggs et al., 1997; Lebret et al., 2000).

Modelos de dispersão de poluentes: Os modelos de dispersão também são empregados para estimar a exposição. Neste caso, informações de emissão, dados meteorológicos e topográficos são necessários para estimar a concentração dos poluentes. Integram-se módulos meteorológicos e químicos na simulação da dinâmica atmosférica dos poluentes, melhorando a acurácia em relação aos modelos de dispersão simples. Têm como vantagem a análise das variações da poluição no tempo e espaço em diferentes escalas, porém são análises que demandam Softwares muito específicos, computadores de alto desempenho e pessoal técnico especializado, gerando alto custo operacional (Bellander et al., 2001).

Modelos integrados de controle de emissão e meteorologia (IME): Os módulos meteorológicos e químicos são acoplados para simular dinâmicas na atmosfera. Nestes modelos, os dados meteorológicos são fornecidos aos módulos de estudo da composição química dos poluentes em tempo real em cada etapa da análise. São modelos úteis em áreas que não possuem estações meteorológicas em quantidades suficientes para uma adequada avaliação da qualidade do ar. Estes modelos não foram utilizados para estudos que tentam vincular a qualidade do ar à saúde, devido aos altos custos de implementação e aos requisitos de dados. No entanto, eles têm um potencial considerável, especialmente para áreas com grandes populações, por meio da detecção dos níveis de poluentes que são formados na atmosfera pelas reações químicas entre os poluentes primários, com destaque para o peróxido de hidrogênio $\left(\mathrm{H}_{2} \mathrm{O}_{2}\right)$, o ácido sulfúrico $\left(\mathrm{H}_{2} \mathrm{SO}_{4}\right)$, o ácido nítrico $\left(\mathrm{HNO}_{3}\right)$, o trióxido de enxofre $\left(\mathrm{SO}_{3}\right)$, os nitratos $\left(\mathrm{NO}_{3}\right.$ ), os sulfatos $\left(\mathrm{SO}_{4}{ }^{2-}\right)$ e o ozônio $\left(\mathrm{O}_{3}\right)$.

Os modelos de IME tipicamente compõem três módulos: meteorológico, transporte de química, e visualização e análise. Existe a descrição de condições atmosféricas, tais como movimento de ar, 
temperatura, campos de pressão barométricos, cobertura de nuvem e precipitação. Permite recursos em tempo real e preditivos que ajudarão a encontrar o destino e o transporte de poluentes em ambientes intraurbanos. Assim, os problemas de qualidade do ar podem ser estudados em combinação com os padrões de atividade do tempo com muito mais precisão do que com os outros modelos analisados. Os modelos requerem sistemas de computação complexos, instalações sofisticadas, Software altamente qualificado e pessoal experiente para sua implementação e operação. Estes requisitos tornam a sua utilização pouco viável em pesquisas de larga escala (Otte; Yin et al., 2001).

Modelos híbridos: Estes combinam o uso de monitoramento pessoal com um dos métodos citados anteriormente, permitindo validar as medidas de concentrações ambientais de poluentes como parâmetro da exposição humana. No entanto, o monitoramento pessoal é caro e depende da facilidade/custo da análise, sendo que sua aplicação requer que as demais técnicas de avaliação de exposição já tenham sido empregadas (Toledo et al., 2011). Na Tabela 1, abaixo, a síntese dos modelos de avaliação indireta da exposição humana aos poluentes atmosféricos. 


\section{Tabela 1 - Métodos de avaliação da exposição ambiental aos poluentes atmosféricos gerados por tráfego veicular}

\begin{tabular}{|c|c|c|c|c|}
\hline Modelo & $\begin{array}{l}\text { Conceito } \\
\text { teórico }\end{array}$ & $\begin{array}{l}\text { Limitações aos } \\
\text { estudos na área da } \\
\text { Saúde }\end{array}$ & Requisitos de dados & $\begin{array}{l}\text { Necessidade } \\
\text { de dados } \\
\text { atualizados }\end{array}$ \\
\hline $\begin{array}{l}\text { Proximidade } \\
\text { baseada }\end{array}$ & Baixo & $\begin{array}{l}\text { Estimativas de } \\
\text { exposição bruta }\end{array}$ & $\begin{array}{l}\text { Volume de tráfego; Distância da } \\
\text { linha de origem; Questionário }\end{array}$ & Baixo \\
\hline Geoestatística & Médio & $\begin{array}{l}\text { Depende da densidade } \\
\text { da rede de } \\
\text { monitoramento }\end{array}$ & Medições de monitoramento & Baixo \\
\hline $\begin{array}{l}\text { Regressão de } \\
\text { uso do solo }\end{array}$ & Médio & $\begin{array}{l}\text { Depende da densidade } \\
\text { de observações }\end{array}$ & $\begin{array}{l}\text { Volume de tráfego; Utilização do } \\
\text { solo Meteorologia; Medidas de } \\
\text { monitorização }\end{array}$ & Médio \\
\hline Dispersão & Médio & $\begin{array}{l}\text { Insumos extensivos } \\
\text { Suposições irrealistas } \\
\text { sobre o transporte de } \\
\text { poluentes }\end{array}$ & $\begin{array}{l}\text { Volume de tráfego; Emissões } \\
\text { provenientes de fontes pontuais; } \\
\text { Meteorologia; Medidas de } \\
\text { monitorização; Topografia }\end{array}$ & Médio \\
\hline $\begin{array}{l}\text { Emissão } \\
\text { meteorológica } \\
\text { integrada }\end{array}$ & Médio & Resolução grosseira & $\begin{array}{l}\text { Volume de tráfego; Emissões } \\
\text { provenientes de fontes pontuais; } \\
\text { Meteorologia; Medidas de } \\
\text { monitorização; Topografia }\end{array}$ & Alto \\
\hline $\begin{array}{l}\text { Híbrido } \\
\text { (monitoramento } \\
\text { pessoal e um } \\
\text { dos métodos } \\
\text { anteriores) }\end{array}$ & Alto & $\begin{array}{l}\text { Amostra pequena e } \\
\text { tendenciosa depende } \\
\text { da combinação }\end{array}$ & $\begin{array}{l}\text { Questionário Dados pessoais de } \\
\text { monitoramento. Outros } \\
\text { dependendo da combinação }\end{array}$ & $\begin{array}{l}\text { Depende da } \\
\text { combinação }\end{array}$ \\
\hline Modelo & $\begin{array}{l}\text { Softwarel } \\
\text { expertise }\end{array}$ & $\begin{array}{l}\text { Custo global de } \\
\text { implementação }\end{array}$ & Benefício marginal & $\begin{array}{l}\text { Trasnmissi- } \\
\text { bilidade }\end{array}$ \\
\hline $\begin{array}{l}\text { Proximidade } \\
\text { baseada }\end{array}$ & GIS Staistics & $\begin{array}{l}\text { Equipamento: baixo } \\
\text { Software: baixo } \\
\text { Pessoal: médio }\end{array}$ & Caso base & Baixo \\
\hline Geoestatística & $\begin{array}{l}\text { GIS Estatística } \\
\text { espacial }\end{array}$ & $\begin{array}{l}\text { Equipamento: médio } \\
\text { Software: médio } \\
\text { Pessoal: baixo }\end{array}$ & $\begin{array}{l}\text { Transferibilidade; Estrutura de } \\
\text { erro da estimativa }\end{array}$ & Baixo \\
\hline $\begin{array}{l}\text { Regressão de } \\
\text { uso do solo }\end{array}$ & $\begin{array}{l}\text { Especialistas em } \\
\text { Monitorização de } \\
\text { Estatísticas do } \\
\text { GIS }\end{array}$ & $\begin{array}{l}\text { Equipamento: médio } \\
\text { Software: médio } \\
\text { Pessoal: médio }\end{array}$ & $\begin{array}{l}\text { Transferibilidade; Estrutura de } \\
\text { erro da estimativa }\end{array}$ & Médio \\
\hline Dispersão & $\begin{array}{l}\text { GIS Statistics } \\
\text { Monitor } \\
\text { especialistas } \\
\text { Dispersion } \\
\text { Software }\end{array}$ & $\begin{array}{l}\text { Equipamento: elevado } \\
\text { Software: elevado } \\
\text { Pessoal: médio }\end{array}$ & Ênfase no processo & Alto \\
\hline $\begin{array}{l}\text { Emissão } \\
\text { meteorológica } \\
\text { integrada }\end{array}$ & $\begin{array}{c}\text { Especialistas em } \\
\text { Monitorização de } \\
\text { Estatísticas do } \\
\text { GIS }\end{array}$ & $\begin{array}{l}\text { Equipamento: elevado } \\
\text { Software: elevado } \\
\text { Pessoal: elevado }\end{array}$ & Ênfase no Processo & Médio \\
\hline $\begin{array}{l}\text { Híbrido } \\
\text { (monitoramento } \\
\text { pessoal e um } \\
\text { dos métodos } \\
\text { anteriores) }\end{array}$ & $\begin{array}{c}\text { Especialistas em } \\
\text { monitores } \\
\text { pessoais Projeto } \\
\text { de levantamento } \\
\text { Depende da } \\
\text { combinação }\end{array}$ & $\begin{array}{l}\text { Equipamento: alto } \\
\text { Software: *Pessoal: } \\
{ }^{*} \text { Depende da } \\
\text { combinação }\end{array}$ & & \\
\hline
\end{tabular}


3 JUSTIFICATIVA 


\section{JUSTIFICATIVA}

As doenças crônicas não transmissíveis (DCNT) representam $72 \%$ das mortes no Brasil (Schmidt et al., 2011). O aumento da carga de DCNT se sobrepõe ao rápido envelhecimento da população, juntamente com os efeitos negativos da rápida crescente urbanização dos grandes centros, a propensão à vida sedentária e dietas com alto teor calórico, juntamente com a mal controlada comercialização de tabaco e álcool, afetando, principalmente, os segmentos mais pobres e mais vulneráveis da população que estão mais expostas aos fatores de risco e por terem menos acesso aos serviços de saúde não participando de programas públicos de promoção da saúde e prevenção de agravos (WHO, 2011). Outros estudos têm demonstrado que os determinantes sociais, como educação, ocupação, renda, gênero e etnia, estão associados à prevalência de DCNT e seus fatores de risco, agravando a carga de morbidade em populações vulneráveis (Malta et al., 2016).

As doenças cardiovasculares são a principal causa de morte no Brasil, apesar da mortalidade causada por essas doenças ter diminuído ao longo dos anos. A alta frequência do problema coloca o Brasil entre os 10 países com maior índice de mortes por doenças cardiovasculares. São, ainda, as patologias que geram os maiores custos com relação a internações hospitalares. De acordo com a Pesquisa Nacional em Saúde (PNS), em 2013, 4,2\% (6,1 milhões) de pessoas de 18 anos ou mais de idade tiveram algum diagnóstico médico de alguma doença do coração. Esta mesma pesquisa, num inquérito epidemiológico de base domiciliar, com amostra representativa nacional avaliou a prevalência de AVC no Brasil calculou o número absoluto estimado de pessoas com AVC e incapacidade por AVC e respectivas prevalências. Estimou-se 2.231.000 pessoas com AVC e 568.000 com incapacidade grave. A prevalência pontual foi $1,6 \% \mathrm{em}$ 
homens e 1,4\% em mulheres, e a de incapacidade $29,5 \%$ em homens e de 21,5\% em mulheres (Benseñor, 2015).

Segundo Marino et al. (2016), o infarto agudo do miocárdio (IAM) ainda é considerado a principal causa de morte no Brasil. Em 2012, foi responsável por $8,8 \%$ do total de mortes, sendo que as doenças do aparelho circulatório representaram $20,6 \%$ de todos os óbitos naquele ano (DATASUS, 2012). No Brasil, apesar do declínio nas taxas de mortalidade, o AVC representa a primeira causa de morte e incapacidade no País, o que cria grande impacto econômico e social. Dados provenientes de estudo prospectivo nacional indicaram incidência anual de 108 casos por 100 mil habitantes, taxa de fatalidade aos 30 dias de $18,5 \%$ e aos 12 meses de 30,9\%, sendo o índice de recorrência após um 1 de 15,9\%.(BRASIL,2013)

Sabe-se que a poluição atmosférica está entre os principais fatores de risco modificáveis responsáveis pela carga de doença em todo o mundo. Segundo análise constante no Global Burden of Disease (GBD, 2013), a partir dos dados dos relatórios de 2010 e 2013, 22\% da população mundial tiveram redução nos anos de vida com qualidade (Disability Adjusted Life Years - DALYs) por efeito da poluição do ar.

Diversos trabalhos mostram a existência de efeitos deletérios à saúde humana, tanto em exposições de curta duração como em longos períodos de contato com poluentes atmosféricos. Como já descrito anteriormente, existem evidências do aumento de doenças do trato respiratório como a exacerbação de asma brônquica, da doença pulmonar obstrutiva crônica e o aumento de internações por infecções respiratórias. Há descrito também, maior incidência de malformações congênitas e o menor ganho de peso fetal durante a gestação. Outras situações, talvez com maior relevância, dizem respeito ao aumento significativo da morbidade e mortalidade por doenças cardiovasculares, principalmente por doença arterial coronariana, naqueles indivíduos expostos a poluentes atmosféricos. A forma como isto tem sido explicado fisiopatologicamente é pela relação existente entre a exposição a poluentes atmosféricos, a ativação do sistema pró-inflamatório sistêmico, o desenvolvimento da doença aterosclerótica e a aterotrombose. 
Vários métodos de imagem e marcadores laboratoriais têm sido utilizados com o propósito de se investigar e estreitar a relação entre níveis de poluentes atmosféricos, e o desenvolvimento de doença aterosclerótica pelo fato de existirem vários mecanismos complexos por trás da relação entre poluição atmosférica e aterogênese. Novas tecnologias têm sido desenvolvidas no sentido de se ajudar a entender, de forma mais ampla, a relação entre a qualidade e quantidade dos diversos agentes poluentes da atmosfera e seus mecanismos na gênese de eventos cardiovasculares.

A concentração de poluentes atmosféricos pode ser avaliada de várias maneiras, sendo muito frequente a utilização de medidas diretas da concentração média dos poluentes feita por estações de monitoramento da qualidade do ar, ou, ainda, de forma indireta, a partir da exposição ao tráfego de veículos com a vantagem desta última em se poder estimar o nível de exposição para um local específico. Dada a enorme população exposta e este fator de risco modificável, esta pesquisa visou, por meio de seus resultados, estabelecer uma associação entre poluição atmosférica e doença aterosclerótica. A partir daí, auxiliar em outros estudos sobre medidas preventivas e geração de políticas públicas que possam atenuar a exposição da população aos poluentes do ar reduzindo os efeitos nocivos destes agentes sobre a saúde humana. 
4 Objetivos 


\section{OBJETIVOS}

Este estudo teve como objetivo avaliar a possível associação entre a exposição a poluentes atmosféricos oriundos de tráfego veicular e a medida da espessura da íntima-média das carótidas em participantes ativos do estudo ELSA-Brasil moradores do município de São Paulo, por meio da utilização de métodos indiretos de mensuração da poluição atmosférica, como o cálculo de tráfego veicular nos locais de trabalho e residência. 
5 Método e Casuística 


\section{MÉTOdO E CASUÍSTICA}

5.1 Tipo de estudo

Foi conduzido um estudo de corte transversal.

\subsection{Caracterização do estudo}

Utilizou-se, para este projeto, uma parcela inicial do banco de dados referente à primeira avaliação (Onda 1) realizada entre 2008 e 2010 do Estudo Longitudinal sobre a Saúde do Adulto (ELSA), correspondente a 5.061 funcionários da Universidade de São Paulo.

5.3 Caracterização da população estudada

Critérios de inclusão: funcionários ativos da Universidade de São Paulo que participaram do projeto ELSA-SP de ambos os sexos com idade entre 35 e 74 anos, servidores civis ativos, todos voluntários e moradores no Município de São Paulo.

Critérios de exclusão: doença cardiovascular prévia (DCV) caracterizada por infarto agudo do miocárdio e/ou acidente vascular cerebral e/ou revascularização prévia. 
Do banco de dados do estudo ELSA (primeira avaliação entre 2008 e 2010), foram obtidos os dados de local de trabalho e residencial de cada sujeito para o georreferenciamento, o questionário com informações pessoais e contextuais contendo condições sociais, história pregressa sobre a saúde com informações sobre doenças crônicas pré-existentes, uso de medicamentos continuados, nível socioeconômico e de escolaridade.

Foram extraídas também as medidas antropométricas, ultrassonografia de carótida e exames bioquímicos de glicose, hemoglobina glicada, colesterol total e frações, e triglicérides.

A etnia foi autodefinida como negra, parda, branca, asiática e nativa (Indígena). Hipertensão foi definida pela referência ao uso de medicamentos de uso contínuo para tratamento desta patologia, além de níveis de pressão arterial sistólica mensurados acima de $140 \mathrm{~mm} \mathrm{Hg}$ ou uma pressão arterial diastólica acima de $90 \mathrm{mmHg}$ na avaliação inicial do estudo ELSA-Brasil.

O diabetes foi definido pela história clínica e o relato do uso de medicamentos para controlá-la, uma glicemia em jejum igual ou maior a 126 $\mathrm{mg} / \mathrm{dl}$, os níveis de hemoglobina glicada $(\mathrm{HbA} 1 \mathrm{c})$ de $6,5 \%$ ou teste de tolerância a glicose oral de 2 horas com valores acima de $200 \mathrm{mg} / \mathrm{dL}$. A intolerância à glicose ou disglicemia foi definida por valores entre 101 e 125 $\mathrm{mg} / \mathrm{dl}$.

A dislipidemia como variável categórica foi definida pela referência de tratamento para redução de lipídeos, ou, ainda, como variável ordinal, níveis de LDL colesterol acima de $130 \mathrm{mg} / \mathrm{dL}$, HDL colesterol menor do que 45 $\mathrm{mg} / \mathrm{dL}$, o colesterol total acima de $240 \mathrm{mg} / \mathrm{dL}$ e os triglicérides acima de 150 $\mathrm{mg} / \mathrm{dL}$.

Obesidade abdominal foi definida como a medida da circunferência da cintura maior $88 \mathrm{~cm}$ para mulheres e maior que $102 \mathrm{~cm}$ em homens. Foram considerados com sobrepeso indivíduos com valores de índice de massa corpórea [IMC= Kg/(altura em m² $)$ ] entre 25 e 29,99; e obesos acima de 30. 
Foram definidos indivíduos de baixo risco cardiovascular aqueles sem hipertensão, diabetes ou dislipidemia diagnóstico e que não tomaram quaisquer medicamentos no espectro cardiovascular, não fumantes ativos ou prévios, que não relataram doenças cardiovasculares prévias e tinham um índice de massa corpórea $(\mathrm{IMC})<30 \mathrm{~kg} / \mathrm{m}^{2}$. Além disso, os indivíduos participantes deste estudo foram divididos em menore $<49$ ou $\geq 49$ anos, pois o risco de doença cardiovascular também aumenta com a idade.

\subsubsection{A medida da espessura da intima média das carótidas no ELSA- Brasil}

A técnica de medição da EIMC no ELSA-Brasil utilizou o mesmo protocolo para a realização dos exames em todos os centros com um Toshiba (Aplio XG ${ }^{\mathrm{TM}}$ ) com um transdutor linear de 7,5 MHz. A EIMC foi medida na parede externa de um segmento pré-definido da carótida de $1 \mathrm{~cm}$ de comprimento, $1 \mathrm{~cm}$ abaixo da bifurcação carótida, durante três ciclos cardíacos consecutivos, e essas aquisições foram encaminhadas ao centro de leitura centralizada em São Paulo. Foram consideradas válidas as imagens claramente visualizadas tanto do lado esquerdo como do direito, as referências anatômicas para as artérias carótidas comuns e as interfaces entre o lúmen e a parede do vaso, sendo essa imagem analisada no eixo longitudinal, em que o segmento arterial é mais perpendicular ao feixe de ultrassom, com ajuste adequado do ganho e da profundidade entre 3,0 e 4,0 $\mathrm{cm}$. As imagens carotídeas foram obtidas por meiodos acessos anterior, posterior ou no esternocleidomastoideo, optando-se por aquela mais retilínea possível e com o padrão de dupla linha bem definido. Especial atenção foi dada aos pontos de colocação do cursor nas interfaces íntimalúmen e média-adventícia, em que o examinador deve ser bastante cauteloso para não superestimar valores (Santos et al., 2014) (Figura 5). A interpretação das imagens foi feita por meio de um Software MIA ${ }^{\mathrm{TM}}$ que registra, automaticamente, medidas unilaterais da EIMC. Foram utilizados para este estudo a EIMC média (média aritmética dos valores médios 
calculados para ambas as carótidas) e EIMC máxima (máximo valor obtido entre as medidas do lado direito e esquerdo) (Santos et al., 2014).

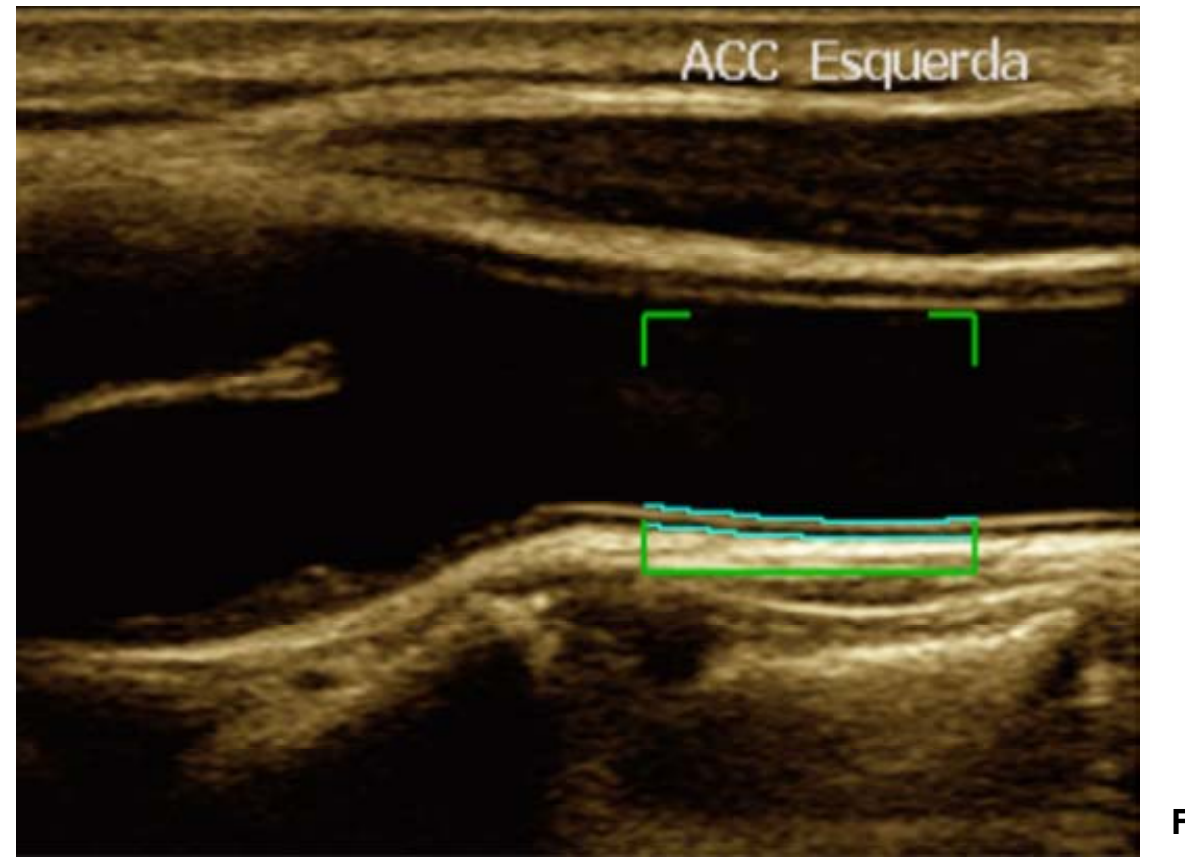

Figura 6

Espessura médio-intimal média da artéria carótida comum (Freire et al., 2015).

\subsubsection{Obtenção dos dados viários e de tráfego}

Foram utilizadas informações viárias e de tráfego veicular do ano de 2007 que correspondem ao período do início do estudo ELSA, as quais incluem a base cartográfica das vias, por classificação, número de faixas de rolagem e velocidade máxima permitida no segmento. Nesta época, a cidade de São Paulo contava com mais de $16.300 \mathrm{~km}$ de vias de tráfego, quase $75 \%$ deles eram classificados como locais. Menos de $2 \%$ eram vias de trânsito rápido, com maiores fluxos de tráfego.

A Companhia de Engenharia de Tráfego (CET) realiza contagem de veículos em algumas vias do município, nos horários de pico da manhã, e utilizam o programa canadense EMME-2 para simular o tráfego nas demais vias do município. Baseando-se nas contagens e simulações, a CET forneceu informações do tráfego médio de 2007. Também foram incluídos dados das vias, por tipo (vias locais, coletoras, arteriais e de trânsito rápido), 
número de faixas de rolamento e velocidade média do fluxo (Habermann et al., 2011).

Para os segmentos que não possuem valor de tráfego, foi atribuído o volume médio, de acordo com a classificação da respectiva via. O tráfego das vias locais foi estimado pela CET em 926 regiões delimitadas para planejamento de tráfego (denominadas Origem-Destino), sendo que a soma de tráfego de cada uma dessas regiões dividida pela soma das extensões das vias locais contidas nelas resultava na densidade de tráfego (fluxo de veículos/metro de via local (i)); posteriormente, essa medida foi multiplicada pelo comprimento dos segmentos de vias locais (SVL), em metros, contidos nas respectivas regiões, obtendo-se o volume de tráfego de cada trecho de via local $(T)$.

$$
T=\left(\underline{\sum} \text { fluxo: } \sum \text { comprimento }\right) \times S V L
$$

\subsubsection{Cálculo da densidade de tráfego ponderada pela distância (DTPD)}

Para cada sujeito do estudo já previamente georreferenciado e constantes no banco de dados do estudo ELSA, foi calculada a DTPD em uma distância no entorno de sua residência, no qual $L$ é largura do buffer e $D$ é a menor distância da casa para cada via dentro do buffer, $Y$ é o valor utilizado para ponderar o fluxo veicular obtido para cada via dentro desta área.

$$
Y=\left(\frac{1}{0,4 \sqrt{2 \pi}}\right) \times \exp \left[\left(\frac{(0,5)\left(\frac{D}{L}\right)^{2}}{(0,4)^{2}}\right)\right]
$$


Divide-se, então, o fluxo veicular da referida rua pelo valor de $Y$, gerando o valor de $X$. Então, se somam os valores ponderados de tráfego $(X)$ de todas as vias contidas no buffer $(n)$, obtendo-se, portanto, a DTPD.

$$
X=\frac{\text { fluxo veicular }}{Y} \quad \text { DTPD }=\sum_{i=1}^{n} X_{i}
$$

Como a densidade e a característica das construções, direção predominante dos ventos, altitude e turbulência gerada pela passagem de veículos interferem na dispersão dos poluentes gerados pelo tráfego, podese assumir larguras variadas de buffers para calcular a DTPD, diminuindo as imprecisões na medida de exposição. Para estes cálculos, foi utilizado o buffer com raio de 500 pés (aproximadamente, 156,5 m). Cálculos semelhantes foram realizados em relação à unidade da Universidade em que cada sujeito do estudo trabalha.

\subsubsection{Cálculo da densidade de tráfego ponderada pela distância combinada (DTPD comb)}

Considerou-se horário comercial (8 horas) o tempo médio de permanência dos funcionários nas respectivas unidades da Universidade de São Paulo durante o período de trabalho. As demais horas do dia (16 horas) foram atribuídas a atividades fora da unidade ou à permanência em domicílio. Portanto, o cálculo da DPTD combinada (DTPD comb) foi feito com a média ponderada de $1 / 3$ do valor da DTPD do local de trabalho (DTPD trab) e 2/3 do valor da DTPD da residência dos sujeitos (DTPD casa).

\subsubsection{Cálculo da exposição ao tráfego veicular tendo como indicador apenas a distância (DP)}

Este método consiste no uso de sistema de informação geográfica (SIG) para mapear um local de interesse e sua distância até uma ou mais 
vias de fluxo intenso de tráfego. A mensuração da exposição se baseou na distância destes pontos em relação às vias. Neste estudo, foram avaliados o tráfego veicular em relação ao domicílio e o local de trabalho de cada um dos sujeitos analisados. São definidas vias com fluxo intenso de tráfego aquelas com volumes de tráfego de veículos maiores do que o percentil 95 ( $\geq 1,876$ veículos/hora) da distribuição. Isso inclui a maioria das vias de trânsito rápido, arterial e coletor.

\subsubsection{Cálculo da distância entre o domicílio e o local de trabalho dos sujeitos do estudo}

Utilizou-se como ferramenta a trigonometria esférica na elaboração do cálculo da distância entre a residência e o local de trabalho. A medida linear de um arco qualquer é a distância entre dois pontos, ou seja, é o comprimento do menor arco de circunferência máxima que passa por dois pontos numa superfície curva (Abreu \& Ottoni, 2015).

A fórmula utilizada foi:

dlon = lon2 - lon1(diferença de longitude trabalho e residência);

dlat = lat2 - lat1(diferença de latitude trabalho e residência);

$a=\left(\sin (\text { dlat } / 2)^{2}+\cos (\right.$ lat 1$){ }^{*} \cos ($ lat 2$) *(\sin (\text { dlon } / 2))^{2}$;

$\mathrm{C}=2{ }^{*} \operatorname{atan} 2(\operatorname{sqrt}(\mathrm{a}), \operatorname{sqrt}(1-\mathrm{a}))$;

$d=R * C$;

(onde R é o Raio da Terra = $6.373 \mathrm{~km}$ );

$<$ lon > e < lat > são latitudes e longitudes de cada ponto p1 (local da residência) e p2 (local de trabalho);

$<$ dlon $>$ e $<$ dlat $>$ são as diferenças entre as coordenadas dos dois pontos;

$<$ sqrt $>$, $<\sin >$, e $<\cos >$ são as funções raiz quadrada, seno, cosseno;

< atan2 > é a função arco-tangente de dois argumentos. 
Trata-se de um estudo transversal que pretendeu analisar a associação entre a exposição a diferentes concentrações de poluentes atmosféricos (por meio dos cálculos da DTPD, DP, e distância entre casa e trabalho) e a medida da espessura da íntima média das carótidas (EIMC). Para esta investigação, utilizou-se como modelo estatístico a regressão linear. Foi realizada a análise univariada entre a variável de desfecho (EIMC), as variáveis de exposição e cada uma das variáveis independentes referentes às características individuais dos sujeitos do estudo, e resultados dos exames laboratoriais.

$\mathrm{Na}$ análise multivariada, foram utilizadas todas as variáveis de exposição individualmente. Foram construídos modelos ajustados para idade, sexo e raça (homens, negros e idosos possuem valores maiores de EIMC quando comparadas às demais características dos sujeitos) e com ajuste completo (sexo, raça, idade, nível educacional, pressão arterial sistólica, índice de massa corpórea, diagnóstico de hipertensão, diabetes mellitus e dislipidemia, status de tabagismo e história familiar de doença cardiovascular precoce (<60 anos)). Foram construídos também modelos para análise por grupo etário (maior ou igual 49 anos ou menor do que 49 anos) e outros de acordo com a classificação de maior ou menor risco para desenvolvimento de doença aterosclerótica. As variáveis dependentes não foram selecionadas com base na significância estatística, pois todas elas são sabidamente fatores de risco que influenciam a EIMC e o desenvolvimento de aterosclerose. Além disso, uma amostra tão grande implicaria em selecionar variáveis que têm associação real muito fraca com a variável de desfecho. A medida de associação utilizada foi o coeficiente de inclinação da reta (coeficiente ß). O nível de significância foi estabelecido em 0,05 . Todas as análises foram realizadas utilizando-se o Software Minitab V16. 


\section{RESULTADOS}




\section{RESULTADOS}

Dentre os 5.061 participantes ELSA-Brasil-SP, foram excluídos 933 $(18,4 \%)$ aposentados, $108(2,1 \%)$ que tinham doença cardiovascular prévia (DCV) caracterizada por infarto agudo do miocárdio e/ou acidente vascular cerebral e/ou revascularização prévia, $2(<0,1 \%$, nos quais não foi possível obter a informação sobre DCV prévia, $102(2,0 \%)$ que não tinham valores válidos de EIMC para alguma das artérias carótidas comuns e $1.316(26,0 \%)$ nos quais não foi possível obter os dados de densidade de tráfego, por morarem ou trabalharem fora da cidade de São Paulo. Assim, foi incluído nas análises um total de 2.600 participantes. As Tabelas 2 e 3 referem-se à análise descritiva das variáveis contínuas e categorizadas. Os homens corresponderam a $44,7 \%$ do total, predominava a etnia branca $(62,0 \%)$ e, em relação ao nível de escolaridade, $52,6 \%$ possuíam nível superior completo. $\mathrm{Na}$ avaliação da presença de comorbidades, $26,8 \%$ eram hipertensos, 16.3 $\%$ eram fumantes ativos, $16,6 \%$ diabéticos, $55,4 \%$ dislipidêmicos, $20,4 \%$ faziam uso de medicação anti-hipertensiva e 15,3\% tinham histórico de doença coronária precoce na família. Em relação às variáveis de exposição, a DTPD_casa foi 2,7 vezes superior aos valores da DTPD_trabalho (veículos $/$ hora $/ \mathrm{Km}^{2}$ ). Quando a variável de exposição foi a distância da residência à via de maior fluxo veicular (DIST_95P_casa) e do local de trabalho (DIST_95P_trabalho), os valores encontrados referentes aos locais de trabalho foram 12 vezes superiores em relação aos domicílios (distância em metros da via principal). Utilizando-se o primeiro quartil (Q1) da Tabela 2 como valor de referência para baixa exposição dos sujeitos aos poluentes do ar, verificamos que a média da DTPD_casa foi 18,5 vezes superior à referência, a do DTPD_trabalho foi 13 vezes maior e o DTPD combinado foi 12,3 vezes superior. Em relação à DIST_95P_casa e DIST_95P_trabalho, os valores em metros foram, aproximadamente, de 2,8 e 1,4 vezes maiores do que os valores de referência (Q1), respectivamente. 
Baseado na média de velocidade automotiva no Município de São Paulo, que, em 2008, era de, aproximadamente, 18,5 km /hora (CET, 2014), calculou-se que o tempo médio gasto para o deslocamento entre casa e trabalho (ida e volta) foi de, aproximadamente, 50 minutos e, no máximo, de 352 minutos.

Em relação à distribuição dos valores obtidos da EIMC, dos 2.600 indivíduos do estudo, 2.577 estavam menores do que de $1 \mathrm{~mm}$; 22 entre $1 \mathrm{~mm}$ e $1,5 \mathrm{~mm}$ e apenas 1 acima de $1,5 \mathrm{~mm}$, com valor máximo de 1,64mm para EIMC média e 2,83 mm para EIMC máxima. Segundo a $V$ Diretriz Brasileira de Dislipidemias e Prevenção da Aterosclerose, a EIMC (patológica) seria para a média definida com valores $>1,0 \mathrm{~mm}$ e a placa carotídea > 1,5 mm (Xavier et al., 2013).

$\mathrm{Na}$ Tabela 4, a análise de regressão univariada para os valores médios da EIMC mostrou uma associação linear com fatores tradicionais de doença aterosclerótica, como a idade, hipertensão arterial referida, pressão arterial sistólica e diastólica aferidas, uso de anti-hipertensivos, IMC, diabetes, tabagismo, dislipidemia e antecedentes familiares de doença cardiovascular. Em relação às variáveis referentes às medidas de exposição indireta aos poluentes, houve correlação estatística apenas com a distância do trabalho a casa (DIST_casa trabalho) com $\mathrm{p}<0,001$.

Quando foi feita a análise em relação aos valores máximos da EIMC (Tabela 5), houve correlação também com idade, hipertensão arterial referida, pressão arterial sistólica e diastólica aferidas, uso de antihipertensivos, IMC, diabetes, tabagismo, dislipidemia e antecedentes familiares de doença cardiovascular. Novamente, quando analisadas as variáveis de exposição em relação ao desfecho, houve correlação estatística apenas com a variável relativa à (DIST_casa trabalho) $(p<0,001)$.

$\mathrm{Na}$ análise multivariada (Tabela 6), houve uma associação apenas com DIST_casa trabalho com $ß=0,532$ para o modelo ajustado para sexo, cor e etnia, lembrando que estes valores são o produto dos iniciais multiplicados por 1000. Nos demais modelos, não houve associação linear. Quando a variável de desfecho foi referente aos valores máximos da EIMC (Tabela 7), 
houve, novamente, uma associação apenas com a variável DIST_casa trabalho com $\beta=0,532$ para o modelo ajustado para sexo, idade e enia. As Tabelas 8 e 9 referem-se à análise do coeficiente de regressão para os valores médios e máximos da EIMC para o grupo de sujeitos com alto risco para doença aterosclerótica em relação às variáveis de exposição. Tanto para os valores médios como os máximos, não houve associação em nenhum dos modelos ajustados. Foram também analisados os grupos de baixo risco para doença aterosclerótica em relação aos valores médios e máximos da EIMC (Tabelas 10 e 11), não havendo associação estatística com nenhuma das variáveis de exposição tanto nos valores médios quanto nos máximos para qualquer um dos modelos (bruto, ajustado para idade, sexo e etnia, e o ajuste completo). Os mesmos resultados foram obtidos para os grupos de sujeitos com idade menor a 49 anos(Tabelas 12 e 13). No modelo que utilizou indivíduos com idade maior ou igual a 49 anos, houve apenas associação no modelo bruto, sabendo-se que estes grupos relativos à idade foram analisados separadamente, tanto para os valores médios quanto os máximos da EIMC (Tabelas 14 e 15). Na tentativa de esclarecer a não associação entre a variável de exposição (DIST casa_trab) e o desfecho nos modelos de ajuste completo, foi feita uma análise de regressão linear univariada entre esta variável de exposição (divididos em grupos pela mediana da distância de $4.9 \mathrm{Km}$ ) e as variáveis ligadas às características dos sujeitos.

Os resultados (Tabela 16) mostraram que os negros e pardos moram em locais mais distantes do trabalho $(p=0,003)$, bem como, os que possuem menor nível de escolaridade $(p=0,010)$. O tabagismo, que também é fator de risco para doença cardiovascular, não mostrou diferença entre os grupos. 
Tabela 2 - Análise descritiva das características dos sujeitos do estudo das (variáveis contínuas)

\begin{tabular}{|c|c|c|c|c|c|c|c|c|c|c|}
\hline Variável & Unidade & $\mathbf{N}$ & $\mathbf{N}^{*}$ & Média & DP & Mínimo & Q1 & Mediana & Q3 & Máximo \\
\hline EIMC médio & $\mathrm{mm}$ & 2600 & 0 & 0,59 & 0,12 & 0,26 & 0,5 & 0,57 & 0,66 & 1,64 \\
\hline EIMC máximo & $\mathrm{mm}$ & 2600 & 0 & 0,79 & 0,19 & 0,47 & 0,65 & 0,75 & 0,88 & 2,83 \\
\hline PAD & $\mathrm{mm} / \mathrm{hg}$ & 2600 & 0 & 74,67 & 10,72 & 46,5 & 67 & 74 & 81 & 130,5 \\
\hline PAS & $\mathrm{mm} / \mathrm{hg}$ & 2600 & 0 & 117,7 & 15,53 & 82 & 106,5 & 116 & 127,4 & 202 \\
\hline IDADE & anos & 2600 & 0 & 49,3 & 7,45 & 34 & 44 & 49 & 55 & 72 \\
\hline IMC & $\begin{array}{c}\text { peso/(alt em } \\
\mathrm{m})^{2}\end{array}$ & 2600 & 0 & 26,9 & 4,7 & 15,58 & 23,68 & 26,18 & 29,39 & 52,17 \\
\hline Glicose & $\mathrm{mg} / \mathrm{dl}$ & 2600 & 0 & 108,4 & 23,74 & 76 & 98 & 104 & 112 & 393 \\
\hline Hemog glicada & $\%$ & 2599 & 1 & 5,39 & 0,85 & 2,6 & 4,9 & 5,3 & 5,7 & 14,6 \\
\hline GTT & $\mathrm{mg} / \mathrm{dl}$ & 2426 & 174 & 129,6 & 39,88 & 42 & 106 & 123 & 146 & 495 \\
\hline Colesterol total & $\mathrm{mg} / \mathrm{dl}$ & 2600 & 0 & 213,8 & 40,66 & 98 & 186 & 211 & 238 & 575 \\
\hline $\mathrm{HDL}$ & $\mathrm{mg} / \mathrm{dl}$ & 2600 & 0 & 56,7 & 13,93 & 20 & 47 & 54 & 65 & 136 \\
\hline LDL & $\mathrm{mg} / \mathrm{dl}$ & 2600 & 0 & 131,2 & 33,89 & 33 & 108 & 129 & 152 & 335 \\
\hline Triglicérides & $\mathrm{mg} / \mathrm{dl}$ & 2600 & 0 & 131,8 & 96,49 & 31 & 78 & 110 & 159 & 2070 \\
\hline DTPD_casa & veic/hora/km2 & 2600 & 0 & 668,4 & 1099 & 0 & 36 & 235,5 & 887,7 & 16537,9 \\
\hline DTPD_trabalho & veic/hora/km2 & 2600 & 0 & 243,3 & 664 & 2,8 & 18,6 & 25,9 & 32,2 & 3293,1 \\
\hline DTPD_COMB & veic/hora/km2 & 2600 & 0 & 385 & 576 & 1,8 & 31,1 & 130 & 506,1 & 5534,1 \\
\hline DIST_95P_casa & metros & 2600 & 0 & 437,4 & 546 & 0,2 & 153 & 304,6 & 532,6 & 13439 \\
\hline DIST_95P_trabalho & metros & 2600 & 0 & 521,6 & 260,8 & 2,06 & 378,2 & 573,51 & 677 & 1103,08 \\
\hline Dist casatrab & kilômetros & 2600 & 0 & 7,66 & 8,06 & 0,12 & 2,63 & 4,93 & 9,53 & 54,36 \\
\hline
\end{tabular}


Tabela 3 - Análise descritiva das características dos sujeitos do estudo (variáveis categorizadas)

\begin{tabular}{|c|c|c|c|}
\hline Variável & $\mathbf{n}$ & Valor absoluto & $\%$ \\
\hline \multicolumn{4}{|l|}{ Sexo } \\
\hline Masculino & 2600 & 1163 & 44,73 \\
\hline Feminino & 2600 & 1437 & 55,27 \\
\hline \multicolumn{4}{|l|}{$\mathrm{N}^{\circ}$ funcionários } \\
\hline Básico & 2600 & 686 & 26,38 \\
\hline Técnico & 2600 & 901 & 34,85 \\
\hline Superior & 2600 & 1013 & 38,96 \\
\hline \multicolumn{4}{|l|}{ Etnia } \\
\hline Negro & 2564 & 298 & 11,62 \\
\hline Pardo & 2564 & 523 & 20,40 \\
\hline Branco & 2564 & 1590 & 62,01 \\
\hline Outros & 2564 & 153 & 5,97 \\
\hline \multicolumn{4}{|l|}{$*=36$} \\
\hline \multicolumn{4}{|l|}{ Escolaridade } \\
\hline Até $2^{\circ}$ grau incompleto & 2600 & 280 & 10,77 \\
\hline $2^{\circ}$ grau completo & 2600 & 952 & 36,62 \\
\hline Graduação superior completa & 2600 & 1368 & 52,62 \\
\hline \multicolumn{4}{|l|}{ Hipertensão } \\
\hline Não & 2598 & 1901 & 73,17 \\
\hline Sim & 2598 & 697 & 26,93 \\
\hline \multicolumn{4}{|l|}{$*=2$} \\
\hline \multicolumn{4}{|l|}{ Tabagismo } \\
\hline Nunca & 2600 & 1428 & 54,92 \\
\hline Ex & 2600 & 747 & 28,73 \\
\hline Atual & 2600 & 425 & 16,35 \\
\hline \multicolumn{4}{|l|}{ Diabetes } \\
\hline Não & 2600 & 2168 & 83,38 \\
\hline Sim & 2600 & 432 & 16,62 \\
\hline \multicolumn{4}{|l|}{ Dislipidemia } \\
\hline Não & 2599 & 1166 & 44,86 \\
\hline Sim & 2599 & 1433 & 55,14 \\
\hline \multicolumn{4}{|l|}{$*=1$} \\
\hline \multicolumn{4}{|l|}{ Uso de anti-hipertensivos } \\
\hline Não & 2600 & 2067 & 79,60 \\
\hline Sim & 2600 & 529 & 20,40 \\
\hline \multicolumn{4}{|c|}{ Doença coronária precoce na família } \\
\hline Não & 2566 & 2172 & 84,65 \\
\hline Sim & 2566 & 394 & 15,35 \\
\hline
\end{tabular}


Tabela 4 - Análise de regressão linear univariada para os desfechos da EIMC (valores médios)

\begin{tabular}{|c|c|c|c|}
\hline Variável & $\beta$ & Erro Padrão & Valor de $p$ \\
\hline \multicolumn{4}{|l|}{ Sexo } \\
\hline Feminino & $-0,042$ & 0,004 & $<0,001$ \\
\hline DTPD trabalho & 0,000 & $<0,001$ & 0,297 \\
\hline DTPD casa & 0,000 & $<0,001$ & 0,986 \\
\hline DTPD comb & 0,000 & $<0,001$ & 0,416 \\
\hline DIST_95P residência & 0,000 & $<0,001$ & 0,543 \\
\hline DIST_95P_trabalho & 0,000 & $<0,001$ & 0,486 \\
\hline DIST casa - trabalho & 0,001 & $<0,001$ & $<0,001$ \\
\hline \multicolumn{4}{|l|}{ Etnia } \\
\hline Pardo & $-0,029$ & 0,009 & 0,001 \\
\hline Brancos & $-0,030$ & 0,007 & $<0,001$ \\
\hline Outros & $-0,019$ & 0,012 & 0,113 \\
\hline Pressão arterial diastólica & 0,002 & $<0,001$ & $<0,001$ \\
\hline Pressão arterial sistólica & 0,002 & $<0,001$ & $<0,001$ \\
\hline Idade & 0,008 & $<0,001$ & $<0,001$ \\
\hline IMC & 0,005 & 0,0005 & $<0,001$ \\
\hline Hipertensão & 0,077 & 0,005 & $<0,001$ \\
\hline Diabetes & 0,063 & 0,006 & $<0,001$ \\
\hline \multicolumn{4}{|l|}{ Tabagismo } \\
\hline Nunca & 0,043 & 0,005 & $<0,001$ \\
\hline Ex-fumante & 0,037 & 0,004 & $<0,001$ \\
\hline Atual & 0,033 & 0,006 & $<0,001$ \\
\hline Uso de anti-hipertensivos & 0,065 & 0,005 & $<0,001$ \\
\hline Glicemia em jejum & 0,001 & 0,000 & $<0,001$ \\
\hline Colesterol total & 0,054 & 0,005 & $<0,001$ \\
\hline HDL & 0,001 & $<0,001$ & $<0,001$ \\
\hline LDL & 0,000 & 0,000 & 0,011 \\
\hline Triglicérides & 0,001 & $<0,001$ & $<0,001$ \\
\hline Dislipidemia & 0,042 & 0,004 & 0,000 \\
\hline Hemoglobina glicada & 0,018 & 0,002 & $<0,001$ \\
\hline Teste de tolerância à glicose & 0,001 & $<0,001$ & $<0,001$ \\
\hline Antecedentes de DCV familiar & 0,017 & 0,006 & 0,012 \\
\hline \multicolumn{4}{|l|}{ Colesterol total } \\
\hline \multicolumn{4}{|l|}{ Escolaridade } \\
\hline Segundo grau completo & 0,008 & 0,007 & 0,261 \\
\hline Superior ou pós graduação & 0,000 & 0,007 & 0,982 \\
\hline
\end{tabular}


Tabela 5 - Análise de regressão linear univariada para os desfechos de EIMC (valores máximos)

\begin{tabular}{|c|c|c|c|}
\hline Variável & $\beta$ & Erro Padrão & Valor de $p$ \\
\hline \multicolumn{4}{|l|}{ Sexo } \\
\hline Feminino & $-0,065$ & 0,007 & $<0,001$ \\
\hline *DTPD comb & 0,001 & $<0,001$ & 0,602 \\
\hline DIST_95P_casa & 0,001 & $<0,001$ & 0,802 \\
\hline DIST_95P_local de trabalho & 0,001 & $<0,001$ & 0,960 \\
\hline DTPD casa & 0,149 & 0,008 & 0,997 \\
\hline DTPD trabalho & 0,001 & $<0,001$ & 0,500 \\
\hline DIST casa - trabalho & 0,001 & $<0,001$ & $<0,001$ \\
\hline \multicolumn{4}{|l|}{ Etnia } \\
\hline Pardo & $-0,039$ & 0,013 & 0,005 \\
\hline Brancos & $-0,046$ & 0,012 & $<0,001$ \\
\hline Outros & $-0,038$ & 0,019 & 0,045 \\
\hline Pressão arterial diastólica & 0,004 & 0,000 & $<0,001$ \\
\hline Pressão arterial sistólica & 0,004 & 0,000 & $<0,001$ \\
\hline Idade & 0,010 & 0,000 & $<0,001$ \\
\hline IMC & 0,011 & 0,008 & $<0,001$ \\
\hline Hipertensão & 0,131 & 0,007 & $<0,001$ \\
\hline Diabetes & 0,105 & 0,009 & $<0,001$ \\
\hline \multicolumn{4}{|l|}{ Tabagismo } \\
\hline Nunca & 0,055 & 0,007 & $<0,001$ \\
\hline Ex-fumante & 0,055 & 0,007 & $<0,001$ \\
\hline Atual & 0,053 & 0,021 & 0,001 \\
\hline Uso de anti-hipertensivos & 0,115 & 0,009 & $<0,001$ \\
\hline Glicemia de jejum & 0,001 & 0,000 & $<0,001$ \\
\hline Tolerância à glicose & 0,001 & $<0,001$ & $<0,001$ \\
\hline HDL & $-0,001$ & 0,001 & $<0,001$ \\
\hline LDL & 0,001 & 0,007 & $<0,001$ \\
\hline Triglicérides & 0,001 & 0,001 & $<0,001$ \\
\hline Dislipidemia & 0,073 & 0,007 & $<0,001$ \\
\hline Hemoglobina glicada & 0,033 & 0,004 & $<0,001$ \\
\hline Histórico de doença CV na família & 0,115 & 0,009 & $<0,001$ \\
\hline Colesterol total & 0,001 & $<0,001$ & $<0,001$ \\
\hline \multicolumn{4}{|l|}{ Escolaridade } \\
\hline Segundo grau completo & $-0,060$ & 0,013 & $<0,001$ \\
\hline Superior ou pós graduação & $-0,079$ & 0,012 & $<0,001$ \\
\hline
\end{tabular}


Tabela 6 - Coeficiente de regressão (intervalo de confiança de 95\%) para a associação entre as medidas indiretas da poluição atmosférica e a média das medidas da espessura da camada íntima média das carótidas da linha de base do estudo ELSA - Brasil-SP - 2008

\begin{tabular}{|c|c|c|c|}
\hline Modelo & Bruto & Idade ,sexo e etnia & Ajuste completo* \\
\hline DTPD trabalho & $0,004(-0,003$ a 0,011$)$ & $0,004(-0,002$ a 0,010$)$ & $0,002(-0,004$ \\
\hline DTPD casa & $0,000(-0,004$ a 0,004$)$ & $-0,003(-0,006$ a 0,001$)$ & $-0,002(-0,006$ a 0,001$)$ \\
\hline DTPD comb & $0,003(-0,005$ a 0,012$)$ & $0.000(-0,007$ a 0,008$)$ & $-0,001(-0,008$ a 0,006$)$ \\
\hline DIST 95P residência & $0,005(-0,004$ a 0,014$)$ & $0,006(-0,002$ a 0,013$)$ & $0,003(-0,005$ a 0,010$)$ \\
\hline DIST 95P trabalho & $0.007(-0,012$ a 0,025$)$ & $-0,012(-0,028$ a 0,004$)$ & $-0,004(-0,019$ a 0,012$)$ \\
\hline DIST casa trabalho & $0,894(0,300$ a 1,489$)$ & $0.532(0,002$ a 1,063$)$ & $0,239(-0,283$ a 0,757 \\
\hline
\end{tabular}

Obs.: Os valores foram multiplicados por 1000.

* Variáveis no ajuste completo: sexo, raça, idade, nível educacional, pressão arterial sistólica, índice de massa corpórea, diagnóstico de HAS, DM, DLP, status de tabagismo e história familiar de DCV precoce ( $<60$ anos)

Tabela 7 - Coeficiente de regressão (intervalo de confiança de 95\%) para a associação entre as medidas indiretas da poluição atmosférica e a medida máxima da espessura da camada íntima média das carótidas da linha de base do estudo ELSA - Brasil-SP - 2008.

\begin{tabular}{|c|c|c|c|}
\hline Modelo & Bruto & Idade, sexo e etnia & Ajuste completo* \\
\hline DTPD trabalho & $0,004(-0,007$ a 0,015$)$ & $0,004(-0,006$ a 0,014$)$ & $0,002(-0,009$ a 0,009$)$ \\
\hline DTPD casa & $0,000(-0,007$ a 0,007$)$ & $-0,003(-0,010$ a 0,002$)$ & $-0,002(-0,009$ a 0,002$)$ \\
\hline DTPD comb & $0,003(-0,009$ a 0,016$)$ & $-0,001(-0,013$ a 0,011 & $-0,001(-0,015$ a 0,006$)$ \\
\hline DIST 95P residência & $0,005(-0,002$ a 0,024$)$ & $0,011(-0,001$ a 0,024$)$ & $0,003(-0,006$ a 0,017$)$ \\
\hline DIST 95P trabalho & $0.007(-0,028$ a 0,029$)$ & $-0,012(-0,053$ a $-0,002)$ & $-0,004(-0,036$ a 0,014$)$ \\
\hline DIST casa trabalho & $1,644(0,727$ a 2,560$)$ & $0.532(0,220$ a 1,897$)$ & $0,239(-0,299$ a 1,310$)$ \\
\hline
\end{tabular}


Tabela 8 - Coeficiente de regressão (intervalo de confiança de 95\%) para a associação entre as medidas indiretas da poluição atmosférica e a medida média da espessura da camada íntima média das carótidas da linha de base do estudo ELSA - Brasil-SP - 2008 para o grupo de sujeitos considerados de alto risco para doença aterosclerótica

\begin{tabular}{|c|c|c|c|}
\hline Modelo & Bruto & $\begin{array}{c}\text { Ajustado idade, sexo e } \\
\text { etnia }\end{array}$ & Ajuste completo* \\
\hline DTPD -trabalho & $0,004(-0,006$ a 0,009$)$ & $0,003(-0,003$ a 0,010$)$ & $0,002(-0,004$ a 0,009$)$ \\
\hline DTPD -casa & $0,000(-0,006$ a 0,004$)$ & $-0,003(-0,007$ a 0,001$)$ & $-0,002(-0,007$ a 0,001$)$ \\
\hline DTPD combinado & $0,003(-0,009$ a 0,009$)$ & $-0.000(-0,008$ a 0,0007$)$ & $-0.001(-0,009$ a 0,006$)$ \\
\hline DIST 95P residência & $0,011(-0,005$ a 0,014$)$ & $0,006(-0,002$ a 0,014$)$ & $0,004(-0,003$ a 0,131$)$ \\
\hline DIST 95P trabalho & $0.001(-0,010$ a 0,030$)$ & $-0,008(-0,026$ a 0,009$)$ & $-0,002(-0,020$ a 0,015$)$ \\
\hline DIST casa trabalho & $0,822(0,185$ a 1,459$)$ & $0,532(-0,045$ a 1,110$)$ & $0,369(-0,194$ a 0,932$)$ \\
\hline
\end{tabular}

Tabela 9 - Coeficiente de regressão (intervalo de confiança de 95\%) para a associação entre as medidas indiretas da poluição atmosférica e a medida máxima da espessura da camada íntima média das carótidas da linha de base do estudo ELSA - Brasil-SP - 2008 para o grupo de sujeitos considerados de alto risco para doença aterosclerótica

\begin{tabular}{|c|c|c|c|}
\hline Modelo & Bruto & $\begin{array}{c}\text { Ajustado idade, sexo e } \\
\text { etnia }\end{array}$ & Ajuste completo* \\
\hline DTPD -trabalho & $0,000(-0,012$ a 0,012$)$ & $0,002(-0,008$ a 0,010$)$ & $-0,000(-0,010$ a 0,010$)$ \\
\hline DTPD -casa & $-0,002(-0,009$ a 0,005$)$ & $-0,005(-0,012$ a 0,013$)$ & $-0,004(-0,011$ a 0,001$)$ \\
\hline DTPD combinado & $-0,002(-0,016$ a 0,011$)$ & $-0.000(-0,008$ a 0,0007$)$ & $-0.001(-0,009$ a 0,006$)$ \\
\hline DIST 95P residência & $0,011(-0,004$ a 0,024$)$ & $0,011(-0,001$ a 0,025$)$ & $0,009(-0,039$ a 0,016$)$ \\
\hline DIST 95P trabalho & $0.004(-0,027$ a 0,035$)$ & $-0,023(-0,052 a 0,004)$ & $-0,011(-0,020$ a 0,015$)$ \\
\hline DIST casa trabalho & $1,521(0,539$ a 2,503$)$ & $1,050(-0,137$ a 1,963$)$ & $0,763(-0,111$ a 1,637$)$ \\
\hline
\end{tabular}

Tabela 10 - Coeficiente de regressão (intervalo de confiança de 95\%) para a associação entre as medidas indiretas da poluição atmosférica e a medida média da espessura da camada íntima média das carótidas da linha de base do estudo ELSA - Brasil-SP - 2008 para o grupo de sujeitos considerados de baixo risco para doença aterosclerótica

\begin{tabular}{lccc}
\hline Modelo & Bruto & Idade, sexo e etnia & Ajuste completo* \\
\hline DTPD trabalho & $0,006(-0,011$ a 0,023$)$ & $0,004(-0,010$ a 0,019$)$ & $-0,004(-0,010$ a 0,019$)$ \\
DTPD casa & $0,004(-0,004$ a 0,013$)$ & $0,000(-0,007$ a 0,079$)$ & $-0,000(-0,007$ a 0,007$)$ \\
DTPD comb & $0,011(-0,007$ a 0,029$)$ & $0,003(-0,012$ a 0,019$)$ & $-0,003(-0,012$ a 0,019$)$ \\
DIST 95P residência & $-0,003(-0,023$ a 0,017$)$ & $-0,000(-0,019$ a 0,017$)$ & $-0,004(-0,022$ a 0,014$)$ \\
DIST 95P trabalho & $0.007(-0,029$ a 0,042$)$ & $-0,015(-0,047$ a 0,017$)$ & $-0,015(-0,047$ a 0,017$)$ \\
DIST casa trabalho & $0,154(-1,189$ a 1,496$)$ & $0,040(-1,179$ a 1,259$)$ & $-0,005(-1,213$ a 1,204$)$ \\
\hline
\end{tabular}


Tabela 11 - Coeficiente de regressão (intervalo de confiança de 95\%) para a associação entre as medidas indiretas da poluição atmosférica e a medida máxima espessura da camada íntima média das carótidas da linha de base do estudo ELSA - Brasil-SP - 2008 para o grupo de sujeitos considerados de baixo risco para doença aterosclerótica

\begin{tabular}{lccc}
\hline Modelo & Bruto & Idade, sexo e etnia & Ajuste completo* \\
\hline DTPD trabalho & $0,008(-0,017$ a 0,034$)$ & $0,007(-0,015$ a 0,030$)$ & $-0,007(-0,015$ a 0,030$)$ \\
DTPD casa & $0,009(-0,003$ a 0,023$)$ & $0,005(-0,006$ a 0,017$)$ & $0,004(-0,007$ a 0,015$)$ \\
DTPD comb & $0,021(-0,006$ a 0,048$)$ & $0,013(-0,011$ a 0,037$)$ & $-0,011(-0,013$ a 0,035$)$ \\
DIST 95P residência & $-0,001(-0,031$ a 0,028$)$ & $-0,000(-0,027$ a 0,029$)$ & $-0,050(-0,003$ a 0,022$)$ \\
DIST 95P trabalho & $0.014(-0,039$ a 0,068$)$ & $-0,014(-0,064$ a 0,034$)$ & $-0,014(0,001$ a 0,010$)$ \\
DIST casa trabalho & $0,470(-1,520$ a 2,470$)$ & $0,251(-1,620$ a 2,122$)$ & $0,229(-0,1622$ a 2,080$)$ \\
\hline
\end{tabular}

Tabela 12 - Coeficiente de regressão Beta (intervalo de confiança de 95\%) para a associação entre as medidas indiretas da poluição atmosférica e a medida média da espessura da camada íntima média das carótidas da linha de base do estudo ELSA - Brasil-SP - 2008 para o grupo de sujeitos com idade menor do que 49 anos.

\begin{tabular}{lccc}
\hline Modelo & Bruto & Idade, sexo e etnia & Ajuste completo* \\
\hline DTPD trabalho & $0,002(-0,006$ a 0,011$)$ & $0,002(-0,005$ a 0,010$)$ & $-0,000(-0,008$ a 0,007$)$ \\
DTPD casa & $-0,001(-0,006$ a 0,005$)$ & $-0,001(-0,007$ a 0,003$)$ & $-0,001(-0,006$ a 0,004$)$ \\
DTPD comb & $0,001(-0,009$ a 0,011$)$ & $0.000(-0,008$ a 0,010$)$ & $-0,001(-0,010$ a 0,007$)$ \\
DIST 95P residência & $0,003(-0,005$ a 0,012$)$ & $0,000(-0,007$ a 0,008$)$ & $-0,002(-0,010$ a 0,005$)$ \\
DIST 95P trabalho & $-0,001(-0,022$ a 0,020$)$ & $-0,004(-0,025$ a 0,015$)$ & $0,002(-0,017$ a 0,021$)$ \\
DIST casa trabalho & $0,530(-0,152$ a 1,213$)$ & $0,185(-0473$ a 0,843$)$ & $0,006(-0,628$ a 0,640$)$ \\
\hline
\end{tabular}

Tabela 13 - Coeficiente de regressão Beta (intervalo de confiança de 95\%) para a associação entre as medidas indiretas da poluição atmosférica e a medida máxima da espessura da camada íntima média das carótidas da linha de base do estudo ELSA-Brasil-SP - 2008 para o grupo de sujeitos com idade menor do que 49 anos.

\begin{tabular}{lccc}
\hline Modelo & Bruto & Idade, sexo e etnia & Ajuste completo* \\
\hline DTPD trabalho & $0,004(-0,009$ a 0,016$)$ & $0,003(-0,008$ a 0,016$)$ & $-0,000(-0,008$ a 0,007$)$ \\
DTPD casa & $-0,001(-0,009$ a 0,007$)$ & $-0,002(-0,010$ a 0,005$)$ & $-0,001(-0,006$ a 0,004$)$ \\
DTPD comb & $0,002(-0,013$ a 0,017$)$ & $0.000(-0,013$ a 0,015$)$ & $-0,001(-0,010$ a 0,007$)$ \\
DIST 95P residência & $0,008(-0,005$ a 0,021$)$ & $0,000(-0,007$ a 0,008$)$ & $-0,002(-0,010$ a 0,005$)$ \\
DIST 95P trabalho & $-0,010(-0,042$ a 0,021$)$ & $-0,017(-0,047$ a 0,012$)$ & $0,002(-0,017$ a 0,021$)$ \\
DIST casa trabalho & $0,878(-0,143$ a 1,900$)$ & $0,357(-0,631$ a 1,346$)$ & $0,006(-0,628$ a 0,640$)$ \\
\hline
\end{tabular}


Tabela 14 - Coeficiente de regressão Beta (intervalo de confiança de 95\%) para a associação entre as medidas indiretas da poluição atmosférica e a medida média da espessura da camada íntima média das carótidas da linha de base do estudo ELSA - Brasil - SP - 2008 para o grupo de sujeitos com idade maior ou igual a 49 anos.

\begin{tabular}{|c|c|c|c|}
\hline Modelo & Bruto & Idade, sexo e etnia & Ajuste completo* \\
\hline DTPD trabalho & $0,001(-0,009$ a 0,011$)$ & $0,003(-0,008$ a 0,016$)$ & $-0,002(-0,014$ a 0,008$)$ \\
\hline DTPD casa & $0,003(-0,009$ a 0,002$)$ & $-0,003(-0,008$ a 0,002$)$ & $-0,002(-0,008$ a 0,002$)$ \\
\hline DTPD comb & $-0,004(-0,016$ a 0,008$)$ & $0.000(-0013$ a 0,015$)$ & $-0,000(-0,011$ a 0,010$)$ \\
\hline DIST 95P residência & $0,018(0,001$ a 0,034$)$ & $0,017(-0,001$ a 0,035$)$ & $0,014(-0,010$ a 0,030$)$ \\
\hline DIST 95P trabalho & $0.002(-0,026$ a 0,029$)$ & $-0,017(-0,047$ a 0,012$)$ & $-0,011(-0,003$ a 0,015$)$ \\
\hline DIST casa trabalho & $1,067(0,183$ a 1,951$)$ & $0,357(-0,631$ a1,346) & $0,534(-0,311$ a 1,397$)$ \\
\hline
\end{tabular}

Tabela 15 - Coeficiente de regressão Beta (intervalo de confiança de 95\%) para a associação entre as medidas indiretas da poluição atmosférica e a medida máxima da espessura da camada íntima média das carótidas da linha de base do estudo ELSA-Brasil-SP - 2008 para o grupo de sujeitos com idade maior ou igual a 49 anos.

\begin{tabular}{|c|c|c|c|}
\hline Modelo & Bruto & Idade, $\mathrm{s}$ & Ajuste c \\
\hline DTP &, $001(-$ & 1) & \\
\hline DTPD & $-0,005(-0,014$ a 0,005$)$ & $-0,004(-0,014$ a 0,004$)$ & a 0,004$)$ \\
\hline DTPD & $-0,008(-0,027$ a 0,011$)$ & $-0.001(-0020$ & $-0,003$ \\
\hline DIST 95 & $029(0,002$ a 0,055$)$ & $0,027(C$ & 0,018 \\
\hline DIST 95P trabalho & $-0,005(-0,050$ a 0,039$)$ & $-0,017(-0,047$ a 0,012$)$ & $-0,022(-0,064$ a 0,020$)$ \\
\hline DIST casa trabalho & $2,169(0,737$ a 3,602$)$ & $1,815(-0,415$ a 3,213$)$ & $0,985(-0,388$ a 2,358$)$ \\
\hline
\end{tabular}


Tabela 16 -Análise de regressão linear univariada para a variável de exposição Distância casa- trabalho (DIST casa_trab)

\begin{tabular}{|c|c|c|c|c|}
\hline Variáveis & $\begin{array}{c}\text { DIST CASA TRAB }< \\
4.9 \mathrm{Km} \text { (mediana) } \\
\text { ( } \mathrm{N}=1299)\end{array}$ & $\begin{array}{c}\text { DIST CASA TRAB >= } \\
4.9 \mathrm{~km} \text { (mediana) } \\
(\mathrm{N}=1301)\end{array}$ & Total $(\mathrm{N}=\mathbf{2 6 0 0})$ & $\mathbf{p}$ \\
\hline Sexo masculino (N (\%)) & $551(42.4 \%)$ & $612(47.0 \%)$ & $1163(44.7 \%)$ & 0.020 \\
\hline Idade(média $\pm \mathrm{DP}$ ) & $49.1 \pm 7.4$ & $49.5 \pm 7.5$ & $49.3 \pm 7.5$ & 0.106 \\
\hline Etnia branca (N (\%)) & $836(65.4 \%)$ & 754 (58.7\%) & 1590 (62.0\%) & 0.003 \\
\hline Etnia parda (N (\%)) & $243(19.0 \%)$ & $280(21.8 \%)$ & $523(20.4 \%)$ & NA \\
\hline Etnia negra $(\mathrm{N}(\%))$ & $127(9.9 \%)$ & $171(13.3 \%)$ & $298(11.6 \%)$ & NA \\
\hline Outras etnias(N (\%)) & $73(5.7 \%)$ & $80(6.2 \%)$ & $153(6.0 \%)$ & NA \\
\hline Não fumantes(N (\%)) & $719(55.4 \%)$ & 709 (54.5\%) & $1428(54.9 \%)$ & 0.716 \\
\hline Ex fumantes $(\mathrm{N}(\%))$ & $364(28.0 \%)$ & $383(29.4 \%)$ & $747(28.7 \%)$ & NA \\
\hline Fumantes (N (\%)) & $216(16.6 \%)$ & 209 (16.1\%) & $425(16.3 \%)$ & NA \\
\hline Diabetes (N (\%)) & 194 (14.9\%) & $238(18.3 \%)$ & $432(16.6 \%)$ & 0.025 \\
\hline $\begin{array}{l}\text { Uso de medicação } \\
\text { antihipertensiva(N (\%)) }\end{array}$ & $220(17.0 \%)$ & $309(23.8 \%)$ & $529(20.4 \%)$ & 0.000 \\
\hline Dislipidemia (N (\%)) & $697(53.7 \%)$ & $736(56.6 \%)$ & $1433(55.1 \%)$ & 0.152 \\
\hline $\begin{array}{l}\text { História familiar de doença } \\
\text { cardiovascular precoce(N (\%)) }\end{array}$ & $187(14.6 \%)$ & $207(16.1 \%)$ & $5.4 \%)$ & 0.322 \\
\hline Pressão sistólica(média $\pm \mathrm{DP}$ ) & $116.2 \pm 14.9$ & $119.2 \pm 16.0$ & $117.7 \pm 15.5$ & 0.000 \\
\hline Pressão diastólica( média $\pm \mathrm{DP}$ ) & $74.0 \pm 10.4$ & $75.4 \pm 11.0$ & $74.7 \pm 10.7$ & 0.001 \\
\hline IMC(média $\pm D P)$ & $26.7 \pm 4.6$ & $27.1 \pm 4.8$ & $26.9 \pm 4.7$ & 0.056 \\
\hline Colesterol total (média \pm DP) & $214.7 \pm 39.2$ & $212.9 \pm 42.1$ & $213.8 \pm 40.7$ & 0.262 \\
\hline LDL (média $\pm \mathrm{DP}$ ) & $131.7 \pm 33.8$ & $130.6 \pm 34.0$ & $131.2 \pm 33.9$ & 0.411 \\
\hline HDL (média \pm DP) & $57.4 \pm 14.2$ & $56.0 \pm 13.7$ & $56.7 \pm 13.9$ & 0.008 \\
\hline Triglicerides (média \pm DP) & $109.0[77.0-155.0]$ & $112.0[79.0-162.0]$ & $110.0[78.0-159.0]$ & 0.459 \\
\hline Glicemia de jejum(média \pm DP) & $106.7 \pm 18.2$ & $110.1 \pm 28.1$ & $108.4 \pm 23.7$ & 0.000 \\
\hline $\begin{array}{l}\text { Hemoglobina glicada } \\
\text { (média } \pm \mathrm{DP} \text { ) }\end{array}$ & $5.3 \pm 0.8$ & $5.4 \pm 0.9$ & $5.4 \pm 0.9$ & 0.006 \\
\hline EIMC (média \pm DP) & $0.581 \pm 0.119$ & $0.597 \pm 0.130$ & $0.589 \pm 0.125$ & 0.001 \\
\hline Segundo grau incompleto( & $131(10.1 \%)$ & $149(11.5 \%)$ & $280(10.8 \%)$ & 0.010 \\
\hline Segundo grau completo( ( $N(\%))$ & $446(34.3 \%)$ & $506(38.9 \%)$ & $952(36.6 \%)$ & NA \\
\hline Superior ou pós N (\%)) & $722(55.6 \%)$ & $646(49.7 \%)$ & $1368(52.6 \%)$ & NA \\
\hline
\end{tabular}


7 Discussão e ConClusão 


\section{DISCUSSÃO E CONCLUSÃO}

A analise ranálise univariada indicaram que há uma associação, embora não consistente, entre a exposição à poluição do ar relacionada ao tráfego veicular e os efeitos sobre a EIMC. Nesta análise, houve associação estatisticamente significante em relação à variável de exposição distância entre casa e trabalho (DIST_casa trabalho), mas não com as demais (distância entre casa e via principal, distância entre o local de trabalho e via principal, DTPD do local da casa, do trabalho e combinada). A DIST_casa trabalho foi a mais consistente na regressão linear mesmo com o ajuste para idade, sexo e raça, tanto na análise dos valores médios como dos máximos da EIMC. Entretanto, quando analisados os resultados com o ajuste completo para sexo, etnia, idade, nível educacional, pressão arterial sistólica, índice de massa corpórea, diagnóstico de HAS, DM, DLP, status de tabagismo e história familiar de DCV precoce (<60 anos), não houve associação em nenhum dos modelos.

Os dados mostram que houve associação para os sujeitos com idade igual ou superior a 49 anos e com o grupo com comorbidades associadas somente no modelo bruto, o que, por si só, aumentaria significativamente as chances de desenvolvimento da doença aterosclerótica. Nos grupos de menor risco e de idade inferior a 49 anos, também não houve resultados estatisticamente significativos, o que demonstra novamente que os fatores de risco tradicionais se sobrepõem ao poder da poluição atmosférica na influência sobre o desfecho, porque a aterosclerose é um processo multifatorial e, quanto maior o número de fatores de risco, maior o grau e a gravidade da doença. Aqueles fatores considerados tradicionais utilizados no modelo completo já foram amplamente estudados e estão bem descritos na literatura sobre o assunto, podendo se aventar a hipótese de que a influência da poluição do ar não teria efeito superior aos fatores de risco tradicionais na EIMC. 
Em relação à densidade de tráfego e a proximidade de vias de maior fluxo dos locais de trabalho e domicílio dos sujeitos estudos mostram a influência sobre os resultados de medidas da EIMC.

Pessoas que habitam num raio de até $100 \mathrm{~m}$ da via principal tiveram um aumento da EIMC anual na ordem de 5,5 $\mu \mathrm{m}$ (IC 95\% 0,13-10,79 $\mu \mathrm{m}$ ) em comparação com pessoas que vivem mais longe do tráfego) (Zhu et al., 2002; Perez et al., 2015). Armijos et al. (2015) examinaram a associação da exposição em longo prazo ao tráfego com EIMC em crianças. Os resultados mostraram que as que residem a menos de 100 metros da estrada de tráfego intenso tiveram um aumento médio e máximo da EIMC de $15 \%$ e $11 \%$ em comparação com os que vivem a mais de 200 metros de distância ( $p=0,0001)$. Um outro estudo realizado pela United States Enviromental Protection Agency (EPA), em 2014, por meio de medições anuais de estações de monitoramento de $\mathrm{PM}_{2,5}$ e $\mathrm{O}_{3}$, indicou que a proximidade do domicílio a vias de maior tráfego veicular, geralmente, influencia a qualidade do ar em poucas centenas metros - cerca de 100 a $200 \mathrm{~m}$ a favor do vento a partir da vizinhança de vias de maior fluxo veicular e, ainda, corredores com significativo tráfego de caminhões ou atividades ferroviárias. Outra metaanálise conduzida por Lockhart et al. (2015) demonstrou que a associação mais forte encontrada foi entre a poluição do tráfego veicular e o desenvolvimento de placas ateroscleróticas constatada por estudos sobre a exposição de animais de laboratório ao diesel por forma inalatória e os efeitos anatomopatológicos sobre as artérias de camundongos.

Uma meta-análise realizada por Liu et al. (2015), a respeito dos impactos da poluição ar $\left(\mathrm{PM}_{2,5}, \mathrm{PM}_{10}\right)$ sobre a EIMC, apresentou vários dados discordantes e a conclusão foi de que a influência da proximidade do tráfego na EIMC foi considerada incerta. Lenters et al. (2010) não encontraram associação consistente entre indicadores de tráfego (proximidade do tráfego, densidade de tráfego) e EIMC. Similarmente, os mesmos resultados foram apresentados por Gan et al. (2014). Também, os resultados obtidos no nosso estudo mostraram que, apesar de haver diferenças significativas nas medidas tanto da DPTD_casa e DTPD_trabalho 
que apresentavam médias de 668,40 e 243,30 veículos/hora/ $\mathrm{km}^{2}$ e das DIST_95P casa com 437,4 e DIST_95P trabalho com 521metros, bem acima dos valores de referência (quartil 1 -Tabela 2), não houve nenhuma associação com a variável de desfecho, fazendo-se supor que a análise de poluentes por medidas indiretas não seja sensível o suficiente para avaliar os efeitos da poluição do ar sobre a EIMC e que esta variável talvez não seja adequada para este tipo de avaliação. Além disso, deve-se levar em consideração que os efeitos causados pelos poluentes individuais é limitada, à medida que as pessoas são expostas a uma mistura de poluentes atmosféricos, sem se saber o impacto específico de cada um, além da influência de fatores ambientais como o clima, estações do ano, configuração de ruas e avenidas, projeto de estradas e a composição da vegetação circundante, tornando difícil a estimativa da poluição do ar relacionada ao tráfego, suas interações sinérgicas num determinado período e o impacto específico de cada um.

A evidência revisada destacou algumas limitações metodológicas. Vários estudos usaram modelos de regressão de uso do solo ou outras técnicas de modelagem para considerar o impacto na saúde ou conjuntos de dados disponíveis ou meta-análises concluídas. Apenas poucas metodologias que utilizam níveis de poluição atmosféricos medidos e estudos de caso-controle fornecem uma evidência mais forte. Embora muitas pesquisas tenham sido concluídas em relação ao impacto da poluição do ar relacionada com o tráfego, ainda existem lacunas no conhecimento como a falta de estudos abrangentes que examinem como as características do ambiente afetam a poluição do ar. A pesquisa deve considerar todos estes fatores e como eles interagem para formar níveis de exposição pessoal. Cada pessoa em uma área tem o mesmo nível de exposição usando dados de uma estação de monitoramento da qualidade do ar, porém, não se levam em consideração determinadas características do ambiente nem as particularidades e suscetibilidades dos indivíduos quando se avaliam os malefícios da poluição do ar relacionados com o tráfego. Em vista do número limitado de estudos existentes sobre a associação entre o 
material particulado e a EIMC, os autores concluíram que estudos análogos deveriam ser conduzidos no futuro para verificar com mais exatidão os resultados. Além disso, pesquisas futuras também poderiam se concentrar em distinguir potenciais fatores de confusão que afetam o efeito de $\mathrm{PM}_{2,5} \mathrm{e}$ $\mathrm{PM}_{10}$ na EIMC, como ruído, mulheres pós-menopáusicas, diabéticos ou exercício físico (Liu et al,2015).

O nosso estudo também apresentou algumas limitações. A utilização de corte transversal para as análises de linha de base é limitante em relação à inferência da causalidade para os achados descritos, uma vez que é sabido que a doença aterosclerótica se desenvolve e progride de forma insidiosa, sendo influenciada por uma série de variáveis no decorrer da vida. Há também como limitação a ausência de uma análise sobre os efeitos dos poluentes primários e secundários isoladamente sobre a EIMC.

O ozônio troposférico, que é um poluente secundário, é formado na atmosfera a partir de gases emitidos pelos veículos (principalmente óxido nitroso e compostos orgânicos voláteis) em conjunto com a luz solar. Quando esses carros estão muito próximos das vias, o ozônio é destruído rapidamente devido a reações com outros poluentes e à movimentação dos automóveis. Quanto mais longe das vias, maior a concentração de ozônio, o que ocorre nas regiões bem arborizadas. O ozônio representa o principal poluente atmosférico para a Região Metropolitana de São Paulo (RMSP), sendo frequentes os dias em que sua concentração excede os padrões. Por se tratar de um poluente secundário, torna-se muito difícil a elaboração de estratégias eficazes para a redução deste poluente (Guerrero, 2016). Estudos em modelos animais identificaram um mecanismo biológico para efeitos de $\mathrm{O}_{3}$ na saúde cardiovascular. A exposição crônica a este poluente resultou num incremento de $179 \%$ na espessura da camada íntima média das arteríolas peribronquiolares em um modelo de estudo utilizando-se macacos (Breton et al., 2012). A exposição infantil a $\mathrm{O}_{3}$ foi associada ao aumento da EIMC em adultos jovens (Breton et al., 2012).

Apesar de não possuir um trânsito pesado no seu interior, o campus da USP no Butantã sofre com o trânsito de seu entorno, especialmente com a 
Marginal Pinheiros e as rodovias que chegam a São Paulo pela Zona Oeste da cidade, como a Raposo Tavares, a Castelo Branco, a Anhanguera e a Bandeirantes. Essa deve ser a principal razão da área ser apontada como a mais poluída entre as 21 estações da Cetesb que monitoram o ar da cidade. A reação química provocada pelos gases emitidos pelos caminhões e automóveis e a luz solar é a responsável pela produção do $\mathrm{O}_{3}$, que teve concentração acima do padrão seguro na Cidade Universitária em 2015 (USP, 2015). Este fator seria, então, outro limitante na análise dos resultados desta tese, uma vez que, aproximadamente, $80 \%$ dos sujeitos deste estudo trabalham na Cidade Universitária e estariam mais expostos a poluentes secundários, principalmente $\circ \mathrm{O}_{3}$, enquanto os demais que trabalham no quadrilátero da USP estariam mais suscetíveis aos poluentes primários, principalmente ao material particulado.

Positivamente, o estudo ELSA-Brasil, cujo grupo amostral deste projeto foi extraído, tem uma das maiores amostras dentre os estudos epidemiológicos observacionais que estudaram a EIMC. Além disso, o ELSA-Brasil aborda uma amostra fora dos EUA e Europa, o que permite avaliar associações em uma população diferente da maioria dos estudos publicados. A medida de EIMC no estudo ELSA-Brasil foi realizada utilizando um protocolo sistemático, auxiliado por Software específico, com rigoroso controle de qualidade das imagens e leitura centralizada. Isto potencializa a confiabilidade e a reprodutibilidade da técnica eliminando vieses de aferição, uma vez que há heterogeneidade entre os estudos quanto à forma de mensuração da EIMC, em especial, se feita manualmente. Tanto a metodologia como o modelo estatístico adotados para este estudo, e ainda os resultados obtidos, são totalmente compatíveis com os demais estudos e meta-análises realizadas no estudo da influência da poluição do ar com a EIMC e, ainda, como fator relevante, tivemos o uso da variável de exposição distancia casa-trabalho que nunca houvera sido analisada em estudos sobre poluição do ar e doença aterosclerótica, e que mostrou uma correlação estatística linear com o desfecho, embora não se mantivesse no ajuste completo. Há de se considerar, entretanto, que as 
pessoas que passam o maior tempo no no trajeto da residência ao local de trabalho estão sujeitas a outras variáveis como o ruído e estresse. Além disso, sabe-se que os moradores mais próximos à periferia dos grandes centros, geralmente tem menor renda familiar e de escolaridade como verificado também nos dados desse projeto. O estrato socioeconômico de menor renda apresenta maior agravo à saúde cardiovascular e, portanto, a associação da variável de exposição DIST_casa trabalho com EIMC poderia ser também influenciada por outras variáveis que não somente os poluentes do ar.

Em relação à plausibilidade biológica deste estudo, sabe-se que a aterosclerose é um processo dinâmico e evolutivo a partir do dano endotelial, que tem origem multifatorial e é considerada uma doença inflamatória da parede vascular acometendo, principalmente, a camada íntima de artérias de médio e grande calibres (Santos et al., 2001). A formação da placa aterosclerótica se inicia com a agressão ao endotélio vascular devido a diversos fatores de risco, como dislipidemia, diabetes, hipertensão arterial ou tabagismo. Há dois mecanismos descritos sobre os efeitos da poluição do ar, em especial do material particulado, que contribuem para o desenvolvimento da doença aterosclerótica. O primeiro é um processo de estresse oxidativo pulmonar que ocorre após o contato de agentes poluentes externos inalados como material particulado, fibras minerais, metais e policarbonetos com a superfície dos alvéolos desencadeando a liberação de mediadores pró-inflamatórios diretamente pelas células pulmonares (Brook et al., 2010). Há outro possível mecanismo alternativo que consiste na translocação direta do material particulado ultrafino $\left(\mathrm{PM}_{0.1}\right)$ ou constituintes como metais e compostos orgânicos para a circulação por meio da interface alvéolo-capilar, desencadeando, assim, um processo de vasoconstrição sistêmica com elevação da pressão arterial, uma maior adesividade plaquetária e um aumento no processo inflamatório com consequente disfunção endotelial e potencial para desencadeamento de eventos como síndrome coronariana, insuficiência cardíaca, arritmias cardíacas, acidente vascular encefálico e doença arterial obstrutiva 
periférica. Muitas experiências em animais também apoiaram o ponto de vista de que a exposição a $\mathrm{PM}_{2,5}$ pode contribuir para o processo de aterosclerose por mecanismos potenciais, incluindo estimulação da medula óssea, liberação de monócitos e alteração do tônus vasomotor (Fuji et al.; Suwa et al., 2002; Sun et al., 2005). Num estudo em que ratos foram submetidos à exposição à $\mathrm{PM}_{2.5}$, observou-se um efeito sobre o tônus vascular, dos níveis de inflamação vascular e aumento da aterosclerose aórtica (Sun et al., 2005). Além disso, experimentos com animais possibilitaram o estudo de outros mecanismos biológicos, que conectam a exposição a partículas do ar ao progresso da aterosclerose a longo prazo, e que a exposição a determinados poluentes poderia influenciar nos níveis de pressão arterial, na função autonômica e na oxidação de lipoproteínas de baixa densidade (Sharman, 2002; Brook, 2004).

Vários estudos têm apontado uma relação entre a função endotelial e a exposição ao material particulado. Briet et al. (2007) e Santoro et al. (2012) demonstraram que a disfunção endotelial pode ocorrer sem alterações estruturais ateroscleróticas em mulheres jovens com endometriose, o que sublinhou a importância de investigar este parâmetro, especialmente em pessoas jovens e saudáveis, para confirmar a precocidade da disfunção endotelial por meio da mensuração da EIMC. Hoffmann et al. (2007) mostraram que a exposição a partículas finas estava associada à calcificação das artérias coronárias (CAC), e relacionada de forma relevante com a EIMC. Wilker et al. (2013) relataram que a concentração média anual de carbono negro foi associada ao aumento da EIMC na população de idosos. Todos estes dados apoiaram a associação entre exposição à poluição atmosférica a longo prazo e aterosclerose.

Os resultados deste projeto como o das meta-análises e das revisões sistemáticas apresentadas mostram a incerteza dos efeitos da poluição atmosférica sobre as medidas da EIMC e poderão auxiliar na concepção de novos trabalhos que devam se concentrar na maior proximidade entre os efeitos do tráfego veicular e a doença aterosclerótica. Segundo estes estudos apresentados, se a relação entre poluentes do ar e doenças 
cardiovasculares é linear, seria de grande importância avaliar se este indicador (EIMC) seria o ideal para refletir os efeitos adversos relacionados à poluição do ar e se mais estudos longitudinais deveriam ser realizados com o intuito de se avaliar a temporalidade e as variáveis que influem na relação ente poluição do ar e doença aterosclerótica. Estas mesmas análises deveriam contemplar várias espécies de poluentes como variáveis de exposição a fim de se identificar e analisar as interações latentes entre os mais prevalentes. 
8 REFERÊNCIAS 


\section{REFERÊNCIAS}

Aaslid R, Markwalder TM, Nornes H. Noninvasive transcranial Doppler ultrasound recording of flow velocity in basal cerebral arteries. J Neurosurg. 1982;57:769-74.

Abreu SM, Ottoni JE. Geometria esférica e trigonometria esférica aplicadas a astronomia de posição [Mestrado Profissional em Matemática em Rede Nacional - PROFMAT]. Alto Paraopeba: Universidade Federal de São João Del-Rei. CAP Sociedade Brasileira de Matemática - SBM; 2015.

Anderson L, Atkinson RW, Peacock JL, Sweeting MJ, Marston L. Ambient particulate matter and health effects: publication bias in studies of short-term associations. Epidemiology. 2005;16(2):155-63.

Armijos RX, Weigel MM, Myers OB, Li WW, Racines M, Berwick M. Residential exposure to urban traffic is associated with increased carotid intima-media thickness in children. J Environ Public Health. 2015; 2015:1-11.

Azevedo C, Rochitte CE, Lima JAC. Escore de cálcio e angiotomografia coronariana na estratificação do risco cardiovascular. Arq Bras Cardiologia. 2012 June;98(6):559-68.

Bateson TF, Scwartz J. Who is sensitive to the effectsof particulate air pollution on mortality? A case-crossoveranalysis of effect modifiers. Epidemiology. 2004;15:143-9.

Bauer M, Moebus S, Möhlenkamp S, Dragano N, Nonnemacher $M$, Fuchsluger $\mathrm{M}$, et al. Urban particulate matter air pollution is associated with subclinical atherosclerosis results from the HNR (Heinz Nixdorf Recall) Study. J Am Coll Cardiol. 2010 Nov 23;56(22):1803-8.

Beelen R, Stafoggia M, Raaschou-Nielsen OO, Andersen ZJ, Xun WW, Katsouyanni $\mathrm{K}$, et al. Long-term exposure to air pollution and cardiovascular mortality: an analysis of 22 European cohorts. Epidemiology. 2014 May;25(3):368-78.

Bell ML, Kim JY, Dominici F. Potential confounding of particulate matter on the short-term association between ozone and mortality in multisite timeseries studies. Environ Health Perspect. 2007;115:1591-5.

Bell ML, McDermott A, Zeger SL, Sarnet JM, Dominici F. Ozone and shortterm mortality in 95 US urban communities, 1987-2000. JAMA. 2004;292:2372-8. 
Bellander T, Berglind N, Gustavsson P, Jonson T, Nyberg F, Pershagen G, et al. Using geographic information systems to assess individual historical exposure to air pollution from traffic and house heating in Stockholm. Environ Health Perspect. 2001;109(6):633-9.

BENSENOR, Isabela M. et al. Prevalência de acidente vascular cerebral e de incapacidade associada no Brasil:Pesquisa Nacional de Saúde 2013. Arquivos de Neuro-Psiquiatria, São Paulo, v. 73, n. 9, p. 746-750, set. 2015.

Bhola R, Gurjar L, Molina TL, Ojha P. Air pollution: health and environmental impacts. Florida: CRC Press, 2012. 556p.

Bots ML, Hoes AW, Koudstaal PJ, Hofman A, Grobbee DE. Common carotid intima-media thickness and risk of stroke and myocardial infarction: the Rotterdam Study. Circulation. 1997;96:1432-7.

Bots $\mathrm{ML}$, Grobbee DE. Intima media thickness as a surrogate marker for generalised atherosclerosis. Cardiovasc Drugs Ther. 2002;16(4):341-51.

Brasil. Ministério da Saúde. Secretaria de Atenção à Saúde. Departamento de Ações Programáticas Estratégicas. Diretrizes de atenção à reabilitação da pessoa com acidente vascular cerebral / Ministério da Saúde, Secretaria de Atenção à Saúde, Departamento de Ações Programáticas Estratégicas. Brasília : Ministério da Saúde, 2013. 72p.

Breton CV, Wang X, Mack WJ, Berhane K, Lopez M, Islam TS, et al. Childhood air pollutant exposure and carotid artery intima-media thickness in young adults. Circulation. 2012 Sep 25;126(13):1614-20.

Briet M, Collin C, Laurent S, Tan A, Azizi M, Agharazii M, et al. Endothelial function and chronic exposure to air pollution in normal male subjects. Hypertension. 2007;50(5):970-6.

Briggs D, Collins S, Elliot P, Fischer P, Kingham S, Lebret E, et al. Mapping urban air pollution GIS: a regression - based approach. In J Geogr Inf Sci. 1997;11(7):699-718.

Brook RD, Franklin B, Cascio W, Hong Y, Howard G, Lipsett M, et al. Air pollution and cardiovascular disease: a statement for healthcare professionals from the expert panel on population and prevention science of the American Heart Association. Circulation. 2004;109(21):2655-71.

Brook RD, Rajagopalan S, Pope CA 3rd, Brook JR, Bhatnagar A, Diez-Roux $A V$, et al. Particulate matter air pollution and cardiovascular disease: An update to the scientific statement from the American Heart Association. Circulation. 2010 June 1;121(21):2331-78.

Brook RD. Cardiovascular effects of air pollution. Clin Sci. 2008;115(6):17587. 
Brook RD. Why physicians who treat hypertension should know more about air pollution. J Clin Hypertens. 2007;9:629-35.

Brucki S, Massaro AR. Doppler transcraniano no acidente vascular cerebral isquêmico. Rev Neurociências. 2001;9(2):49-56.

Budoff MJ, Gul KM. Expert review on coronary calcium. J Vasc Health Risk Manag. 2008;4(2):315-24.Cançado JE, Braga A, Pereira LA, Arbex MA, Saldiva PH, Santos UP. Clinical repercussions of exposure to atmospheric pollution. J Bras Pneumol. 2006;32(Suppl. 2):S5-11.

Carlucci EMS, Gouveia JAG, Oliveira AP, Silva JP, Cassiano ACM, Bennemann RC. Obesidade e sedentarismo: fatores de risco para doença cardiovascular. Com Ciências Saúde. 2013;24(4):375-84.

Cendon S, Pereira LA, Braga AL, Conceição GM, Cury Junior A, Romaldini $\mathrm{H}$, et al. Myocardial infarction. Rev Saúde Publica. 2006;40(3):414-9.

CET - Companhia de Engenharia de Tráfego. Plano de mobilidade urbana 2014 [Citado 02 dez 2016]. Disponível em http://www.prefeitura.sp.gov.br/cidade/secretarias/upload/chamadas/planmob -texto-base_1424729529.pdf, 2014.

CETESB - Companhia Ambiental do Estado de São Paulo. Relatório de qualidade do ar do Estado de São Paulo. 2010.

Cintra M. Os custos dos congestionamentos na cidade de São Paulo. São Paulo: Escola de Economia de São Paulo da Fundação Getulio Vargas Workind Paper; 2014. 38p.

COMEAP - Comittee on the Medical Effects of Air Pollution. The mortality effects of long-term exposure to particulate air pollution in the United Kingdom. A report by the Committee on the Medical Effects of Air Pollution (COMEAP), 2006.

Danni-Oliveira IM. Poluição do ar como causa de morbidade e mortalidade na população urbana. RA'EGA - O Espaço Geográfico em Análise. 2008;15:113-26.

DATASUS. Morbidade hospitalar do SUS - por local de residência Brasil. [Citado 20 jan. 2015]. Disponível em: http://tabnet. datasus.gov.br/cgi/deftohtm.exe?sih/cnv/nruf.def, 2012.

Den Ruijter HM, Peters SA, Anderson TJ, Briton AR, Dekker JM, Eijker MJ, et al. Common carotid intima-media thickness measurements in cardiovascular risk prediction: a meta-analysis. JAMA. 2012;308(8):796-803.

DETRANhttps://www.detran.sp.gov.br/wps/wcm/connect/portaldetran/detran/ detran/estatisticastransito/sa-frotaveiculos/acessado em 01/11/2017 
Dominici F, Peng RD, Bell ML, Pham L, McDermott A, Zeger SL, et al. Fine particulate air pollution and hospital admission for cardiovascular and respiratory diseases. JAMA. 2006;295:1127-34.

Dubowsky SD, Suh H, Schwartz J, Coull BA, Gold DR. Diabetes, obesity, and hypertension may enhance associations between air pollution and markers of systemic inflammation. Environ Health Perspect. 2006;114:9928.ELSA-Brasil. ELSA-Brasil - estrutura e objetivos [Citado 02 dez 2016]. Disponível em http://www.elsa.org.br/objetivos.html, 2016.

ESCAPE Project - European Study of Cohorts for Air Pollution Effects [cited 2015 July 11]. Available from: http://www.escapeproject.eu/index.php, 2014.

Ferrara LD. A mobilidade como contradição do espaço urbano. PPGCOM. Rev Matrizes. 2010 jul/dez;4(1):165-77.

Forastieri A. Assessing the link between air pollution and heart failure. Lancet. 2013 Sep 21;382(9897):1008-10.

Franklin M, Zeka A. Association between PM2.5 and all-cause and specificcause mortality in 27 US communities. J Exp Sci Environ Epidemiol. $2007 ; 17: 279-87$.

Freire CMV, Alcantara ML, Santos SN, Amaral SI, Veloso O, Porto CLL, et al. Recomendação para a quantificação pelo ultrassom da doença aterosclerótica. Arq Bras Cardiol. 2015; 28(nº especial):e1-e64.

Freitag B. Teorias da cidade. Capítulo 6. A "megalopolização" das cidades latino-americanas na virada do milênio. $4^{a}$ ed. Campinas: Paipurus; 2012. p. 123-77.

Freitas C, Bremmer S, Gouveia N, Pereira L, Saldiva P. Internações e óbitos e sua relação com a poluição atmosférica em São Paulo, 1993 a 1997. Rev. Saúde Pública. 2004;38(6):751-7.

Fujii T, Hayashi S, Hogg JC, Mukae H, Suwa T, Goto Y, et al. Interaction of alveolar macrophages and airway epithelial cells following exposure to particulate matter produces mediators that stimulate the bone marrow. $A m \mathrm{~J}$ Respir Cell Mol Biol. 2002;27(1):34-41.

Gan WQ, Allen RW, Brauer M, Davies HW, Mancini GB, Lear SA. Long-term exposure to traffic-related air pollution and progression of carotid artery atherosclerosis: a prospective cohort study. BMJ Open. 2014;4:e004743

GBD - Global Burden of Disease Study. Global, 2010. Results by risk factor 1990-2010, 2010.

GBD - Global Burden of Disease Study. Global, regional, and national comparative risk assessment of 79 behavioural, environmental and 
occupational, and metabolic risks or clusters of risks in 188 countries, 19902013: a systematic analysis for the Global Burden of Disease Study; 2013.

Gouveia N, Freitas CU, Martins LC, Marcilio IO. [Respiratory and cardiovascular hospitalizations associated with air pollution in the city of São Paulo, Brazil]. Cad Saúde Pública. 2006;22(12):2669-77.

Gouveia N, Mendonça GAS, Leon AP, de Correia JEM, Junger WL, Freitas CU de. Poluição do ar e efeitos na saúde nas populações de duas grandes metrópoles brasileiras. Epidemiol Serv Saúde. 2003;12(1):29-40.

Greenland J, Abrams J, Aurigemma GP, Bond MG, Clark LT, Criqui MH, et al. Prevention Conference V: Beyond secondary prevention: identifying the high-risk patient for primary prevention: noninvasive tests of atherosclerotic burden: Writing Group III. Circulation. 2000;101(1):E16-E22.

Guerrero VVU. Condições atmosféricas associadas à dispersão de poluentes nas cidades de São Paulo e Santiago [Tese]. São Paulo: Instituto de Astronomia, Geofísica e Ciências Atmosféricas - Universidade de São Paulo; 2016.

Habermann M, Gouveia N. Socioeconomic position and low birth weight among mothers exposed to traffic-related air pollution. PLOS One. 2014;9(11):e113900.

Habermann M, Medeiros APP, Gouveia N. Tráfego veicular como método de avaliação da exposição à poluição atmosférica nas grandes metrópoles. Rev Bras Epidemiol. 2011;14(1):120-30.

Hansson GK. Inflammation, atherosclerosis, and coronary artery disease. $N$ Engl J Med. 2005;352(16):1685-95.

HEI - Health Effects Institute. Outdoor air pollution among top global health risks 2010. Risks especially high in developing countries of Asia. The Lancet at the Royal Society in London, 2012.

Hoffmann B, Moebus F, Dragano N, Stang A. Chronic residential exposure to particulate matter air pollution and systemic inflammatory markers. Environ Health Perspect. 2009;117(8):1302-8.

Hong YC, Lee JT, Kim H, Kwon HJ. Air pollution: a new risk factor in ischemic stroke mortality. Stroke. 2002;33(9):2165-9.

Ibald-Mulli A, Stieber J, Wichmann HE, Kolnig W, Peters A. Effects of air pollution on blood pressure: a population-based approach. Am J Public Health. 2001;91:571-7.

IBGE - Instituto Brasileiro de Geografia e Estatística. População estimada 2014. [Citado 13 jan. 2015]. Disponível em: http://www.cidades.ibge/. 
IBGE- Informações metodológicas sobre o cálculo das estimativas 2016 podem ser obtidas no relatório: http://biblioteca.ibge.gov.br/index.php/ biblioteca-catalogo?view=detalhes\&id=297868 (atualizado em 12/09/2016)

Infocidade - Prefeitura de São Paulo [Citado 18 mar. 2011]. Disponível em: http://infocidade.prefeitura.sp.gov.br/htmls/12_veiculos_cadastrados_no_detr an_1980_681.html. 2011.

IPEA - Instituto de Pesquisas Econômicas e Aplicada. Comunicado $n^{\circ} 113$ poluição atmosférica [Citado 09 jan. 2015]. Disponível em: www.IPEA.gov.brlportallimages/stories|PDFIcomunicadol113poluição veicular atmosférica, 2011.

IPEA - Instituto de Pesquisas Econômicas e Aplicada. Dinâmica populacional e sistema de mobilidade nas metrópoles. Comunicados do IPEA [Citado 13 jan. 2015]. Disponível em: www.IPEA.gov.br comunicado 120106, 2011b.

IPEA - Instituto de Pesquisas Econômicas e Aplicada. Indicadores de mobilidade urbana da PNAD 2012. Comunicados do IPEA [Citado 09 jan. 2015]. Disponível em: www.IPEA.gov.brlportallimages/stories\PDFI comunicadol131024, 2013.

Jerrett M, Arain A, Kanaroglou P, Beckerman B, Potoglou D, Sahsuvaroglu $\mathrm{T}$, et al. A review and evaluation of intraurban air pollution exposure models. J Expo Anal Environ Epidemiol. 2005;15(2):185-204.

Jerrett M, Sears M, Giovis C, Burnett R, Kanaroglou P, Elliott S, et al. Intraurban air pollution exposure and asthma prevalence in hamilton, canada. presented at the international society of exposure analysis. Charleston, SC, USA, 2001.

Katsouyani K. Ambient air pollution and health. Br Med Bull. 2003;68:143-56.

Kaufman JD, Adar SD, Barr RG, Budoff M, Burke GL, Curl CL, et al, Association between air pollution and coronary artery calcification within six metropolitan areas in the USA (the Multi-Ethnic Study of Atherosclerosis and Air Pollution): a longitudinal cohort study. Lancet. 2016;388(10045):696-704.

Kim JK, Huen K, Adams S, Smorodinski S, Hoats A, Malig B, et al. Residential traffic and children's respiratory health. Envir Health Perspectives. 2008;116(09):1274-9.

Künzli N, Jerrett M, Garcia-Esteban R, Basagaña X, Beckerman B, Gilliland $\mathrm{F}$, et al. Ambient air pollution and the progression of atherosclerosis in adults. PLoS One. 2010;5(2):e9096.

Künzli N, Jerrett M, Mack WJ, Beckerman B, LaBree L, Gilliland F, et al. Ambient air pollution and atherosclerosis in Los Angeles. Environ Health Perspect. 2005 Feb.;113(2):201-6. 
Le Tertre A, Medina S, Samoli E, Forsberg B, Michelozzi P, et al. Short-term effects of particulate air pollution on cardiovascular diseases in eight European cities. J Epidemiol Community Health. 2002;56(10):773-9.

Lebret E, Briggs D, Van Reeuwijk H, Fischer P, Smallbone K, Harssema H, et al. Small area variations in ambient $\mathrm{NO}_{2}$ concentrations in four European areas. Atmosph Environ. 2000;34(2):177-85.

Lenters V, Uiterwaal CS, Beelen R, Bots ML, Fischer P, Brunekreef B, et al. Long-term exposure to air pollution and vascular damage in young adults. Epidemiology. 2010;21:512-20.

Libby P, Theroux P. Pathophysiology of coronary artery disease. Circulation. 2005;111(25):3481-8.

Lima PV, Duarte SFP. Prevalência de obesidade em idosos e sua relação com hipertensão e diabetes. InterScientia. 2013;1(3):80-92,

Lin CA, Amador Pereira LA, Kishi HS, Milani R Jr, Ferreira Braga AL, Saldiva $\mathrm{PHN}$. Between air pollution and ischemic cardiovascular emergency room visits. Environ Res. 2003;92(1):57-63.

Liu X, Lian H, Ruan I, Liang R, Rhoultlege R. Association of exposure to particular matter and carotid intima-media thickness: a systematic review and meta-analysis. Int J Environ Res Public Health. 2015 Oct;12(10):12924-40.

Lockhart D, Vaganay M, Maclntire, Joseph P. A meta analysis of the impact of traffic-related air pollution on health and factors affecting exposure. WIT Transact Ecol Environ. 2015;198(12):193-204.

Lombardi SEM, Prado FG, Terra M, Santos UP. Poluição do ar e efeitos cardiorrespiratórios: a importância na prática clínica. Rev Poluição Ind. 2010;210-25.

Lorenz MW, Von Kegler S, Steimetz H, Markus HS, Sitzer M. Carotid intimamedia thickening indicates a higher vascular risk across a wide age range: prospective data from the Carotid Atherosclerosis Progression Study (CAPS). Stroke. 2006;37:87-92.

Lotufo PA. O escore de risco de Framingham para doenças cardiovasculares. Rev Med São Paulo. 2008 out-dez;87(4):232-7.

Lozano R, Naghavi M, Foreman K, Lim S, Shibuya K, Aboyans V, et al. Global and regional mortality from 235 causes of death for 20 age groups in 1990 and 2010: a systematic analysis for the Global Burden of Disease Study 2010. Lancet. 2012;380(9859):2095-12

Malta DC, Bernal RTI, Souza MFM, Szwarcwald CL, Lima MG, Barros MBA. Social inequalities in the prevalence of self-reported chronic non- 
communicable diseases in Brazil: national health survey 2013. Int J Equity Health. 2016;15(1):153.

Mansur A, Favarato D. Mortalidade por Doenças Cardiovasculares no Brasil e na Região Metropolitana de São Paulo: Atualização 2011. Arq Bras Cardiol. 2012;99(2):755-61.

Marino BCA, Marcolino MS, Reis Júnior RS, França ALN, Passos PFO, Lemos TR, et al. Perfil epidemiológico e indicadores de qualidade em pacientes com síndrome coronariana aguda na Região Norte de Minas Gerais. Arq Bras Cardiol. 2016;107(2):106-15.

Medeiros APP, Gouveia N, Machado RPP, Souza MR, Alencar GP, Novaes HMD, et al. Traffic-related air pollution and perinatal mortality: A case-control study. Environ Health Perspect. 2009;117(1):127-32.

Medina-Ramón M, Golberg R, Mittlemann MA, Schwartz J. Residential Exposure to traffic-related air pollution and survival after heart failure. Environ Health Perspect. 2008;116(4);481-5.

Meng Y, Wilhelm M, Rull RP, English P, Ritz B. Traffic and outdoor air pollution levels near residences and poorly controlled asthma in adults. Ann Allergy Asthma Immunol. 2007;98:445-63.

Metzger KB, Tolbert PE, Klein M, Flanders WD, Peel JL, Mulholland JA, et al. Ambient air pollution and cardiac arrhythmias in patient with implantable defibrillators. Epidemiology. 2007;18:585-92.

Meuwese MC, Stroes ES, Hazen SL, van Miert JN, Kuivenhoven JA, Schaub $\mathrm{RG}$, et al. Serum myeloperoxidase levels are associated with the future risk of coronary artery disease in apparently healthy individuals: the EPIC-Norfolk Prospective Population Study. J Am Coll Cardiol. 2007 Jul. 10;50(2):159-65.

Mills NL, Donaldson K, Hadoke PW, Boon NA, MacNee W, Cassee FR, et al. Adverse cardiovascular effects of air pollution. Nat Clin Pract Cardiovasc Med. 2009 Jan;6(1):36-44.

Miraglia SG, Saldiva PH, Böhm GM. An evaluation of air pollution health impacts and costs in São Paulo, Brazil. Environ Manage. 2008 May; 35(5):667-76.

Monteiro MC, Fonseca F, Francisco AH. Aterosclerose e inflamação. Rev. Soc Cardiol Estado de São Paulo. 2006 jul-set;16(3):187-92.

Morris R, Koo B, Wang B. Technical support document for vistas emissions and air quality modeling to support regional haze state implementation plans. Novato, CA: 2011. 
Myeburg RJ, Castellanos A. Cardiac arrest and sudden death. In: Braunwald E. (editor). Textbook of cardiovascular medicine. 6thed. Philadelphia: W.B. Saunders; 2001. p. 890-923.

Nambi V, Chambless L, Folsom AR, He M, Hu Y, Mosley T, Volcik K, et al. Carotid intima-media thickness and presence or absence of plaque improves prediction of coronary heart disease risk: the ARIC (Atherosclerosis Risk In Communities) study. J Am Coll Cardiol. 2010 Apr. 13;55(15):1600-7.

Nardocci AC, Freitas CU, De Leon ACMP, Junger WL, Gouveia NC. Poluição do ar e doenças respiratórias e cardiovasculares: estudo de séries temporais em Cubatão, São Paulo, Brasil. Cad Saúde Pública. 2013 set;29(9):1867-76.

Nemmar A, Hoet PH, Vanquinkeborne B, Dinsdale D, Thommer MM, Hoylaerts MF, et al. Passage of inhaled particles into the blood circulation in humans. Circulation. 2002;105(4):411-7.

Nemmar A, Hoylaerts MF, Nemery B. Effects of particulate air pollution on hemostasis. Clin Occup Environ Med. 2006;5(4):865-8.

Newby D, Pier MM, Grethe ST, Andrea A, Bacarelli A, Donaldson K ,et al. Expert position paper on air pollution and cardiovascular disease. Eur Heart J. 2015 Jan 7;36(2):83-93b.

O'Leary DH, Polak JF, Wolfson Jr SK, Bond MG, Bommer W, Sheth S, et al. Use of sonography to evaluate carotid atherosclerosis in the elderly. The Cardiovascular Health Study. Stroke. 1999;22:1155-63.

Oren A, Vos LE, Uiterwaal CS, Grobbee DE, Bots ML.Aortic stiffness and carotid intima - media thickness: two independent markers of subclinical vascular damage in young adults? Eur J Clin Invest. 2003 nov. 33;(11):94954.

Otte T. Using MM5v3 with ETA analyses for air quality modelling at the EPA. Proceedings of the 11th PSU/NCAR MM5 user's workshop (2001). National Center for Atmospheric Research, Boulder, Colorado.

Oudkerk M, Stilman AE, Halliburton SS, Kalender WA, Möhlenkamp S, McCollough $\mathrm{CH}$, et al. Coronary artery calcium screening: current status and recommendations from the European Society of Cardiac Radiology and North American Society for Cardiovascular Imaging. Int $\mathrm{J}$ Cardiovasc Imaging. 2008;24(6):645-71.

Paes J, Silva J, Galvarro S. Considerações sobre a poluição do ar em grandes metrópoles. Rev Ponto de Vista. 2006;5:21-4.

Painschab MS, Davila-Roman VG, Gilman RH, Vasquez-Villar AD, Pollard SL, Wise RA, et al. CRONICAS Cohort Study Group. Chronic exposure to biomass fuel is associated with increased carotid artery intima-media 
thickness and a higher prevalence of atherosclerotic plaque. Heart. 2013;99:984-91.

Pasceri V, Chang J, Willerson JT, Yeh ETH. Modulation of C-reative proteinmediated monocyte chemoattactan protein 1 induction in human endothelial cells by anti-atheroslcerosis drugs. Circulation. 2003;103(21):2531-4.

Pearson RL, Watchel H, Ebi KL. Distance-weighted traffic density in proximity to a home is a risk factor for leukemia and other childhood cancers. Air Waste Manag Assoc. 2000;50(2):175-80.

Peel JL, Metzger KB, Klein M, Flanders WD, Mulhollanda JA, Tolbert PE. Ambient air pollution and cardiovascular emergency department visits in potentially sensitive groups. Am J Epidemiol. 2007;165:625-33.

Pereira Filho MA, Pereira LA, Arbex FF, Conceição GM, Santos UP, Lopes $A C$, et al. Effect of air pollution on diabetes and cardiovascular diseases in São Paulo, Brazil. Braz J Med Biol Res. 2008 Jun;41(6):526-32.

Perez L, Wolf K, Hennig F, Penell J, Basagana X, Foraster M, et al. Air pollution and atherosclerosis: A cross-sectional analysis of four european cohort studies in the ESCAPE study. Environ Health Perspect. 2015;123:795-605.

Picon PX, Leitão CB, Gerchman F, Azevedo MJ, Silveiro SP, Gross JL, et al. Medida da cintura e razão cintura/quadril e identificação de situações de risco cardiovascular: estudo multicêntrico em pacientes com diabetes melito tipo 2. Arq Bras Endocrinol Metab. 2007 Apr;51(3):443-9.

Pitanga FJG, Lessa I. Indicadores antropométricos de obesidade como instrumento de triagem para risco coronariano elevado em adultos na cidade de Salvador- Bahia. Arq Bras Cardiol. 2005;85(1):26-31..

Pope CA, Burnett RT, Thurston GD, Thun MJ, Calle EE, Krewski D, et al. Cardiovascular mortality and long-term exposure to particulate air pollution: epidemiological evidence of general path physiological pathways of disease. Circulation. 2004;109:71-7.

Pope CA, Dockery DW. Health effects of fine particulate air pollution lines that connect. J Air Waste Manag Assoc. 2006;56:709-42.

Pope CA, Hansen ML, Long RW, Nielsen KR, Eatough NL, Wilson WE, et al. Ambient particulate air pollution, heart rate variability, and blood markers of inflammation in a panel of elderly subjects. Environ Health Perspect. 2004b;112:339-45.

Pope CA. Mortality effects of longer term exposures tofine particulate air pollution: review of recent epidemiological evidence. Inhal Toxicol. 2007;19(suppl)1:33-8. 
Portal Brasil. Metade dos brasileiros está com excesso de peso. Disponível em: http://www.brasil.gov.br/saude/2015/04/metade-dos-brasileiros-estacom-excesso-de-peso, 2015.

Programa Cidades Sustentáveis. Indicadores. Índice de congestionamentos. 2013. [citado Jan 2015]. Disponível em: http://indicadores.cidadessustentaveis.org.brlSP-sãopaulo-indice-decongestionamentos.

Redberg RF, Benjamin EJ, Bittner V, Braun LT, Goff DC Jr, Havas S, et al. ACCF/AHA 2009 performance measures for primary prevention of cardiovascular disease in adults: a report of the American College of Cardiology Foundation/American Heart Association Task Force on Performance Measures (Writing Committee to Develop Performance Measures for Primary Prevention of Cardiovascular Disease) Research. $\mathrm{J}$ Am Coll Cardiol. 2009;54(14):1364-405.

Reynolds P, Behren JV, Gunier RB, Goldberg DE, Hertz A, Smith D. Traffic patterns and childhood cancer incidence rates in California, United States. Cancer Causes Control. 2002;13:665-73.

Reynolds P, Behren JV, Gunier RB, Goldberg DE, Hertz A. Residential exposure to traffic in California and childhood cancer. Epidemiology. 2004;15(1):6-12.

Rich KE, Petkau J, Vedal S, Brauer M. A case-crossover analysis of particulate air pollution and cardiac arrhythmia in patients with implantable cardioverter defibrillators. Inhal Toxicol. 2004;16:363-72.

Rivera M, Basagaña X, Aguilera I, Foraster M, Agis D, De Groot E, et al. Association between long-term exposure to traffic-related air pollution and subclinical atherosclerosis: the REGICOR study. Environ Health Perspect. 2013;121:223-30.

Rumberger JA. Tomographic (plaque) imaging: state of the art. Am J Cardiol. 2001;88(2A):66E-69E.

Sahshuvaroglu T, Arain A, Kanaroglou P, Filkenstein N, Newbold B. Um modelo de regressão de uso da terra para prever as concentrações ambientais de dióxido de nitrogênio em Hamilton, Ontário. Air Waste Manage Assoc. 2006;56:1059-69

Salonen RO, Pennanen AS, Hälinen AI, Hirvonen MR, Sillanpää M, Hillamo $\mathrm{R}$, et al. A chemical and toxicological comparison of urban air PM10 collected during winter and spring in Finland. Inhal Toxicol. 1993;12(suppl. 2):95-103.

Samet JM, Dominici F, Curriero FC, Coursac I, Zeger SL. Fine particulate air pollution and mortality in 20 U.S. cities, 1987-1994. N Engl J Med. 2000;343:1742-9. 
Samoli E, Peng R, Pipikou M, Touloni G, Dominici F, Burnett R, et al. Acute Effects of Ambient Particulate Matter on Mortality in Europe and North America: Results from the APHENA Study. Environ Health Perspect. 2008;116(11):1480-6.

Santoro L, D'Onofrio F, Campo S, Ferraro PM, Tondi P, Campo V, et al. Endothelial dysfunction but not increased carotid intima-media thickness in young European women with endometriosis. Hum Reprod. 2012;27:1320-6.

Santos IS, Bittencourt MS, Oliveira IR, Souza AG, Meireles DP, Rundek T, et al. Carotid intima-media thickness value distributions in the Brazilian Longitudinal Study of Adult Health (ELSA-Brasil). Atherosclerosis. 2014 Nov;237(1):227-35.

Santos RD, Duncan A, Moriguchi CA, Rosito EH, Bodanese GBA, Clausell LC, et al. III Diretrizes Brasileira Sobre Dislipidemias e Diretriz de Prevenção da Aterosclerose do Departamento de aterosclerose da Sociedade Brasileira de Cardiologia. Arq Bras Cardiol. 2001;77(Supl.3):1-48.

Santos UP, Terra-Filho M, Lin CA, Pereira LA, Vieira TC, Saldiva PH, et al. Cardiac arrhythmia emergency room visits and environmental air pollution in Sao Paulo, Brazil. J Epidemiol Community Health. 2008;62(3):267-72.

SBC- Sociedade Brasileira de Cardiologia HTTP:// www. Cardiometro .com. br/ anteriores.asp.acessado em 15/11/2017 as 9:40 h

Schmidt MI, Duncan BB, Azevedo e Silva G, Menezes AM, Monteiro CA, Barreto SM, et al. Chronic noncommunicable diseases in Brazil: burden and current challenges. Lancet. 2011;377(9781):1949-61.

Sharman JE, Cockroft JR, Coombes JS. Cardiovascular implications of exposure to traffic air pollution during exercise. Q J Med. 2002;97:637-43.

Silva CBPS, Miraglia SGE. Valorização dos benefícios do metrô para a saúde pública com a redução da poluição do ar em São Paulo. VIII Encontro da Sociedade Brasileira de Economia Ecológica. Cuiabá - Mato Grosso Brasil 5 a 7 de agosto de 2009.

Smeeth I, Thomas SL, Hall AJ, Hubbard R, Farington P, Vallance R. Risk of myocardial infarction and stroke after acute infection or vaccination. $N$ Engl J Med. 2004;351:2611-8.

Stafoggia M, Cesaroni G, Peters A, Andersen G. Long-term exposure to ambient air pollution and incidence of cerebrovascular events: results from 11 European Cohorts within the ESCAPE. Project Environ Health Perspect. 2014 Sept 9;222(9):919-25.

Sun Q, Wang A, Jin X, Natanzon A, Duquaine D, Brook RD, et al. Long-term air pollution exposure and acceleration of atherosclerosis and vascular 
inflammation in an animal model. J Am Med Assoc. 2005;294:3003-10.

Suwa T, Hogg JC, Quinlan KB, Ohgami A, Vincent R, van Eeden SF. Particulate air pollution induces progression of atherosclerosis. $\mathrm{J} \mathrm{Am} \mathrm{Coll}$ Cardiol. 2002;39:935-42.

Tatto JA. Mobilidade urbana em São Paulo: aplicação de soluções imediatas e eficazes [Dissertação]. São Paulo: Escola Politécnica da Universidade de São Paulo. Departamento de Engenharia de Energia a Automação Elétricas. São Paulo; 2015.

Todd H, Daniel WC, Chris K, Bijoy K. Clinical use of carotid intima media thickness: review of literature. Am J Echocardiogr. 2007;20(7):907-14.

Toledo GIFM, Nardocci AC. Poluição veicular e saúde da população: uma revisão sobre o município de São Paulo (SP), Brasil. Rev Bras Epidemiol. 2011;14(3):445-54.

Torén K, Bergdahl IA, Nilsson T, Javholm B. Occupational exposure to particulate air pollution and mortality due to ischaemic heart disease and cerebrovascular disease. Occup Environ Med. 2007;64:515-9.

Torres FS, Moreira CM, Vianna FF, Gus M. Medida da espessura das camadas íntima e média das artérias carótidas para avaliação do risco cardiovascular. Rev Bras Hipertens. 2007;14(3):167-71.

Touboul PJ, Vicault E, Labreuche J, Belliard JP, Cohens S, Kownator S, et al. Design, baseline characteristics and carotid intima-media thickness reproducibility in the PARC study. Cerebrovasc Dis. 2005;19:57-63.

Tresmondi ACCL, Beli E, Tomaz E, Piccinini MDLR. Concentração de material particulado inalável MP10 em Espírito Santo do Pinhal - SP. Rev Engenharia Ambiental. 2008;5(1):133-44.

Tsimikas S, Willerson JT, Ridker PM. C-reactive protein and other emerging blood biomarkers to optimize risk stratification of vulnerable patients. J Am Coll Cardiol. 2006;47(8 Suppl.):C19-31.

USP - Universidade de São Paulo. Cidade universitária é a área mais afetada pelo Ozônio em SP [citado 1 maio 2017]. Disponível em: http://jornal.usp.br/atualidades/cidade-universitaria-e-a-area-mais-afetadapelo-ozonio-em-sp/, 2015.

Valavanidis A, Vlacchogianni T, Fiotakis K, Loridas S. Pulmonary oxidative stress, inflammation and cancer: respirable particulate matter, fibrous dusts and ozone as major causes of lung carcinogenesis through reactive oxygen species mechanisms. Int J Environ Res Public Health. 2013 Sep;10(9):3886907. 
Van Eiken E, Moraes C. Prevalência de fatores de risco para doenças cardiovasculares entre homens de uma população urbana do sudeste do Brasil. Cad Saúde Pública. 2009;25:111-23.

Vasconcelos EA. Congestionamento no trânsito e financiamento da mobilidade - avaliação dos estudos no Brasil e das perspectivas metodológicas. Revista da ANTP. 2014;36(136):7-27.

Vedal S, Rich K, Brauer M, White R, Petkauj. Air pollution and cardiac arrhythmias in patients with implantable cardioverter defibrillators. Inhal Toxicol. 2004;16:353-62.

Viebig RF, Valero MP, Araújo F, Yamada AT, Mansur AJ. Perfil de saúde cardiovascular de uma população adulta da região metropolitana de São Paulo. Arq Bras Cardiol. 2006;86(5):353-9.

Wellenus GA, Schwartz J, Mittelmann MA. Air pollution and hospital admissions for ischemic and hemorrhagic stroke among medicare beneficiaries. Stroke. 2005;36:2549-53.

WHO - World Health Organization. Burden of disease from ambient air pollution for 2012 [cited 2015 Oct 11]. Available from: www.who.int/phe/health_topics/outdoorair/databases/burden_disease/en/.A; 2012.

WHO - World Health Organization. Cardiovascular diseases - fact sheet [cited 2016 Aug 10]. Available from: http://www.who.int/mediacentre/factsheets/fs317/en/; 2016.

WHO - World Health Organization. Global recommendations on physical activity for health. Geneva: World Health Organization; 2010.

WHO - World Health Organization. Global status report on noncommunicable diseases 2010 [Internet]. Geneva: World Health Organization; p. 176. Available from: http://www.who.int/nmh/publications/ncd_report2010/en/, 2011.

WHO - World Health Organization. Integrated management of cardiovascular risk: report of a WHO meeting. Geneva: World Health Organization; 2002. p. 9-12.

Wilhelm M, Meng Y, Rull RP, English P, Balmes J, Ritz B. Environmental public health tracking of childhood asthma using california health interview survey, traffic, and outdoor air pollution data. Environ Health Perspect.

Wilker EH, Mittleman MA, Coull BA, Gryparis A, Bots ML, Schwartz J, et al. Long-term exposure to black carbon and carotid intima-media thickness: the normative aging study. Environ Health Perspect. 2013;121:1061-7. 
Wittekoek ME, de Groot E, Prins MH, Trip MD, Büller HR, Kastelein JJ. Differences in intima-media thickness in the carotid and femoral arteries in familial hypercholesterolemic heterozygotes with and without clinical manifestations of cardiovascular disease. Atherosclerosis. 1999;146:271-9.

Woodruff TJ, Parker JD, Darrow IA, Slama R, Bell ML, Choi H, et al. Methodological issues in studies of air pollution and reproductive health. Environ Res. 2009;109(3):311-20.

Xavier HT, Izar MC, Faria Neto JR, Assad MH, Rocha VZ, Sposito AC, et al. $\checkmark$ Diretriz Brasileira de Dislipidemias e Prevenção da Aterosclerose. Arq Bras Cardiol. 2013;101(4Supl. 1):1-22.

Yin D, Jiang W, Roth $\mathrm{H}$, Singleton DL. Impact of land surface simulations on modeled meteorological fields during a pollution episode in the lower Fraser Valley. Available http://www.mmm.ucar.edu/mm5/workshop/ws01/yin.pdf, 2001.

from:

Zanobetti A, Schwartz J. Are diabetics more susceptible to the health effects of airborne particles? Am J Respir CareMed. 2001;164:831-3.

Zanobetti A, Schwartz J. Particulate air pollution, progression, and survival after myocardial infarction. Environ Health Perspect. 2007;115(5):315-7.

Zhu Y, Hinds WC, Kim S, Sioutas C. Concentration and size distribution of ultrafine particles near a major highway. J. Air Waste Manag. Assoc. 2002;52:1032-42. 